\title{
Der Untergang des Oybiner Cölestinerklosters während der Reformation"
}

\author{
von \\ PETR HRACHOVEC
}

\section{Statt einer Einfübrung: Heinrich Rybisch auf dem Oybin (1534)}

Als am 24. Februar 1534 der schlesische Rentmeister Heinrich Rybisch (14851544) den böhmischen König Ferdinand I. (1526-1564) über seine kurz davor im königlichen Auftrag stattgefundene Visitation des Cölestinerklosters auf dem Oybin bei Zittau informierte, war er durch die majestätische Lage dieser Klosterburg im Zittauer Gebirge augenscheinlich tief beeindruckt: Dann, allergn[edig]ster konig und her $[r], e \beta$ ist di $\beta$ schlo $\beta$ eyn solich bubsch schlo $\beta$ und so woll und fest gelegenn, wan es Ew[e]r Koe. Mt. sehenn sollt, so wurde E. Mt. ey[n] ßunderliche gefallen dorob hab[en]. ${ }^{1}$ Rybisch gefiel das Kloster auch in anderer Hinsicht. Die Träger dieser Klosterstiftung, die Cölestinermönche, sollen sich sehr ,standesgemäß` verhalten und dem Rentmeister ein Darlehen für den König ohne Widerrede herausgegeben haben. ${ }^{2} \mathrm{Um}$ den altgläubigen liturgischen Stiftungsvollzug ange-

* Dieser Beitrag konnte mittels des „Jahresstipendiums für ausländische Doktoranden und Nachwuchswissenschaftler" des Deutschen Akademischen Austauschdienstes im Jahr 2015/16 am Institut für Sächsische Geschichte und Volkskunde e. V. realisiert werden. Die sprachliche Korrektur meines Textes hat Gunter Oettel (Görlitz/Zittau) durchgeführt; bzgl. der Zitate aus Archivquellen steht das Zeichen $<>$ für durchgestrichen und das Zeichen \# \# für darüber bzw. am Seitenrand geschrieben. Die meisten Abkürzungen in den Quellenzitaten wurden in eckigen Klammern aufgelöst, abgesehen von der herrschaftlichen oder akademischen Titulatur: wie Eur. Ro. Kay. Mt. usw.; dieser Beitrag stellt einen Auszug eines Kapitels meiner sich in Druckvorbereitung befindenden Dissertation dar.

1 Národní archiv Praha/Nationalarchiv in Prag (im Folgenden: NA Praha), Bestand: České oddělení dvorské komory/Böhmische Abteilung der Hofkammer (im Folgenden: ČDKM) IV, Kart. 169 (Oybin, okr. Žitava, Sasko/Oybin, Kreis Zittau, Sachsen), fol. $89^{v}$ f.; Státní oblastní archiv v Litoměřicích - pobočka Děčín/Staatsgebietsarchiv in Leitmeritz - Filiale Tetschen (im Folgenden: SOA Litoměčice/Děčín), Bestand: Rodinný archiv Clam-Gallasů/Familienarchiv Clam-Gallas (im Folgenden: RA ClamGallas), Sign. 2168/72, Kart. 584, inv. č. 2169 (Oybin), S. 6; die Edition dieses Schriftstückes vgl. im Anhang; [Moritz Oskar] Sauppe, Geschichte der Burg und des Cölestinerklosters Oybin, in: Neues Lausitzisches Magazin 62 (1886), S. 88-110; 79 (1903), S. 177-240; 83 (1907), S. 110-195; hier 83 (1907), S. 115 f.; Gunter Oettel, Die Auflösung des Klosters Oybin unter König Ferdinand I. von Böhmen, in: Zittauer Geschichtsblätter NF 9 (2002), H. 1, S. 21-30, hier S. 23.

2 [...] alß ich nach bevelch Ew[e]r Roe. Koe. Mt. uff das schloß und closter Owynn ko[m]me [n] bynn, hab ich die brueder daselbst mitt irem prior ganzs alß rechte fromme und 
sichts der reformatorischen Bedrohung innerhalb der Klostermauern erhalten zu können, wurden dem Konvent seitens der Ordenszentrale in Italien sechs Ordensgenossen aus Frankreich als Hilfe gesendet. Doch diese Religiosen gefielen Rybisch gar nicht. Sie selbst fühlten sich auf dem Oybin nicht wohl und rechneten mit baldiger Rückkehr. Darüber hinaus befürchtete Rybisch, dass sie im Fall ihres Verbleibs die Verwaltung des Klosters übernehmen könnten; auch bzgl. ihrer Rückkehr müsste man mit einer Wegzehrung für sie rechnen. ${ }^{3}$ Trotz des tadellosen geistlichen Zustands im Kloster war nach Rybisch mit seiner baldigen Auflösung infolge der Überalterung des Restkonvents und anschließender Sequestrierung in die weltliche Hand eines adeligen Untertanen des Königs zu rechnen. ${ }^{4}$ Schließlich besprach Rybisch mit dem Konvent noch die Frage der Klosterschätze, ein äußerst virulentes Problem der frühen Reformationszeit, da infolge der Reformation die klosterflüchtigen Mönche häufig die Kleinode mitnahmen und zugleich, weil das Königtum infolge der Türkengefahr in derselben Zeit viele Kirchen- und Klosterschätze für die militärischen Ausgaben einschmelzen und verkaufen ließ. Die Oybiner Mönche zeigten sich gegenüber Rybisch bereit, ihre Schätze wiegen zu lassen, was eine Vorstufe zu ihrer Einschmelzung darstellte. ${ }^{5}$

demutige closterleuth fundenn, die sich uff Ew[e]r Matt. beger[n] ganzs unterdenigklichen gebaltenn und an alle widderred und weyten bedacht haben sie Ewer[n] Koe. Mt. tausent gulden ungerisch mir ausgezallt [...]. Und weill Ew[e]r Koe. Mt. bevelh und beger[n] nur uff 1.450 gulden sich erstrackt, so bab ich gleichwol ire demutige und guttwilligs erbietenn der tausent guldenn auff Ew[e]r Koe. Mt. gefalle[n] angen[n]om$[m]$ enn un[n]d inen derbalbenn uff die sum[m]a ey[ne] obligationn zugestallt. Und mag E. Koe. Mt. in warbeyt anzaigenn, das sie dogegenn auch kein ungeberd, daß gellt $z u$ gebenn, sich gestallt habenn und an meiner person fast ey[nen] gutte[n] wille[n] getrag[en], alß der mit inen woll ist: NA Praha, ČDKM IV, Kart. 169, fol. $89^{\mathrm{r}}$.

3 Allayn will ich E. Koe. Mt. nit verhaltenn, das bey den alten brudern newe bruder sex $\beta$ auß Franckreych $k o[m] m e[n]$ seynt, die gefalle[n] mit gar nichts. Ich verstebe auch von inen selbst, das sie nicht lang bleibenn werdenn, dan ir thun stett nur uff wol lebenn unnd ist zu besorgen, wan sie bleibe[n] wurdenn und das regiment in die bandt beqweme [n], sie wurden wenig guts dem closter ausrichtenn und beute adder morg[en], wan es inenn gefiell, das ubrig, so furbandenn, gey[n] Franckreich adder welsche land schickenn. Disseß meyns verdachts hab Ew[e]r Koe. Mt. disse ursach, das sie mich selbst angelangett unnd gebetenn, an stat Ew[e]r Koe. Mt. zuzulaßen, wan sie willens, widderumb enheym zu ziben, werenn, das man inen vonn dem ubrigen gellt, so noch beym closter, zerung gebenn wollt: NA Praha, ČDKM IV, Kart. 169, fol. $89^{\mathrm{r}}$ f.; nach SOA Litoměčice/Děčín, RA Clam-Gallas, Sign. 2168/72, Kart. 584, inv. č. 2169, S. 5, ging es um Mönche aus Italien.

4 [...] und gleichwol in bedacht stellen, wan die andern alte bruder abginge[n], wie dan das nit lang wirt bleibenn anstebenn, das ey[n] solich fest und schon bau $\beta$ so weytleufftig[en] frembden persone[n] solt vertraut werdenn. Ap sich $\beta$ auch sunst, allergn[edig]ster her[r], zutrug, daß derhalb[en] adder des schloß halb[en] jmandes von berschafft[en] Ew[e]r Koe. Mt. umb begnadung bitte[n] wurde, als man sich dan versicht, das es in kurzen jaren mocht loßsterbenn: NA Praha, ČDKM IV, Kart. 169, fol. $90 \mathrm{r}$.

5 [...] auserhalbe[n] der klenodienn noch vermog der inventarienn, dan alleß silbern geschir, was das ist an kelch, cru\#ci\#fixenn, monstranze[n], pate[nen] und andern wirt schwerlich uber anderbalbhundert margk seynn unnd dennoch wergksilber $\beta$ daß 


\section{Methode und Quellenlage}

Dieses Beispiel wurde ausführlich behandelt, da man hier vielen Aspekten der Schicksale des Klosters während der Reformation begegnet, wie den mit dem landesherrlichen Kirchenregiment ${ }^{6}$ verbundenen Fragen: der erhöhten Besteuerung der Klostergüter durch das böhmische Königtum infolge der Türkengefahr,7 der Verwaltung der Klostergüter (Sequestration und Säkularisation), der Überalterung der Konvente sowie dem Problem der Kontinuität des liturgischen Stiftungsvollzuges in den Klöstern und der damit verbundenen Frage der physischen An- oder Abwesenheit der Träger solcher Stiftungen, der Mönche. Viele diese Aspekte werden im Folgenden erörtert.

schwerlich uber tzwelff lott feyn held und haben sich erbottenn, dasselbenn alles zu wegenn lassenn, wenn es E. Mt. befilht: NA Praha, ČDKM IV, Kart. 169, fol. 90r f.; dazu: KaI WenzeL, Inventarisiert und versiegelt. Die Kirchenschätze der Oberlausitz als politische Verhandlungsmasse im Zeitalter der Reformation, in: Bohemia. Zeitschrift für Geschichte und Kultur der böhmischen Länder 48 (2008), H. 1, S. 158-191, hier S. 171, 173.

6 Dazu vor allem Fallstudien aus dem wettinischen Sachsen: Helga-Maria KüHn, Die Einziehung des geistlichen Gutes im albertinischen Sachsen 1539-1553 (Mitteldeutsche Forschungen 43), Köln/Graz 1966; GüNTHER WARTEnbERG, Landesherrschaft und Reformation. Moritz von Sachsen und die albertinische Kirchenpolitik bis 1546, Weimar 1988; Manfred Schulze, Fürsten und Reformation. Geistliche Reformpolitik weltlicher Fürsten vor der Reformation (Spätmittelalter und Reformation, Neue Reihe 2), Tübingen 1991; Christoph Volkmar, Reform statt Reformation. Die Kirchenpolitik Herzog Georgs von Sachsen 1488-1525 (Spätmittelalter, Humanismus, Reformation 41), Tübingen 2008; Ders., Die Stunde des Laienstandes? Landesherrliche Kirchenreform am Vorabend der Reformation, in: Historisches Jahrbuch 128 (2008), S. 367-407; EnNo Bünz/Christoph Volkmar, Das landesherrliche Kirchenregiment in Sachsen vor der Reformation, in: Enno Bünz/Stefan Rhein/Günther Wartenberg (Hg.), Glaube und Macht. Theologie, Politik und Kunst im Jahrhundert der Reformation (Schriften der Stiftung Luthergedenkstätten 5), Leipzig 2005, S. 89-109; weiter: Alexander Sembdner, Franziskanerobservanz und landesherrliches Kirchenregiment in der spätmittelalterlichen Oberlausitz, in: Herbergen der Christenheit. Jahrbuch für deutsche Kirchengeschichte 38/39 (2014/2015), S. 53-88; Ders., Zur falschen Zeit am falschen Ort? Zur Geschichte des Kamenzer Franziskanerklosters St. Annen vor der Reformation, in: Sylke Kaufmann (Hg.), 450 Jahre Wendische Kirche in Kamenz. Vorträge des Festwochenendes vom 18. bis 20. September 2015, Kamenz 2016, S. 31-56.

7 OldŘich Chládek, „Páni fundátoři toho nedopustí ...“. Spor mezi Korunou a zakladateli žd’árského kláštera [„Die Herren Fundatoren werden dies nicht erlauben ... “. Der Streit zwischen der Krone und den Gründern des Klosters in Žd'ár/Saar], in: Časopis Matice Moravské 130 (2011), H. 2, S. 271-293; JAN Zdichynec, Klášter Osek v 16. století. Možnosti poznání cisterciáckého kláštera v době reformací [Das Kloster Osek/Osseg im 16. Jahrhundert. Möglichkeiten der Erkenntnis des ZisterzienserKlosters in der Zeit der Reformationen], in: Ústecký sborník historický 2005, S. 77-120; Ders., „Cur cisterno ademptum Ossecum?“. Předání oseckého kláštera pražskému arcibiskupství [... Die Übergabe des Osseger Klosters an das Erzbistum Prag], in: Folia historica Bohemica 22 (2006), S. 29-65; Ders., Ferdinand I. a kláštery v Praze [Ferdinand I. und die Klöster in Prag], in: Historie - otázky - problémy 7 (2015) [Prag Residenz des Habsburgers Ferdinand I. 1526-1564], H. 2, S. 98-110. 
Insbesondere will ich in diesem Beitrag die These der Berliner ,StiftungsSchule“ Michael Borgoltes erproben, inwieweit die Stiftungen wirklich jenes „Feld [waren], auf dem Reformation sozusagen verhandelt wurde"? Stellten sie tatsächlich die „Medien des kulturellen Wandels“ im Zeitalter der Reformation dar?8 Kann man also auf dem Feld der Klosterstiftungen einen ,kulturellen Umbruch der Reformation feststellen? ${ }^{9}$ Welche Stiftungen ${ }^{10}$ gingen infolge der Reformation zugrunde, welche überlebten, welche wurden den neuen reformatorisch geprägten religiösen und kulturellen Vorstellungen angepasst? Diese ,Schule' interpretiert die vormodernen Stiftungen kulturwissenschaftlich als eine Wechselbeziehung zwischen dem Stifter, der Stiftungsverwaltung und den Stiftungsdestinatären, wobei es um keine juristischen Personen, sondern immer um natürliche Personen bzw. Personenverbände ging, ${ }^{11}$ weshalb für die Dauer einer Stiftung der Vollzug dieser Stiftungen selbst entscheidend war. ${ }^{12}$ Die Stiftungen wurden zu Garanten der liturgischen u. a. Memoria des Stifters auch nach seinem Tod (sog. Gegenwart der Toten). ${ }^{13}$

8 Benjamin Scheller, Memoria an der Zeitenwende. Die Stiftungen Jakob Fuggers des Reichen vor und während der Reformation (ca. 1505-1555) (StiftungsGeschichten 3; Veröffentlichungen der Schwäbischen Forschungsgemeinschaft IV/28; Studien zur Fuggergeschichte 37), Berlin 2004, S. 282 f.

9 Ebd., S. 279 f.; wesentlich abgeschwächtes Urteil bzgl. der Bedeutung der Reformation für das Stiftungswesen (Umbruch nur auf dem Feld der sog. Seelgeräte): Michael Borgolte, Periodisierungen. 4.2. Lateinische Christen, in: Ders. (Hg.), Enzyklopädie des Stiftungswesens in mittelalterlichen Gesellschaften, Bd. I: Grundlagen, Berlin 2014, S. 252-275, hier S. 268, 271; Ders., Stifter. 11.2. Lateinische Christen, in: Ders. (Hg.), Enzyklopädie des Stiftungswesens in mittelalterlichen Gesellschaften, Bd. II: Das soziale System Stiftung, Berlin 2016, S. 359-380, hier S. 372 f. (reformatorische Stiftungsumwidmungen).

$10 \mathrm{Zu}$ Klöstern als sog. Kultusstiftungen bzw. Rahmenstiftungen: Tillmann Lohse, Typologisierungen. 3.2. Lateinische Christen, in: Borgolte, Enzyklopädie des Stiftungswesens I (wie Anm. 9), S. 167-182, hier S. 171; DeRS., Stiftungsorganisation. 13.2. Lateinische Christen, in: Borgolte, Enzyklopädie des Stiftungswesens II (wie Anm. 9), S. 519-530, hier S. 521.

11 LoHse, Stiftungsorganisation (wie Anm. 10), S. 519-528.

12 Zum sozialen Mechanismus vormoderner Stiftungen mittels des Gabentausches: TiLLMANN LoHse, Stiftung - Mittelalterlicher Sprachgebrauch und moderner Begriff. 1.2. Lateinische Christen, in: Borgolte, Enzyklopädie des Stiftungswesens I (wie Anm. 9), S. 23-36, hier S. 31 f.; Ders., Forschungsgeschichten. 2.2. Lateinische Christen, in: ebd., S. 87-103, hier S. 91 f.; Ders., Religiöses Verdienst und weltliche Ambitionen. 7.2. Lateinische Christen, in: Borgolte, Enzyklopädie des Stiftungswesens II (wie Anm. 9), S. 27-36, hier S. 27, 32; DERs., Stiftungsvermögen und -erträge. 10.2. Lateinische Christen, in: ebd., S. 288-300, hier S. 288; Philipp Winterhager, Stiftungsbegünstigte. 12.2. Lateinische Christen, in: ebd., S. 442-462, hier S. 442-458; BorgolTE, Stifter (wie Anm. 9), S. 364-370; Lohse, Stiftungsorganisation (wie Anm. 10), S. 519-521; Claudia Moddelmog, Königliche Stiftungen des Mittelalters im historischen Wandel. Quedlinburg und Speyer, Königsfelden, Wiener Neustadt und Andernach (StiftungsGeschichten 8), Berlin 2012, S. 16 f., 271-274; Tillmann Lohse, Die Dauer der Stiftung. Eine diachronisch vergleichende Geschichte des weltlichen Kollegiatstifts St. Simon und Judas in Goslar (StiftungsGeschichten 7), Berlin 2011, S. 14-19, 214.

13 Lohse, Stiftung - Mittelalterlicher Sprachgebrauch (wie Anm. 12), S. 31; Ders., Forschungsgeschichten (wie Anm. 12), S. 91; Ders., Typologisierungen (wie Anm. 10), 
Arbeiten über reformatorische Klosteraufhebungen gehören zum festen Bestandteil der Forschung, da die „Klosterfrage“ zur „Kernfrage der Reformationsgeschichte" erwuchs; ${ }^{14}$ ebenso wie die Frage nach dem Ausmaß und der Qualität eventueller Säkularisation bzw. Umwidmung der Klostergüter. Die Protestanten pflegten nämlich auf die Klostergüter mit dem Argument zuzugreifen, dass sie die Güter für den angeblich ursprünglichen - jedoch durch die römische Kirche entfremdeten - Stiftungszweck (das Armen-, Schul- und Kirchenwesen) restituieren wollten (sog. Umwidmungen). Demgegenüber bestanden die Katholiken auf der buchstabengetreuen Einhaltung der vorreformatorischen Stiftungen (vor allem der liturgischen Memoria). ${ }^{15}$ Ging es also im Fall der reformatorischen Aufhebung

S. 170, 176-178; Borgolte, Periodisierungen (wie Anm. 9), S. 261-271; Tillmann LoHse, Gedenken und Kultus. 8.2. Lateinische Christen, in: Borgolte, Enzyklopädie des Stiftungswesens II (wie Anm. 9), S. 91-108, hier S. 91-98, 103 f.; Borgolte, Stifter (wie Anm. 9), S. 363 f.

14 Eike Wolgast, Die Einführung der Reformation und das Schicksal der Klöster im Reich und in Europa (Quellen und Forschungen zur Reformationsgeschichte 89), Gütersloh 2014; Christopher Ocker, Church Robbers and Reformers in Germany 1525-1547. Confiscation and Religious Purpose in the Holy Roman Empire (Studies in Medieval and Reformation Traditions 114), Leiden/Boston 2006; zu Sachsen: STEFAN Oenmig, Mönchtum - Reformation - Säkularisation. Zu den demographischen und sozialen Folgen des Verfalls des Klosterwesens in Mitteldeutschland, in: Jahrbuch für Geschichte des Feudalismus 10 (1986), S. 209-249; Ders., Stadt und Säkularisation. Zum Verlauf und zu den Folgen der Aufhebung der Leipziger Klöster, in: Erich Donnert (Hg.), Europa in der Frühen Neuzeit. Festschrift für Günter Mühlpfordt, Bd. V: Aufklärung in Europa, Köln/Weimar/Wien 1999, S. 135-186; EnNo BüNZ, Das Ende der Klöster in Sachsen. Vom „Auslaufen“ der Mönche bis zur Säkularisation (15211543), in: Harald Marx/Cecilie Hollberg (Hg.), Glaube und Macht. Sachsen im Europa der Reformationszeit, Bd. Aufsätze, Dresden 2004, S. 80-90; Ders., Schicksale von Mönchen und Nonnen in der Reformationszeit. Ihre Zukunftsperspektiven nach Aufhebung der Klöster im Kurfürstentum Sachsen, in: Werner Greiling/Armin Kohnle/ Uwe Schirmer (Hg.), Negative Implikationen der Reformation? Gesellschaftliche Transformationsprozesse 1470-1620 (Quellen und Forschungen zu Thüringen im Zeitalter der Reformation 4), Köln/Weimar/Wien 2015, S. 81-108; weiter: JohanNes Schilling, Gewesene Mönche. Lebensgeschichten in der Reformation (Schriften des Historischen Kollegs - Vorträge 26), München 1990; Ders., Klöster und Mönche in der hessischen Reformation (Quellen und Forschungen zur Reformationsgeschichte 67), Gütersloh 1997, S. 14 (Zitat); Manfred Sitzmann, Mönchtum und Reformation. Zur Geschichte monastischer Institutionen in protestantischen Territorien (BrandenburgAnsbach/Kulmbach, Magdeburg) (Einzelarbeiten aus der Kirchengeschichte Bayerns 75), Neustadt/Aisch 1999, S. 9 (Klöster als zentrales Thema der Reformationsgeschichte); Anna Sauerbrey, Die Straßburger Klöster im 16. Jahrhundert. Eine Untersuchung unter besonderer Berücksichtigung der Geschlechtergeschichte (Spätmittelalter, Humanismus, Reformation 69), Tübingen 2012.

15 Ocker, Church Robbers (wie Anm. 14), S. 17 f., 141 f., 145 f., 154 f., 167-169, 177, 193 f., 197, 203, 208 f., 217, 225-228, 247-249, 260; SAUERbrey, Straßburger Klöster (wie Anm. 14), S. 117, 119; WInfrIEd Müller, Säkularisationen vor der Säkularisation von 1803. Zum Umgang mit dem Kirchengut im Alten Reich, in: Harm Klueting (Hg.), 200 Jahre Reichsdeputationshauptschluss. Säkularisation, Mediatisierung und Modernisierung zwischen Altem Reich und neuer Staatlichkeit (Schriften der Historischen Kommission für Westfalen 19), Münster 2005, S. 67-85, hier S. 71 f.; DERs., Herrschafts- 
des Klosters Oybin um Säkularisation, um eine bloße Umwidmung, bei der das Stiftungsvermögen für die kirchlichen Aufgaben zweckgebunden blieb, oder um beides zugleich?16 Inwieweit waren die Oybiner Cölestiner imstande, gegen die

säkularisation und Vermögenssäkularisation. Zwei Forschungsbegriffe auf dem Prüfstand, in: Rolf Decot (Hg.), Kontinuität und Innovation um 1803. Säkularisation als Transformationsprozess. Kirche, Theologie, Kultur, Staat (Veröffentlichungen des Instituts für Europäische Geschichte Mainz. Abteilung für abendländische Geschichte, Beiheft 65), Mainz 2005, S. 93-107, hier S. 93-95; Ders., Vorwort des Herausgebers, in: Ders. (Hg.), Reform - Sequestration - Säkularisation. Die Niederlassungen der Augustiner-Chorherren im Zeitalter der Reformation und am Ende des Alten Reiches (Publikationen der Akademie der Augustiner-Chorherren von Windesheim 6), Paring 2005, S. 1-7, hier S. 5; Wolgast, Einführung der Reformation (wie Anm. 14), S. 30, 33; Ders., Säkularisationen und Säkularisationspläne im Heiligen Römischen Reich Deutscher Nation vom 16. bis zum 18. Jahrhundert, in: Rottenburger Jahrbuch für Geschichte 23 (2004), S. 25-43, hier S. 25 f.; Hermann Ehmer, Die Kirchengutsfrage und Reformation, in: ebd., S. 45-59, hier S. 48 f.; Franz Brendle, Säkularisationen in der Frühen Neuzeit, in: Decot, Kontinuität und Innovation (a. a. O.), S. 33-55, hier S. 41; Harm Klueting, Enteignung oder Umwidmung? Zum Problem der Säkularisation im 16. Jahrhundert, in: Irene Crusius (Hg.), Zur Säkularisation geistlicher Institutionen im 16. und im 18./19. Jahrhundert (Veröffentlichungen des Max-Planck-Instituts für Geschichte 124; Studien zur Germania Sacra 19), Göttingen 1996, S. 57-83, hier S. 72 f.; Ders., Staat und Kirche. Säkularisation und Säkularisierung von der Reformation bis 1803, in: Hans Ulrich Rudolf/Markus Blatt (Hg.), Alte Klöster - neue Herren. Die Säkularisationen im deutschen Südwesten 1803. Aufsätze, Bd. I: Vorgeschichte und Verlauf der Säkularisation, Ostfildern 2003, S. 65-76, hier S. 73; WARTENBERG, Landesherrschaft (wie Anm. 6), S. 102; KüHN, Einziehung (wie Anm. 6), S. 31, 34 f., 41 f., 97, 104, 107 f.; Schilling, Klöster und Mönche (wie Anm. 14), S. 214; Sitzmann, Mönchtum und Reformation (wie Anm. 14), S. 105, 117, 156 f., 159 f., 182.

16 In der Forschung ist man sich nicht einig, ob man die Klosteraufhebungen als Säkularisation (Harm Klueting, Franz Brendle u. a.) oder als eine Sequestration (Winfried Müller, Martin Heckel u. a.) bezeichnen soll; andere Forscher beziehen eine vermittelnde Position (z. B.: Eike Wolgast, Enno Bünz): Müller, Säkularisationen (wie Anm. 15), S. 69-72; Ders., Herrschaftssäkularisation (wie Anm. 15), S. 93-95; DERs., Vorwort (wie Anm. 15), S. 3-5; Bünz, Ende der Klöster (wie Anm. 14), S. 81, 83, 86; Ders., Schicksale (wie Anm. 14), S. 88 f., 102-105, 108; Michael Beyer, Die Neuordnung des Kirchengutes, in: Helmar Junghans (Hg.), Das Jahrhundert der Reformation in Sachsen, Leipzig 2005, S. 93-114, hier S. 93; Schilling, Klöster und Mönche (wie Anm. 14), S. 205 f.; Wolgast, Säkularisationen (wie Anm. 15), S. 25; Ders., Einführung der Reformation (wie Anm. 14), S. 36 f., 46 f., 57, 71, 88-90, 97, 107 f., 112, 117, 120, 130-132, 175, 181, 194-196, 218-221, 226, 229, 246, 248, 251, 262 f., 265, bes. S. 266-268, 276; Sitzmann, Mönchtum und Reformation (wie Anm. 14), S. 41 f.; Brendle, Säkularisationen (wie Anm. 15), S. 39 f., 45; Klueting, Enteignung (wie Anm. 15), S. 74-83; Ders., Staat und Kirche (wie Anm. 15), S. 69 f.; Ders., Der Staat bemächtigt sich mit vollem Recht des „angemaßten Eigenthums“ der Kirche. Territorial- und Klostersäkularisation vom 16. bis 19. Jahrhundert, in: Claudio Donati/Helmut Flachenecker (Hg.), Le secolarizzazioni nel Sacro Romano Impero e negli antichi Stati italiani: premesse, confronti, conseguenze [Säkularisationsprozesse im Alten Reich und in Italien: Voraussetzungen, Vergleiche, Folgen] (Annali dell'Istituto storico italo-germanico in Trento/Jahrbuch des italienischdeutschen historischen Instituts in Trient - Contributi/Beiträge 16), Bologna/Berlin 2005, S. 25-55, hier S. 43; Anton Schindling, Die Reformation in den Reichsstädten und die Kirchengüterfrage. Straßburg, Nürnberg und Frankfurt im Vergleich, in: Jürgen Sydow (Hg.), Bürgerschaft und Kirche (Stadt in der Geschichte 7), Sigmaringen 1980, S. 67-88, 172. 
Reformation Widerstand (Beharrung) zu zeigen, oder haben sie sich eher der unfreundlichen Lage angepasst ${ }^{27}$ Insbesondere ging es mir darum, die Frage auszuloten, wie ein Kloster inmitten einer protestantischen Umgebung - trotz einer altgläubigen Landesherrschaft - unterging?18 All dies hängt unmittelbar mit dem Schicksal der Klostergüter und der Verfügungsgewalt über sie zusammen, die grundsätzlich Angelegenheit der „herrscherlichen Autorität“ war. ${ }^{19}$

Die folgende Darstellung wird eher problemorientiert als chronologisch sein. Sie konzentriert sich vor allem auf die Aspekte des landesherrlichen Kirchenregiments und des Wandels im Vollzug der Oybiner Stiftung im Reformationsjahrhundert. Vieles muss - wegen der reichen Quellenüberlieferung - aus Platzmangel ausgeklammert oder kann nur summarisch angedeutet werden (vor allem die Entwicklung in der zweiten Hälfte des 16. Jahrhunderts). Erschwerend kommt hinzu, dass keine Studien über die deutschen Cölestiner in der Reformation zum Vergleich herangezogen werden können, da es um 1520 im deutschsprachigen Raum nur zwei Konvente dieses Ordens gab: das Mutterkloster auf dem Oybin und seine Filiale auf dem Königstein bei Pirna. ${ }^{20}$ Dank seiner attraktiven ,fotogenen` Lage - Burg und Kloster , unter einem Dach' auf einem Felsenplateau

17 Diese Kategorien Widerstand/Beharrung und Anpassung untersuchte: KLAus-BerNWARD SPRINGER, Die deutschen Dominikaner in Widerstand und Anpassung während der Reformationszeit (Quellen und Forschungen zur Geschichte des Dominikanerordens NF 8), Berlin 1999, S. VII, 1, 76, 293, 307-334; bzw. „Opposition“ vs. „Kooperation“ bei: SAuerbrey, Straßburger Klöster (wie Anm. 14), S. 310-346.

$18 \mathrm{Zu}$ der Ausgangslage in den neugläubigen Staaten vgl. die symptomatische Charakteristik K.-B. Springers: „Über den Fortbestand der Klöster entschied generell das obrigkeitliche ius reformandi. Das Klosterwesen endete in neugläubigen Gemeinwesen nicht, weil es moralisch am Ende war, sondern weil ihm die institutionellen Grundlagen, vor allem der Schutz der Landesherren bzw. der Magistrate, entzogen wurde“: SPRINGER, Deutsche Dominikaner (wie Anm. 17), S. 294; war also das Fehlen der vornehmen Protektoren („noble protectors“), also meistens altgläubiger Herrscher, für den Untergang der Klöster an unserem Beispiel wirklich so ausschlaggebend, wie: OcKER, Church Robbers (wie Anm. 14), S. 36, meint?

19 „Lay interventions may serve as an index of ruling power“; bzw.: „Church property was an issue that had very much to do with the nature and extent of ruling authority"; bzw.: "Church property had to do with ruling authority over religion, or the question of sovereignty“: Ocker, Church Robbers (wie Anm. 14), S. 68, 130.

20 Zur allgemeinen Geschichte des Cölestinerordens ist vor allem die Habilitation Karl Borchardts von 2006 hervorzuheben: Karl BorchardT, Die Cölestiner. Eine Mönchsgemeinschaft des späteren Mittelalters (Historische Studien 488), Husum 2006; dieser Verfasser berücksichtigte in seinem Werk auch Oybin: S. 94-96, 126, 154-156, 190, 199, 201, 216, 258, 284 f. und 319-341 (der Orden während der Reformation). Die Anfänge des Ordens gehen auf den charismatischen Peter vom Morrone ( $\dagger$ 1296) zurück, der 1294 unter dem Namen Cölestin V. für kurze Zeit bis zu seiner Abdankung Papst war. Obwohl die Cölestiner zur Ordensfamilie der Benediktiner gehörten, wiesen sie auch zahlreiche Züge der Mendikanten auf (begrenzte Dauer der Ordens- und Konventämter, starke Zentralisierung usw.): S. 13-33, 171, 181 f., 196 (Cölestiner als ,moderner Ordenstyp des 13. Jahrhunderts'), S. 286, 301-303 (Kontrolle des Abtes des Hauptklosters auf dem Morrone über alle Liegenschaftsdispositionen bei den Ordenshäusern). 
inmitten der Berge und Wälder - ist Oybin schon seit der Frühen Neuzeit zum Gegenstand zahlreicher Forschungen geworden.

Das Kloster auf dem Berg Oybin stiftete am 17. März 1369 der Kaiser und böhmische König Karl IV. (1346-1378). Mit der Gründungsurkunde befreite der Herrscher das Kloster von allen Steuern abgesehen von der königlichen Berna, einer unregelmäßigen direkten Grundsteuer, die in den böhmischen Kronländern meistens anlässlich der Krönungen, Geburten oder Heiraten in der königlichen Familie erhoben wurde. Das Kloster erhielt zugleich die niedere Gerichtsbarkeit sowie erste Dotationen zugeteilt und wurde als unentfremdbar von der Böhmischen Krone deklariert. ${ }^{21}$ Sein Mutterkloster war das Hauptkloster des ganzen Ordens S. Spirito auf dem Berg Morrone bei Sulmona in den Abbruzen, wo die Oybiner Mönche auch die Generalkapitel besuchten.22 Die Baulast für das Kloster übernahm der Zittauer Rat, der dem Konvent auch seine Rente in der Höhe von 92 Schock jährlich abführen musste. ${ }^{23}$ Der Rat übernahm infolgedessen die provisio, einen rechtlichen Schutz, über den Konvent, und beide - Stadt und Kloster vereinte Karl IV. untrennbar. ${ }^{24}$ Die Bauarbeiten an der Klosterstiftung schritten rasch voran und bereits 1384 wurde die Klosterkirche geweiht. ${ }^{25}$

Die Geschichte Oybins während der Reformation behandelten monografisch im Jahr 1840 Christian Adolph Pescheck (auf der Grundlage Görlitzer und Dresdener Quellen) ${ }^{26}$ und Alfred Moschkau 1883/84 (eher Kompilation). ${ }^{27}$ Neun

21 Johannes Benedictus Carpzovius, Analecta Fastorum Zittaviensium Oder Historischer Schauplatz der Lo̊blichen Alten Sechs-Stadt des Marggraffthums Ober-Lausitz ZITTAU [...], 5 Teile, Zittau 1716, hier Teil I, S. 163-165, Nr. B; JoAchim Prochno (Hg.), Zittauer Urkundenbuch, Bd. I: Regesten zur Geschichte der Stadt und des Landes Zittau 1234-1437, in: Neues Lausitzisches Magazin 113 (1937), S. 79-198; 114 (1938), S. 1-421 (im Folgenden: ZUB), hier (1937), S. (99 f.), Nr. 316; Richard NĚmec, Caroli IV. imperatoris Romani fundatio. Kostel kláštera celestinů na Ojvíně u Žitavy [... Cölestinerklosterkirche auf dem Oybin bei Zittau], in: Průzkumy památek 11 (2004), H. 1, S. 3-52, hier S. 47, Nr. 1; [Moritz Oskar] SAuppe, Regesta castri et monasterii Oywinensis, in: Neues Lausitzisches Magazin 63 (1887), S. 370-377, hier S. 370.

22 Obwohl während der Hussitenkriege ihr Anschluss an die französische Provinz erwogen wurde: Borchardt, Cölestiner (wie Anm. 20), S. 154 f., 199; Ders., Die Cölestiner, in: Friedhelm Jürgensmeier/Regina Elisabeth Schwerdtfeger (Hg.), Orden und Klöster im Zeitalter der Reformation und katholischer Reform 1500-1700 (Vereinsschriften der Gesellschaft zur Herausgabe des Corpus Catholicorum 67), Münster 2007, S. 112-122, hier S. 116, 118; [Moritz Oskar] Sauppe, Zur Geschichte des Klosters Oybin im 15. Jahrhundert, in: NASG 13 (1892), S. 315-322, hier S. 318 f. ZUB (wie Anm. 21), S. 100 f., Nr. 318 f.; SAuppe, Regesta (wie Anm. 21), S. 370.

24 ZUB (wie Anm. 21), S. 103, Nr. 331; SAuppe, Regesta (wie Anm. 21), S. 375: Fundator Monasterii divae Memoriae Carolus IV. et post eum Sigismundus colligavit et inseparabiliter univit Monasterium cum Zittavia, et commisit Monasterium Zittaviensibus, ut provisoribus voluitque, ut nunquam separari debeant.

25 Zur Grüdung des Klosters neuerdings: Richard NĚMEc, Architektur - Herrschaft Land. Die Residenzen Karls IV. in Prag und den Ländern der Böhmischen Krone, Petersberg 2015, S. 228 f., 248-252, 257-265.

26 Christian Adolph Pescheck, Geschichte der Coelestiner des Oybins, Zittau 1840, S. $65,78-84$.

27 Alfred Moschkau, Oybin-Chronik. Urkundliche Geschichte von Burg, Cölestinerkloster und Dorf Oybin bei Zittau, Leipa in Böhmen 1884, S. 243-263. 
Briefe zwischen den Oybiner bzw. Königsteiner Cölestinern und dem Herzog Georg von Sachsen (1500-1539) gab Christian Adolph Pescheck heraus. ${ }^{28}$ Die bisher umfassendste Darstellung legte um 1900 der Oybiner Pfarrer Moritz Oskar Sauppe vor, der sehr akribisch die Prager und Wiener Archive auswertete. ${ }^{29}$ Noch heute findet man im Altbestand der Cristian-Weise-Bibliothek in Zittau mehrere Bände von Sauppes Abschriften. ${ }^{30}$ Den Aufenthalt der Prager Jesuiten auf dem Oybin um 1560 behandelte in seinen Arbeiten Adolf Kroes. ${ }^{31}$ Aktuell wurde Oybin zum Gegenstand der Forschung eher aus kunstgeschichtlicher und archäologischer Sicht (Gunter Oettel, Joanna Wojnicz ${ }^{32}$ ). Die 2015 erschienene kunstgeschichtliche Dissertation Richard Němecs behandelte die Oybiner Anlage als Beispiel einer Visualisierung königlicher Macht, die „die staatsrechtlichen und territorialen Ansprüche des Kaisers im Zittauer Land geltend machte. "33 Gunter Oettel widmete dem Oybin mehrere Aufsätze. Für unsere Fragestellung ist vor allem sein Aufsatz über „Die Auflösung des Klosters Oybin unter König Ferdinand I. von Böhmen“ wichtig, da Oettel einer der wenigen Oberlausitzer Geschichtsforscher ist, der die reichen Prager Quellen berücksichtigte. ${ }^{34}$ Diese Quellen edierte (z. T.) Wolfgang Ludwig. ${ }^{35}$ Weiter widmete sich Christian Speer dem Kloster am Beispiel seiner Beziehungen zu Görlitz. ${ }^{36}$ Die schlesischen Besitzungen des Klosters Oybin behandelte auf der Grundlage Breslauer Quellen, von

28 [Christian Adolph] Pescheck, Briefwechsel des Herzog Georgs des Bärtigen von Sachsen und der Cölestiner des Oybins, 1525, in: Neues Lausitzisches Magazin 18 (1840), S. 382-393.

29 SAuppe, Geschichte (wie Anm. 1).

30 Tino FröDE (Hg.), Regestenwerk zur Urkundensammlung von Moritz Oskar Sauppe: zur Geschichte der Oberlausitz, des Klosters Oybin sowie der Städte Görlitz und Zittau, Olbersdorf 2000; auf der Grundlage dieser Abschriften verfasste seinen Aufsatz über die Zittauer Jesuitenpension auch: Günther Rautenstrauch, Die Zittauer Jesuiten-Pension. Chronik einer unendlichen Geschichte, in: Neues Lausitzisches Magazin NF 4 (2001), S. 55-72.

31 Alois Kroes, Der Untergang des Cölestinerklosters auf dem Oybin bei Zittau, in: Mitteilungen des Vereins für Geschichte der Deutschen in Böhmen 47 (1908), S. 229247; Ders., Geschichte der Böhmischen Provinz der Gesellschaft Jesu, Bd. I: Geschichte der ersten Kollegien in Böhmen, Mähren und Glatz von ihrer Gründung bis zu ihrer Auflösung durch die böhmischen Stände 1556-1619 (Quellen und Forschungen zur Geschichte, Literatur und Sprache Österreichs und seiner Kronländer 11), Wien 1910. Joanna Wojnicz, Burg- und Klosteranlage Oybin (Archaeonaut 1), Dresden 2002.

33 NĚMEC, Architektur (wie Anm. 25), S. 189-265.

34 OetTel, Auflösung (wie Anm. 1).

35 Wolfang Ludwig (Hg.), Kloster Oybin 1551-1574, Dresden 1999; Ders., Oybinischer Schatz Zettel 1552, in: Familie und Geschichte. Hefte für Familienforschung im sächsisch-thüringischen Raum 2 (1993), Bd. I, H. 3, S. 315-318.

36 Christian Speer, Die Bedeutung der Cölestiner für die Frömmigkeitspraxis städtischer Eliten im Spätmittelalter, in: Lenka Bobková (Hg.), Česká koruna na rozcestí. K dějinám Horní a Dolní Lužice a Dolního Slezska na přelomu středověku a raného novověku (1437-1526) [Die Böhmische Krone am Scheideweg. Zur Geschichte der Ober- und Niederlausitz sowie Niederschlesiens im Spätmittelalter und in der Frühen Neuzeit] (Tempora et memoria 1), Praha 2010, S. 294-338. 
denen viele heute wohl Kriegsverluste sind, Konrad Wutke. ${ }^{37}$ Die mittelalterlichen Handschriften der Oybiner Klosterbibliothek analysierte Ivan Hlaváček. ${ }^{38}$

Item in unndersten kblainen gewelb des closters privilegii unnd confirmationes von Karolo quarto bis auf yezige regierennde Ro. Ku. Mt.: Dies notierten am 10. Juni 1556 in ihrem Inventar die königlichen Kommissare bei der Übergabe des Klosterareals an den letzten Cölestiner Balthasar Gottschalk. ${ }^{39}$ Von diesem Urkundenreichtum des Klosters Oybin ist leider nichts übrig geblieben, da das Archiv des Konvents höchstwahrscheinlich beim Zittauer Stadtbrand 1757 unterging. Doch dies bedeutet keineswegs, dass zum Kloster Oybin der Reformationszeit keine Archivquellen überliefert wären. Im Gegenteil: Die reiche Überlieferung beginnt mit den Görlitzer Quellen bereits um 1500 in Gestalt der Briefbücher (Libri missivarum) des Görlitzer Rates im dortigen Ratsarchiv ${ }^{40}$ wie auch der losen Korrespondenz seit 1509.41 Ebenso ist im Ratsarchiv Görlitz ein Karton überliefert, der einige infolge der Reformation umgewidmete Görlitzer Stiftungen auf dem Oybin betrifft. ${ }^{42}$ Im Staatsfilialarchiv des Bautzener Archivverbundes findet man barocke Akten zur Oybiner bzw. Zittauer Jesuitenpension. ${ }^{43}$ Neun Konvolute zu dieser Pension befinden sich im Sächsischen Staatsarchiv - Hauptstaatsarchiv Dresden, ${ }^{44}$ wo man noch drei Konvolute zum Oybiner Tochterkloster Königstein findet, in denen sich zahlreiche Briefe des Oybiner Konvents befinden. ${ }^{45}$

Am wichtigsten für unsere Fragestellung sind jedoch die infolge der Ausübung des Kirchenregiments der böhmischen Könige entstandenen Quellen im Prager Nationalarchiv: die Kopialüberlieferung, sog. Královská registra/Königliche Register (der Böhmischen Hofkanzlei und der Böhmischen Kammer), ${ }^{46}$ die häufig auch im Original im Bestand České odděleni dvorské komory/Böbmische Abteilung der Hofkammer ${ }^{47}$ oder im Bestand Lužické spisy/Lausitzer Schriften vorlie-

37 Konrad Wutke, Die schlesischen Besitzungen des Coelestinerklosters Oybin, in: Zeitschrift des Vereins für Geschichte Schlesiens 48 (1914), S. 34-73.

38 Ivan Hlaváček, Z knižního bohatství ojvínského kláštera (I - Rukopisy knihovny ojvínských celestinů) [Aus dem Bücherreichtum des Oybiner Klosters (I - Die Handschriften der Bibliothek der Oybiner Cölestiner)], in: Aleš Mudra/Michaela Ottová (Hg.), Ars videndi. Professori Jaromír Homolka ad honorem (Opera Facultatis Theologiae catholicae Universitatis Carolinae Pragensis. Historia et historia artium 5), Praha 2006, S. 35-45.

39 NA Praha, Archiv Pražského arcibiskupství/Archiv des Prager Erzbistums (im Folgenden: APA) I - Historica, Sign. C 148/3, Kart. 2260 (Ojvín inventáře/Oybin Inventare), unpag.

40 Im Folgenden: RA Görlitz, LM.

41 RA Görlitz, Varia 226 (Briefe den Oybin betreffend, 1509-1555).

42 RA Görlitz, I-246v-62 (Regal VI, Fach 36; Das Kloster Oywin Kapitel und Zinsen).

43 Im Folgenden: AV Bautzen - StFilA Bautzen, 50009/3255, 50009/4447, 50009/5447.

44 Im Folgenden: HStA Dresden, 10024 Geheimer Rat (Geheimes Archiv), Loc. 9344/05, Loc. 9346/11-13, Loc. 9582/01, Loc. 9582/03, Loc. 9593/21; 10026 Geheimes Kabinett, Loc. 2387/04; 10036 Finanzarchiv, Loc. 32510, Rep. 23, Gen. Nr. 128.

45 HStA Dresden, 10024 Geheimer Rat (Geheimes Archiv), Loc. 8941/28-30.

46 Im Folgenden: NA Praha, RG.

47 NA Praha, ČDKM IV, Kart. 169 und Kart. 324 (Žitava - Oibínské statky/Zittau Oybiner Güter 1566-1605). 
gen. ${ }^{48}$ Ein sehr umfassendes Urbar des Klosters von 1553 sowie die Taxierungen des Klostervermögens anlässlich seines Verkaufs an den Zittauer Rat im Jahr 1574 findet man im Bestand Stará manipulace - urbáře/Alte Manipulation - Urbare. ${ }^{49}$ Ein anderes Exemplar desselben Urbars aber darüber hinaus noch Inventare der Klosterschätze, -bibliothek und anderen Vermögens befinden sich im Bestand Archiv pražskébo arcibiskupství/Archiv des Prager Erzbistums. ${ }^{50} 15$ Originalurkunden des 16. Jahrhunderts mit Bezug auf Oybin werden im Bestand České gubernium - listiny/Böhmisches Gubernium - Urkunden aufbewahrt. ${ }^{51}$ Im selben Archiv findet man auch im Bestand Jesuitica barocke Quellen zur Oybiner Pension: in drei Kartons und in zwei Büchern. ${ }^{52}$ Aus weiteren Prager Archiven ist vor allem Strabovská Knibovna/Bibliothek des Klosters Strabov zu nennen, wo sich das älteste Diarium der Prager Jesuiten befindet, die um 1560 den Oybin verwalteten; ${ }^{53}$ sowie einige Codizes im Bestand Archiv metropolitni kapituly/ Archiv des Metropolitankapitels im Archiv Pražskébo hradu/Archiv der Prager Burg. ${ }^{54}$ Eine Oybiner Chronik der Reformationszeit befindet sich im Státní oblastní archiv v Litoměřicích - pobočka Děčín/Staatsgebietsarchiv in Leitmeritz - Filiale Tetschen im Bestand Rodinný archiv Clam-Gallasü/Familienarchiv Clam-Gallas. ${ }^{55}$ Nur ungenügend konnte ich die Wiener Quellen einbeziehen, vor allem den Bestand Böhmische Gedenkbücher im Finanz- und Hofkammerarchiv des Österreichischen Staatsarchivs. ${ }^{56}$ Ebenso konnte ich das Archivum Romanum Societatis Iesu nicht auswerten, aus dem Otto Braunsberger in seiner Edition des Briefwechsels Peter Canisius' zahlreiche Briefe in Bezug auf Oybin herausgegeben hat und wo man noch viel Ungedrucktes voraussetzen kann. ${ }^{57}$

\section{Oybin und die Aufhebung seines Tochterklosters Königstein (1523/24)}

Erste Belege über das ,Einschleichen` der lutherischen ,Häresie“ ins Oybiner Kloster erfährt man im Zusammenhang mit der Krise des Cölestinerklosters auf dem

48 Im Folgenden: NA Praha, Lž.

49 Im Folgenden: NA Praha, SM-UR, Sign. 111, Kart. 15.

50 NA Praha, APA I - Historica, Sign. C 148/3, Kart. 2260; die Editionen von: Ludwig, Kloster Oybin (wie Anm. 35); Ders., Oybinischer Schatz Zettel (wie Anm. 35), beziehen sich eben auf diesen Karton.

51 Im Folgenden: NA Praha, ČG-L.

52 Im Folgenden: NA Praha, Js XXXVIII, Kart. 84-86; Js, čís. poř. [Nr.] 58, nová sign. [neue Sign.] RKP 12 [Mscr. 12]; und: čís. poř. [Nr.] 59, nová sign. [neue Sign.] RKP 13 [Mscr. 13].

53 Im Folgenden: SK Praha, Sign. DC III 20 (Diarium Collegii Societatis Jesu Pragae ad sanctum Clementem 1560-1583).

54 Im Folgenden: APH-AMK.

55 SOA Litoměčice/Děčín, RA Clam-Gallas, Sign. 2168/72, Kart. 584, inv. č. 2169; und Anhang.

56 Im Folgenden: ÖStA-FHKA, Böhmische Gedenkbücher, Bd. 304 ff.

57 Otto Braunsberger (Hg.), Beati Petri Canisii, Societatis Iesu, epistulae et Acta, Bd. I-IV, Friburgi Brisgoviae 1896-1901 (im Folgenden: Briefwechsel Canisius). 
Königstein bei Pirna, einer Stiftung des sächsischen Herzogs Georg des Bärtigen von 1516. ${ }^{58}$ Bereits Ende Juni 1523 musste dies Herzog Georg konstatieren. Die ,Vergiftung' der Oybiner und Königsteiner Mönche durch die ,Ketzerei‘ führte er auf die Lektüre der lutherischen Bücher durch die Mönche zurück. Er wollte dieser Gefahr mit der Hilfe des Administrators des Prager Erzbistums begegnen, der den reformationsfreundlichen Oybiner Prior absetzen und die lutherischen Mönche verbannen sollte. Die der Reformation freundlich gesinnten Religiosen sollten von Königstein nach Oybin bzw. in die umgekehrte Richtung versetzt werden. ${ }^{59}$ Herzog Georg verlangte vom Oybiner Kloster zwei Punkte: einerseits die Aufnahme der vom Königsteiner Kloster ausgelaufenen Mönche und Laienbrüder, ${ }^{60}$ andererseits die Herausgabe der Stiftungsurkunde des Königsteiner Klosters (über einen Zins von 200 fl. rh. jährlich), die unter unbekannten Umständen in das Oybiner Klosterarchiv gelangt war. Der Oybiner Konvent verlangte demgegenüber von Herzog Georg die Herausgabe seiner Bücher und Schätze, die der Konvent anlässlich der Gründung des Königsteiner Klosters zur Verfügung stellte. ${ }^{61}$

58 Volkmar, Reform (wie Anm. 6), S. 524-526; Markus BitTerlich, Das Kloster des Lobes der Wunder Mariae auf dem Königstein (Schriftenreihe der Festung Königstein), Königstein 2016, S. 16-23; SPEER, Bedeutung (wie Anm. 36), S. 317-319, 337 f.

59 Felician Gess (Hg.), Akten und Briefe zur Kirchenpolitik Herzog Georgs von Sachsen (Mitteldeutsche Forschungen - Sonderreihe: Quellen und Darstellungen in Nachdrucken 6/I-II), Bd. I, Leipzig 1905 [ND: Köln/Wien 1985] (im Folgenden: ABKG), S. 534 f., Nr. 529.

60 ABKG I (wie Anm. 59), S. 563-565, Nr. 564 (der Königsteiner Prior Johannes Mantel flüchtete nach Wittenberg; der Laienbruder Urban Keiser zuerst ins nordböhmische Tetschen, 8.11.1523); S. 578 f., Nr. 575 (4.12.1523); S. 658 f., Nr. 651 (24.4.1524); S. 662, Nr. 656 (11.5.1524); S. 662 f., Nr. 656, Anm. 3 (Mai 1524). Nach Oybin gelangten - oder wollten gelangen - im Auftrag Hz. Georgs aus Königstein sicher der durch Hz. Georg verhörte Br. Simon aus Luckau: HStA Dresden, 10024 Geheimer Rat (Geheimes Archiv), Loc. 8941/29, fol. $8^{\text {r }}$ (fehlt in ABKG I, S. 662 f., Nr. 656, Anm. 3); ebd. S. 671 f., Nr. 659 (Simon von Luckau und Martin von Liebenwerda; 16.5.1524); Pescheck, Briefwechsel (wie Anm. 28), S. 384 f.; die ausgelaufenen Königsteiner Cölestiner, die sich um ihre Aufnahme auf dem Oybin bewarben, waren also keine dauerhaften Apostaten, die sich ganz dem Ordensleben entsagten, sondern nur temporäre Fugitivi; zu dieser Unterscheidung zwischen beiden Arten der Klosterflucht: SPRINGER, Deutsche Dominikaner (wie Anm. 17), S. 6, Anm. 17.

61 ABKG I (wie Anm. 59), S. 577, Nr. 573 (2.12.1523); S. 675, Nr. 663 (22.5.1524); S. 677 f., Nr. 668 (28.5.1524); HStA Dresden, 10024 Geheimer Rat (Geheimes Archiv), Loc. 8941/28, fol. $14^{\mathrm{r}}$ (Hz. Georg an den Pirnaer Landvogt Hans Karras; 29.5.1524; fehlt in ABKG I); ABKG I (wie Anm. 59), S. 678, Nr. 669 (29.5.1524); Pescheck, Briefwechsel (wie Anm. 28), S. 388; ABKG I (wie Anm. 59), S. 679 f., Nr. 672 (2.6.1524); Pescheck, Briefwechsel (wie Anm. 28), S. 389-391; HStA Dresden, 10024 Geheimer Rat (Geheimes Archiv), Loc. 8941/29, fol. $17^{\mathrm{r}}$ (Hans Karras an Hz. Georg; 4.6.1524; fehlt in ABKG I); ABKG I (wie Anm. 59), S. 680 f., Nr. 673 (5.6.1524); S. 681, Nr. 674 (9.6.1524); HStA Dresden, 10024 Geheimer Rat (Geheimes Archiv), Loc. 8941/28, fol. 16r (Prager Administrator Ernst von Schleinitz an Hz. Georg; 6.5.1525; fehlt in ABKG I); noch 1530 befand sich die Stiftungsurkunde auf dem Oybin: Heiko Jadatz/Christian Winter (Hg.), ABKG III, Köln/Weimar/Wien 2010, S. 300, Nr. 1886 (28.1.1530); wohl erst kurz vor der Gründung des Dresdener Hospitals St. Jakob, dem die Königsteiner Stiftungszinse vom Hz. Georg überwiesen wurden, gab Oybin die Urkunde heraus: 
Doch die Oybiner Cölestiner verweigerten sehr lang, beides zu tun, da sie selbst in der frühen Reformationszeit vielen Schwierigkeiten standhalten mussten und wegen beider Sachen ihr Mutterkloster in den Abruzzen konsultieren wollten. ${ }^{62}$ Es mag auch das Versagen des Oybiner Mutterklosters in Bezug auf seinen Tochterkonvent auf dem Königstein gewesen sein, was Herzog Georg zur Aufhebung seiner Königsteiner Klosterstiftung bewog. ${ }^{63}$

\section{Das Oybiner Kloster und die frübe Reformation: landesherrliches Kirchenregiment}

Im Unterschied zum Königsteiner Konvent überstand das Oybiner Kloster den ersten ,Anprall' der neuen Lehre in den 1520er-Jahren. Am 14. November 1532 kritisierte zwar der böhmische König Ferdinand I. das mangelhafte religiöse Leben daselbst, ${ }^{64}$ der damalige Oybiner Prior Christoph Uthmann bestritt dies

Heiko Jadatz/Christian Winter (Hg.), ABKG IV, Köln/Weimar/Wien 2012, S. 336 f., Nr. 3068; Alexandra-Kathrin Stanislaw-Kemenah, Spitäler in Dresden. Vom Wandel einer Institution (13.-16. Jahrhundert) (Schriften zur sächsischen Geschichte und Volkskunde 24), Leipzig 2008, S. 264, 280 f., 480.

62 ABKG I (wie Anm. 59), S. 673, Nr. 661; Ernst Friedrich Haupt, Beiträge zur Geschichte des Oybins, in: Neues Lausitzisches Magazin 4 (1825), S. 35-47, 181-214, 321-336, 461-478, hier S. 477, Nr. 1; Pescheck, Briefwechsel (wie Anm. 28), S. 385 (20.5.1524); ABKG I (wie Anm. 59), S. 677, Nr. 667; Pescheck, Briefwechsel (wie Anm. 28), S. 386 (27.5.1524); ABKG I (wie Anm. 59), S. 678, Nr. 670 (1.6.1524); Pescheck, Briefwechsel (wie Anm. 28), S. 388 f.; ABKG I (wie Anm. 59), S. 684 f., Nr. 677; Pescheck, Briefwechsel (wie Anm. 28), S. 392 f. (11.6.1524); der Oybiner Konvent schlug diesen ausgelaufenen Mönchen vor, die in den Orden zurückkehren wollten, sich zuerst nach Rom oder an den Abt des Oybiner Mutterklosters in Sulmona zu wenden, wofür jedoch die Königsteiner kein Geld hatten: ebd., S. 685, Nr. 677, Anm. 2 (der Laienbruder Urban Kaiser; undatiert; Jahr 1524); Pescheck, Briefwechsel (wie Anm. 28), S. 386 f.; weiter: HStA Dresden, 10024 Geheimer Rat (Geheimes Archiv), Loc. 8941/29, fol. $15^{\mathrm{r}}$ (Simon, Prokurator des Königsteiner Klosters an Hz. Georg; nach dem 25.7.1525; fehlt in ABKG I); Pescheck, Briefwechsel (wie Anm. 28), S. $391 \mathrm{f}$.

63 Vgl. die symptomatische Beschwerde Hz. Georgs gegenüber der Mutterabtei Oybins auf dem Berg Morrone bei Sulmona hinsichtlich des Unwillens des Oybiner Konventes bzgl. der Probleme des Königsteiner Klosters (Hz. Georg an den Morroner Abt Petrus; 13.8.1524): ABKG I (wie Anm. 59), S. 721 f., Nr. 713; sowie ebd., S. 762-764, Nr. 750, die Antwort des neuen Morroner Abtes Placidus vom 5.11.1524, der die Maßnahmen der Ordenszentrale bzgl. der Abwehr der Reformation auf dem Oybin erwähnte (Visitation und päpstliches Breve); [Christian Adolph] Pescheck, Neue Nachlese über den Oybin und die Cölestiner, in: Neues Lausitzisches Magazin 21 (1843), S. 137192, hier S. 160; Kroes, Untergang (wie Anm. 31), S. 231.

64 [...] unns hatt der wolgeborn unnser lieber getrewer Zdislawen von der Leypp und Tawpp auf Reichstat, unnsers kunigreichs Behaim obrister rechtsprecher unnd lanndtvogt in Oberlausiz, unnder annderm seinem schreyben unnd[er]thenigclich zu erkhennen geb[en], wie sich die closterleut des closters Oybin ze ainziger (?) weyß zertrennen unnd hinweegmachen unnd khain sonnder comunitet oder ordenlichs leben halten, sonnder ain yeder fur sich selbst sein wesen unnd leben, irem gevallen nach ze halten, gedennkhen und trachten: NA Praha, RG 8 (Kopiáŕ nařízení pro českou komoru/ Kopial der Befehle für die Böhmische Kammer 1531-37), S. $231 \mathrm{f}$. 
aber in seinem Brief an den König energisch als eine Verleumdung. Die verbliebenen Brüder sollen auch weiterhin ein geistliches Leben im Konvent geführt haben. ${ }^{65}$ Der König traute den verbliebenen Mönchen nicht. Er verdächtigte sie der Flucht sowie des Entwendens des Klostermobiliars. Deswegen befahl er am 6. Juni 1536 dem Landvogt Zdislav Berka von Dubá († 1553), im Kloster ,geheime Späher ${ }^{6}$ zu unterhalten. ${ }^{66}$ Auch später warf er den Oybinern die lutherische ,Häresie vor und drohte dem Prior mit der Absetzung. ${ }^{67}$ Die überlieferten Inventare der Oybiner Klosterbibliothek aus der Reformationszeit zeigen dabei nur wenige reformatorische Bücher, durch deren Lektüre sich die Oybiner Mönche hätten ,angesteckt‘ haben können. Eher die Werke der zeitgenössischen altgläubigen Kontroverstheologen konnte man auf dem Oybin finden; was eher für die ,Rechtgläubigkeit‘ der Oybiner spräche. ${ }^{68}$

An der Wende vom Mittelalter zur Frühneuzeit kam es in vielen Staaten zur Ausbildung des landesherrlichen Kirchenregiments. ${ }^{69}$ Die Böhmische Krone war

65 NA Praha, ČDKM IV, Kart. 169, fol. $6^{\mathrm{r}}$ f. (22.12.1532); diese Beteuerung Uthmans über tadelloses geistliches Leben im Konvent bestätigten am Tag davor dem König auch die königlichen Visitatoren: Wir kun[n]en auch nichtes befunde[n] und erkenne[n] an den dasige [n], dy nach alby dann, das sy sich zuchtigk, erlich und auffrichtigk, wy frome [n] ordensleuten zwstehet, vorhaltten. So sy doch von andern leuten, sunderlich dene [n], dy von yne [n] geloffen, vil andersch angegebe[n] werden, aber soferr wyr uns der sache[n] erfaren, beschicht yne [n] unrecht: ebd., fol. $3^{\mathrm{v}}$.

66 Doch ist daneben unnser bevelh, dein vleissig aufmergkhn zu haben, ob die monich willens sich, aus dem kbloster ze thun, unns unverzuglichn bericht thueest, auch in gehaym dein spech habest und verordnung thueest, so sy darauß khemben, dz durch sy dem kloster nichts entphrembt werde: NA Praha, RG 14 (Německé missivy/Deutsche Missive 1535-36), fol. 243v.

67 NA Praha, RG 26 (Německé missivy/Deutsche Missive 1543), fol. 45r'; SAuppe, Geschichte 1907 (wie Anm. 1), S. 120 f.

68 Es ging wohl nur um ein Werk Konrad Pellikans (1478-1556): Conradus Pellicanus in evang[elia]: NA Praha, APA I - Historica, Sign. C 148/3, Kart. 2260 (Ojvín spisy), fol. $8^{\mathrm{r}}$ (26.3.1556); zu den altgläubigen Kontroverstheologen: Faber super evangelia [...], Io[ann]es Ditenb[e]rgius contra Lutherum, Scaterus contra Lutherum [...], Faber pro primatu Petri [...], Eccius de sanctys deutsch [...], Tractatus contra haereticos [...], Scrutini[us] contra Lutherum [...]: ebd., fol. 8 ${ }^{\mathrm{r}}$, 9v , 10r, 10v (26.3.1556); weiter ebd., fol. $13^{\mathrm{r}}, 14^{\mathrm{r}}, 15^{\mathrm{r}}, 15^{\mathrm{v}}$ : Bennonis Misnenss[is] (!) vita, Contra Valdensses, Postilla Eckii 1 [...], Roffenssis contra Lutheru[m]; an dieser Stelle kann keine ausführliche Behandlung der umfassenden Inventare der Bücher, Schätze, Kunstwerke und Ornate des Oybiner Klosters unternommen werden; SAUPPE, Geschichte 1907 (wie Anm. 1), S. 151 f., 155 157, 170 f.; Kroes, Untergang (wie Anm. 31), S. 246; Ders., Geschichte I (wie Anm. 31), S. 54, 176; HlaváČex, Z knižního bohatství (wie Anm. 38); Borchardt, Cölestiner (wie Anm. 20), S. 253; zur ähnlichen katholisch-kontroversen Ausrichtung der zeitgenössischen Klosterbibliothek in Osseg/Osek in Nordböhmen: Zdichynec, Klášter Osek (wie Anm. 7), S. 113 f.

69 Ein sehr entwickeltes landesherrliches Kirchenregiment bereits am Vorabend der Reformation betonen am Beispiel des sächsischen Hz. Georg des Bärtigen: VolKMaR, Reform (wie Anm. 6), S. 3-8, 13 f., 21, 24 f., 34-40, 50, 52-54, 61-65, 88-101, 105, 110 f., 251-263 (in Bezug auf den Regularklerus), S. 312-315 (landesherrliche Klerusbesteuerung), S. 326-336, 421-438, 440 f. (trotzdem Beschränkungen des vorreformatorischen Landeskirchenregiments durch Kirchenorganisation und -recht), S. 613-616, 622-624; Volkmar, Stunde des Laienstandes (wie Anm. 6), S. 370-376, 389, 405-407; BünZ/ 
dabei keine Ausnahme. Eine wichtige Rolle in diesem Prozess spielten die Türkenkriege, die das Königtum zu einer erhöhten Besteuerung des geistlichen Besitzes sowie zur wesentlichen Intensivierung seines Einflusses auf die Klöster bewogen. ${ }^{70}$ Vor allem unter Ferdinand I. mussten die Klöster dem König zahlreiche Darlehen gewähren, ${ }^{71}$ wofür ihnen dieser erlaubte, die Klosterschätze einzuschmelzen bzw. ihre Klostergüter zu verpfänden. ${ }^{72}$ Der König konnte sich dabei sowohl auf die Stellung der geistlichen Güter als Kammergüter und seines, Schutzes' über die Klöster als auch auf die päpstlichen Privilegien - Unterschied zum Kirchenregiment eines Georg des Bärtigen ${ }^{73}$ - stützen. ${ }^{74}$ Das Königtum interes-

Volkmar, Landesherrliches Kirchenregiment (wie Anm. 6), S. 90-93, 108; WARTENBERG, Landesherrschaft (wie Anm. 6), S. 20-102; KüHN, Einziehung (wie Anm. 6), S. 8-17; Schulze, Fürsten und Reformation (wie Anm. 6), S. 1, 7, 13-45, 74-76 (Partikularität des vorreformatorischen Landeskirchenregiments), S. 153, 192-197; weiter dazu: Sembdner, Franziskanerobservanz (wie Anm. 6), S. 57 f., 74-77, 85 f.; Ders., Zur Geschichte (wie Anm. 6), S. 46 f., 49, 55; Schilling, Klöster und Mönche (wie Anm. 14), S. 50-55, 75-80, 84, 99-119; Sitzmann, Mönchtum und Reformation (wie Anm. 14), S. 20-22, 30-37; demgegenüber hebt einen qualitativen wie auch quantitativen Unterschied zwischen dem vor- und nachreformatorischen landesherrlichen Kirchenregiment hervor: Wolgast, Einführung der Reformation (wie Anm. 14), S. 14-17.

70 Zur Türkensteuer in der Oberlausitz: Norbert Kersken, Die Oberlausitz und die Türkenkriege, in: Joachim Bahlcke/Volker Dudeck (Hg.), Welt - Macht - Geist. Das Haus Habsburg und die Oberlausitz 1526-1635, Görlitz/Zittau 2002, S. 111-120.

71 Christian Ritter D’Elvert, Die Kammer-Beihilfen und Anlehen der Klöster und landesfürstlichen Städte und die Kloster-Visitationen in den böhmischen Ländern, in: Notizenblatt der historisch-statistischen Section der kais. königl. mährisch-schlesischen Gesellschaft zur Beförderung des Ackerbaues, der Natur und Landeskunde, Jg. 1880, Nr. 4, S. 25-32; Nr. 5, S. 33-40; Tomáš Borovskŕ, Kláštery, panovník a zakladatelé na stř̌edověké Moravě [Klöster, Herrscher und Stifter im mittelalterlichen Mähren] (Knižnice Matice moravské 16), Brno 2005, S. 128 f.; Chládek, Spor (wie Anm. 7), S. 271, 277, 281, 283 f.; Zdichynec, Klášter Osek (wie Anm. 7), S. 95, 106-108; Ders., Předání (wie Anm. 7), S. 36 f.; Ders., Ferdinand I. (wie Anm. 7), S. 102; Ralph AndrascheKHolzer, Klöster und „neue“ Orden in Niederösterreich 1520-1650. Erbe des Mittelalters, Sicherung der Vermögenswerte, neue Orden, Aufschwung, in: Evangelisch! Gestern und heute einer Kirche. Ausstellung des Landes Niederösterreich und der Evangelischen Kirche in Niederösterreich, Schallaburg 2002, S. 109-119, hier S. 110; Ders., Die erbländischen Klöster unter Ferdinand I.: Visitation und „Reformation“, in: Martina Fuchs/Alfred Kohler (Hg.), Kaiser Ferdinand I. Aspekte eines Herrscherlebens (Geschichte in der Epoche Karls V. 2), Münster 2003, S. 61-70, hier S. 62.

72 Zdichynec, Klášter Osek (wie Anm. 7), S. 105-107; Petr Hrachovec, Zum zehenden beweisen mir die von der Zittaw die unnachbarschafft. Die Aufhebung der Johanniterkommenden im Zittauer Land (ca.1521-1571), in: Enno Bünz (Hg.), Neue Forschungen zu sächsischen Klöstern. Ergebnisse und Perspektiven (im Druck).

73 Volkmar, Reform (wie Anm. 6), S. 67 f., 72 f., 112-168, hier bes. S. 154 f., 162-168 (in Bezug auf die Kirchenpolitik Ferdinands I. „blieb Bayern [k]ein Einzelfall“ bzgl. der Besteuerung der Kirche durch weltliche Herrscher, wie es Ch. Volkmar vermutet), S. 234 f., 293-298, 311 f., 337 f., 603; Volkmar, Stunde des Laienstandes (wie Anm. 6), S. 377-387, 404 f.; BüNZ/Volkmar, Landesherrliches Kirchenregiment (wie Anm. 6), S. $94-96$.

74 Chládek, Spor (wie Anm. 7); Zdichynec, Klášter Osek (wie Anm. 7); Ders., Ferdinand I. (wie Anm. 7); oder zahlreiche Aufsätze Tomáš Černušáks; während seiner 
sierte sich also für die Klöster vor allem in finanzieller Hinsicht: Sie sollten als eine verlässliche Quelle der geistlichen Steuern und außerordentlicher Darlehen dienen. Deswegen mussten sie einer stärkeren königlichen Kontrolle unterzogen werden, die z. B. 1567/68 in Niederösterreich zur Gründung einer speziellen Behörde, des sog. Klosterrats, führte. ${ }^{75}$

Um die Klöster in finanzieller sowie religiöser Hinsicht besser kontrollieren zu können, musste das Königtum nicht nur eine Übersicht über möglichst viele Teile des Vermögens der Klöster haben, sondern auch die freie Wahl der Vorsteher der Ordenshäuser abschaffen. ${ }^{76}$ Auf dem Oybin kam es

Regierung verpfändete Ferdinand I. Kirchenvermögen in der Höhe von mindestens 167821 Talern und veräußerte es für 50400 Taler: František Kavka/Anna SkÝbová, Husitský epilog na koncilu tridentském a původní koncepce habsburské rekatolizace Čech. Počátky obnoveného pražského arcibiskupství 1561-1580 [Der hussitische Epilog auf dem Konzil in Trient und die ursprüngliche Konzeption der habsburgischen Rekatholisierung Böhmens. Die Anfänge des erneuerten Erzbistums Prag 1561-1580], Praha 1969, S. 42; zur Lage in Österreich, wo Ferdinands I. kuriale Politik besser als in den böhmischen Ländern erforscht ist: Franz Bernhard von Bucholtz, Geschichte der Regierung Ferdinand des Ersten, Bd. VIII, Wien 1831-1838 [ND: Graz 1968], S. 142-151, 293-296; KARL Eder, Glaubensspaltung und Landstände in Österreich ob der Enns 1525-1602 (Studien zur Reformationsgeschichte Österreichs 2), Linz 1936, S. 15-23, 45; Отнмав Pickl, Fiskus, Kirche und Staat in Innerösterreich im Zeitalter der Reformation und Gegenreformation (16./17. Jahrhundert), in: Hermann Kellenbenz/Paolo Prodi (Hg.), Fiskus, Kirche und Staat im konfessionellen Zeitalter (Schriften des Italienisch-Deutschen Historischen Instituts in Trient 7), Berlin 1994, S. 91-110, hier S. 100-110 (außerodentliche Steuern oder Einziehung des Klostervermögens 1523/24, 1526, 1529, 1537-1543, 1556, 1571-1574 usw.).

75 Eder, Glaubensspaltung (wie Anm. 74), S. 128 f.; Silvia Petrin, Der niederösterreichische Klosterrat 1568-1629, in: Gustav Reingrabner/Gerald Schlag (Hg.), Reformation und Gegenreformation im Pannonischen Raum (Wissenschaftliche Arbeiten aus dem Burgenland 102), Eisenstadt 1999, S. 145-156.

76 Winfried Töpler, Das Kloster Neuzelle und die weltlichen und geistlichen Mächte 1268-1817 (Studien zur Geschichte, Kunst und Kultur der Zisterzienser 14), Berlin 2003, S. 87-113; zu den vom Königtum aufgezwungenen Verpfändungen des Klostervermögens meistens infolge der Türkensteuern bes. S. 93-100; zu Prager Klöstern: Zdichynec, Ferdinand I. (wie Anm. 7), S. 102 f.; zur Entfernung oder Beschränkung der freien Wahl des Abtes in Žd'ár/Saar, Osek/Osseg und in verschiedenen Prager Klöstern: CHLÁdeK, Spor (wie Anm. 7), S. 272, 288, 291; Zdichynec, Klášter Osek (wie Anm. 7), S. 99, 101, 103 f., 115 f.; Ders., Předání (wie Anm. 7), S. 34 f.; Ders., Ferdinand I. (wie Anm. 7), S. 105, 108; zu Ferdinands I. älterem Bruder Karl V.: Ocker, Church robbers (wie Anm. 14), S. 72-74 („That was a ruler who managed his churches"); weiter: Volkmar, Reform (wie Anm. 6), S. 304 f., 512 f.; Ders., Stunde des Laienstandes (wie Anm. 6), S. 400 f.; notwendige Anerkennung der Abtswahlen durch den wettinischen Landesherrn: Schulze, Fürsten und Reformation (wie Anm. 6), S. 135-137 und $142 \mathrm{f}$. (Absetzung des Abtes von Pforte); zum Verbot der Dispositionen mit dem Vermögen der Klöster ohne das königliche Wissen bereits im Spätmittelalter: VÁclaV VANĚČEK, Základy právního postavení klášterů a klášterního velkostatku ve starém českém státě (12.-15. stol.). Zakladatelská práva - Pozemková vrchnost - Imunita [Die Grundlagen der Rechtsstellung der Klöster und des klösterlichen Großgrundbesitzes im alten böhmischen Staat (12.-15. Jahrhundert). Gründerrechte - Grundobrigkeit Immunität], Teil I: Zakladatelská práva [Gründerrechte], Praha 1933, S. 61; diese Kontrolle übte schon vor der Reformation auch Wilhelm III. von Thüringen aus: Schulze, Fürsten und Reformation (wie Anm. 6), S. 60, 66, 107-111; weiter dazu: Wolgast, 
dazu schon in den 1530er-Jahren, als Ferdinand I. seine Vorsteher selbst einsetzte;77 anderswo, z. B. in Neuzelle, konnte sich das Königtum erst in der zweiten Hälfte des 16. Jahrhunderts durchsetzen. ${ }^{78}$ Den aktuellen finanziell-ökonomischen wie auch dogmatischen Zustand in den Klöstern einschließlich des Oybins erfuhr der König mittels regelmäßiger Visitationen: ${ }^{79}$

Einführung der Reformation (wie Anm. 14), S. 221 f.; Sitzmann, Mönchtum und Reformation (wie Anm. 14), S. 86-88.

77 NA Praha, RG 21 (Německé missivy/Deutsche Missive 1539), fol. 390r f., 390 v. (4.12. 1539); die Würdenträger auf dem Oybin haben vor Ort den Oberlausitzer Landvogt einund abgesetzt und ihren altgläubigen liturgischen Stiftungsvollzug beaufsich-tigt: ebd., fol. 391'r sowie: ebd., RG 33 (Německé missivy/Deutsche Missive 1545), fol. $65^{\mathrm{r}}$ f.: Ann lanndthofmaister [Zdislav Berka - P. H.], ainen teugliche [n] ordennsmann zu ainem prior auff Oybin einzusezenn. [...] Wolgebornner lieber getrewer, dieweill wir vernemben, $d z$ der prior auff Oybin inn demselben priorat nit zu verbleyben vermaint, derwegen unnser bevelh, welche person dich unnder den anndern ordenßbrued[er]n inn solchem kloster fur teuglich unnd schicklich annsehen thuet, dieselb zu ainem prior daselbst installierest, doch bei ime verfuegest, sich gehorsamblich unnd nit zuwider zu verhallt[en], damit der dienst gottes, wie sich gepurt, verricht werde (4.3.1545); SAUppe, Geschichte 1903 (wie Anm. 1), S. 207; Ders., Geschichte 1907 (wie Anm. 1), S. 119 f., 125 f.

78 Töpler, Kloster Neuzelle (wie Anm. 76), S. 108 f., 126, 146-153, 158, 163-165, 168, 186 (schon freie Ein- und Absetzungen des Abts durch den König); D’Elvert, KammerBeihilfen (wie Anm. 71), S. 31 f.

79 Töpler, Kloster Neuzelle (wie Anm. 76), S. 144-185; Zdichynec, Klášter Osek (wie Anm. 7), S. 108; D'Elvert, Kammer-Beihilfen (wie Anm. 71), S. 26-36; Österreich (1528, 1535/36, 1544/45, 1545, 1555, 1561/63): ANDrascheK-Holzer, Erbländische Klöster (wie Anm. 71), S. 63-70; Ders., Beobachtungen zum erbländischen Klosterwesen unter Ferdinand I. und Maximilian II., in: Jozef Bad’urík/Kamil Sládek (Hg.), Politický zrod novovekej sjednej Európy. 500. výročie narodenia Ferdinanda I. zakladatel'a habsburskej monarchie [Die politische Geburt des neuzeitlichen Europa. 500. Jahrestag des Geburtstags Ferdinands I. - des Gründers der Habsburgermonarchie], Bratislava 2005, S. 143-147, hier S. 144 f.; Petrin, Niederösterreichischer Klosterrat (wie Anm. 75), S. 246 f.; EDER, Glaubensspaltung (wie Anm. 74), S. 39-43, 57-63, 91100, 123-128, 131-133 (Visitation 1569, die bisher einzige, die die Kirche selbst befahl); die Habsburger verfügten bereits seit 1446 über ein solches päpstliches Privilegium zur Visitation: Rudolf K. Höfer, Die landesfürstliche Visitation der Pfarren und Klöster in der Steiermark in den Jahren 1544/1545. Edition der Texte und Darstellung zu Nachrichten über das kirchliche Leben (Quellen zur geschichtlichen Landeskunde der Steiermark 14), Graz 1992, S. 64 f., 67; Alfred Kohler, Ferdinand I. 1503-1564. Fürst, König und Kaiser, München 2003, S. 192-199; zu Klostervisitationen Hz. Georgs des Bärtigen: Volkmar, Reform (wie Anm. 6), S. 72 f., 105, 259-263, 424, 518 f. (Pfarrvisitationen in der Reformationszeit); BüNZ/VOLKMAR, Landesherrliches Kirchenregiment (wie Anm. 6), S. 104; Felician Gess, Die Klostervisitationen des Herzogs Georg von Sachsen, Leipzig 1888, bes. S. 22-45; weiter: Uwe SCHIRmer, Reformation und Staatsfinanzen. Vergleichende Anmerkungen $\mathrm{zu}$ Sequestration und Säkularisation im ernestinischen und albertinischen Sachsen (1523-1544), in: Michael Beyer/Jonas Flöter/ Markus Hein (Hg.), Christlicher Glaube und weltliche Herrschaft. Zum Gedenken an Günther Wartenberg (Arbeiten zur Kirchen- und Theologiegeschichte 24), Leipzig 2008, S. 179-192, hier S. 181-184, 187; Oенмig, Stadt und Säkularisation (wie Anm. 14), S. 139, 141 f., 171-174; Schulze, Fürsten und Reformation (wie Anm. 6), S. 132 f., 137139, 144; WolgaSt, Einführung der Reformation (wie Anm. 14), S. 32-34, 56-60, 65, 69, 73 f., 88, 94, 99, 106 f., 114, 133, 138, 148, 150, 153, 157, 160, 176, 178 f., 197, 258, 263, 289, 300 f.; KüHN, Einziehung (wie Anm. 6), S. 34-71. 
Petr Hrachovec

$1528,{ }^{80} 1537 / 38,811544^{82}$ oder 1562/6383 wurden die Kleinode der Klöster und der Kirchen inventiert, z. T. beschlagnahmt oder versiegelt. Diese Ferdinandäischen Visitationen dürfen m. E. nicht als „antirömische Maßnahme, die den Übergang zur Reformation vorbereitete“ gedeutet werden; wie Günther Wartenberg die Visitationen des altgläubigen sächsischen Herzogs Georg interpretierte, sonders es ging um ein genuines Instrument eines romtreuen Landeskirchenregiments. ${ }^{84}$

Ferdinand I. interessierte sich wegen der klösterlichen Darlehen und Türkensteuern ebenso für den sehr reichen Kleinodien- und Paramentenschatz des Oybiner Klosters. ${ }^{85}$ Oybin visitierten deswegen erstmals 1532 die königlichen Amtleute. ${ }^{86}$ Seine Kirchenschätze und Geldvorräte wurden dabei nach dem an-

80 Die Protokolle der Visitation 1528 in der Steiermark edierte: Anton Albrecher, Die landesfürstliche Visitation und Inquisition von 1528 in der Steiermark. Edition der Texte und Darstellung der Aussagen über die kirchlichen Zustände (Quellen zur geschichtlichen Landeskunde der Steiermark 13), Graz 1997; dazu schon: KARL EdER, Die Visitation und Inquisition von 1528 in der Steiermark. Gesamterscheinung und kritische Würdigung, in: Mitteilungen des Instituts für Österreichische Geschichtsforschung 63 (1955), S. 312-322.

$81 \mathrm{Zu}$ den Visitationen der Jahre 1537/38 allgemein: NA Praha, ČDKM IV, Kart. 279 (Slezsko církevní kontribuce/Schlesien Kirchenkontribution 1528-1623), fol. 25 ${ }^{\mathrm{r}}-28^{\mathrm{v}}$, 40r-42v; ebd., ČDKM IV, Kart. 280 (Slezsko církevní půjčky/geistliche Anleihen Schlesiens 1537-1576), fol. 4r-9v.

82 Sauppe, Geschichte 1907 (wie Anm. 1), S. 123-125 (auf Grundlage der mir bisher unzugänglichen Quellen, die wohl noch heute in Wien überliefert sind); WenzeL, Inventarisiert (wie Anm. 5), S. 177-184; die Protokolle der Visitation 1544/45 in der Steiermark edierte: HöFer, Landesfürstliche Visitation (wie Anm. 79); dazu schon: KARL Eder, Die landesfürstliche Visitation von 1544/1545 in der Steiermark (Forschungen zur Verfassungs- und Verwaltungsgeschichte der Steiermark 15), Graz 1955.

$83 \mathrm{Zu}$ den Klostervisitationen in den Jahren 1528, 1544 (des Pönfalls 1547/48) und 1562 vgl. auch: Petr_Hrachovec, Die Auflösung des Zittauer Franziskanerklosters während der Reformation. Eine Spurensuche, in: Annegret Gehrmann/Dirk Schumann/Marius Winzeler (Hg.), Die Bettelorden in den beiden Lausitzen. Geschichte - Architektur Kunst, Berlin 2017, S. 398-448, hier S. 418-429; auf keinen Fall stellten diese ,katholischen“ Visitationen „eine ausgesprochene Klerikervisitation“ dar, wie die altgläubigen Visitationen im 16. Jahrhundert Peter Thaddëus Lang, Die Kirchenvisitationsakten des 16. Jahrhunderts und ihr Quellenwert, in: Rottenburger Jahrbuch für Kirchengeschichte 6 (1987), S. 133-153, hier S. 145, interpretiert; und zwar schon in der Hinsicht, dass die meisten Visitatoren in unserem Fall Laien waren.

84 Wartenberg, Landesherrschaft (wie Anm. 6), S. 92 f.; Ders., Der Umgang mit Klostergut im mitteldeutschen Raum im 16. Jahrhundert, in: Müller, Reform Sequestration - Säkularisation (wie Anm. 15), S. 9-24, hier S. 18.

851532 machte die Böhmische Kammer den König darauf aufmerksam, wie das closter, so Oybin genannt, ain ansebenliche parschafft ain (?) clainetern unnd gellt, doch verporgen, beyeinannder haben: NA Praha, RG 9 (Dobrozdání české komory ke dvoru/Gutachten der Böhmischen Kammer an den Hof 1531-34), S. 233.

$86[\ldots]$ so ist an euch unnser bevelch, das ir von unnsern wegen ain ieder zwo tewglich und vertraut personnen, nach ewrem gwtbedunckben zu comissarien verordnet unnd inen aufleget, sich daselbsthin zu erbeben unnd die munich und clost[er]spersonnen, so noch verhannden, aigenntlich unnd mit guetter schickblichait auch ainem ernnst besprechen, wo unnd wievill des angezaigten parn geltts unnd clainetern verbannden sein und alles vleyssig beschreyben unnd inventiern, sich auch darneben ires wesens unnd thuens 
fänglichen Bedenken der Mönche inventarisiert. Sie sollen bisher von den Mönchen bestens verwahrt worden sein. Laut den Visitatoren bestand keine Gefahr ihrer Entwendung. ${ }^{87}$ Folgenschwer für den Konvent war jedoch die Tatsache, dass ihm die Visitatoren im Namen des Königs die Disposition über die Klostergüter und -finanzen ohne Wissen des Landesherrn verboten. ${ }^{8}$

Weitere Visitationen, zuerst durch den Wiener Bischof Johann Fabri (1534) ${ }^{89}$ und kurz danach durch den schlesischen Rentmeister Heinrich Ribisch ${ }^{90}$ forderten vom Konvent vor allem hohe Darlehen für den König. Andere Visitationen zwecks der Inventierung der Klosterschätze, die wohl auch Oybin einbezogen, fanden $1537^{91}$ und $1546^{92}$ statt. Während man 1532 die Schätze nur einschloss und auf dem Oybin behielt, schritt das Königtum 1539 zu ihrer partiellen Einschmelzung. ${ }^{93}$ Zugleich erlaubte Ferdinand I. dem durch die reformatorischen Umwälzungen bedrängten Oybiner Konvent, für seinen Bedarf die Klosterschätze, die mangelhaft waren, in der Höhe von einhundert Mark zu vermarkten. ${ }^{94}$

Neben den durch die Reformation bedingten Schwierigkeiten lag der Grund dieses Entgegenkommens Ferdinands I. sicher auch in der Absicht, seinen erheblichen Steuerdruck auf den Konvent ein wenig zu mildern. Allein die zeitgenössische Chronik des Stifts Oybin beinhaltet zwischen 1532 und 1545 mindestens

aigenntlich erkhunden: NA Praha, RG 8, S. 232 (Ferdinand I. an die Böhmische Kammer; 14.11.1532).

87 NA Praha, ČDKM IV, Kart. 169, fol. $3^{\text {r }}$ f. (Zdislav Berka und Hans Gotsch auf Kynast/ Chojnik an Ferdinand I.; 21.12.1532); das Inventar vom 20.12.1532 ist noch heute überliefert: fol. 4r-7v (22.12.1532); RG 8, S. 250 f. (4.1.1533); OETTEL, Auflösung (wie Anm. 1), S. 22 f.; Sauppe, Geschichte 1903 (wie Anm. 1), S. 206; Ders., Geschichte 1907 (wie Anm. 1), S. 112-114; Wenzel, Inventarisiert (wie Anm. 5), S. 174 f.

88 [...] doch ynen ynn name[n] E. Kho. Mt. mit ganzem ernst befolben, an sulch [e]m allem ausserbalb E. Kho. Mt. bewillung und vorwisse[n] gar nichtes zu vormyndern, nach zu vorrucke[n] lassen auch selber nicht thun: NA Praha, ČDKM IV, Kart. 169, fol. 3v, 8; dazu auch: D'Elvert, Kammer-Beihilfen (wie Anm. 71), S. 28.

89 SOA Litoměčice/Děčín, RA Clam-Gallas, Sign. 2168/72, Kart. 584, inv. č. 2169, S. 5; zu Fabris Reise durch die Nebenländer: RA Görlitz, LM (1531-1534), fol. 628v f.; NA Praha, ČDKM IV, Kart. 278 (Slezsko, duchovní věci a statky/Schlesien, geistliche Sachen und Güter 1534-1629), fol. $1^{\mathrm{r}}-5^{\mathrm{v}}$.

90 Vgl. Anm. 1-5.

91 NA Praha, RG 17 (Německé missivy/Deutsche Missive 1536-1537), fol. 71 ${ }^{\mathrm{r}}$ (Ferdinand I. an die Oberlausitzer Stände; 17.4.1537); weiter dazu: fol. $71^{\mathrm{r}}$ f., $187^{\mathrm{r}}$ f., fol. 187v, $220^{\mathrm{r}}$.

92 NA Praha, ČDKM IV, Kart. 145 (Biergeld in der Oberlausitz 1546-1574), unpag. (Ulrich von Nostitz an Ferdinand I.; 9.11.1546).

93 SOA Litoměčice/Děčín, RA Clam-Gallas, Sign. 2168/72, Kart. 584, inv. č. 2169, S. 9: hier vgl. den Bericht über die Einschmelzung des Klosterschatzes in Görlitz vor dem 24.6.1539 und zugleich ein Verzeichnis der damals verschonten Klosterkleinode. Vieles wurde nicht eingeschmolzen, was die Verzeichnisse der Schätze, die 1556 und 1560 die Jesuiten nach Prag transportieren ließen, belegen: NA Praha, APA I - Historica, Sign. C 148/3, Kart. 2260, fol. $5^{\mathrm{r}}-8^{\mathrm{r}}, 10^{\mathrm{v}}-12^{\mathrm{v}}$ (26.3.1556); $13^{\mathrm{r}}, 16^{\mathrm{v}}$ (5./6.6.1556); ebd., unpag. (Inventar der Ausstattung vom 10.6.1556); SK Praha, Sign. DC III 20, fol. $33^{\mathrm{r}}$, 34v (Jahr 1560); das letzte Inventar von 1562: NA Praha, ČDKM IV, kart. 169, fol. 275r ${ }^{\mathrm{r}} 279^{\mathrm{r}}$; Sauppe, Geschichte 1903 (wie Anm. 1), S. 206 f.

94 NA Praha RG 21, fol. 202 ${ }^{\text {r }}$ (8.5.1539); SAuppe, Geschichte 1907 (wie Anm. 1), S. 119; Oettel, Auflösung (wie Anm. 1), S. 23. 
zwanzig Einträge über Geldabgaben des Konventes, die sich auf mehrere Tausend ungarische Gulden beliefen. ${ }^{95}$ In den 1530er- und 1540er-Jahren musste sich das Kloster darüber hinaus mit dem Problem auseinandersetzen, mit welchem Oberlausitzer Stand es seine Steuern abführen soll. ${ }^{96}$ Sowohl der gemeinsame Stand der Adligen und Prälaten (sog. Land) als auch der Städtestand (die Stadt Zittau) verlangten die Oybiner Steuern für sich. ${ }^{97}$ Doch der König bzw. die Böhmische Kammer bestanden vielmehr darauf, dass Oybin von beiden Ständen exemt sein sollte, da es direkt der Böhmischen Kammer als ein königliches Kammergut untergeordnet sein sollte. ${ }^{98} 1542$ ordnete Ferdinand I. Oybin in Steuerabgaben allein der Kammer unter. ${ }^{99}$ Doch in der sog. Decisio Ferdinandea vom 8. Februar 1544 ließ Ferdinand I. wiederum die Möglichkeit zu, dass das Kloster seine Steuern auch mit beiden Ständen abführen könnte. ${ }^{100}$ Die Frage der ,Mitleidung' des Klosters wurde nie eindeutig geregelt.

Die bereits erwähnte Stellung der Klöster als Kammergüter war dabei eines von drei Rechtsinstituten, mit denen die Habsburger auf die Klostergüter zurückgriffen. Dazu gesellte sich noch das Institut des ,Schutzes' und darüber hinaus betrachteten sich die Habsburger als oberste Vögte bzw. oberste Kollatoren aller Klöster auf ihrem Herrschaftsgebiet. Der Ursprung der territorialen obersten Vogtei, die sich jedoch für Oybin nicht nachweisen lässt, liegt in Österreich in der zweiten Hälfte des 13. Jahrhunderts. Sie umfasste sicher die Bestätigungen der Vorsteher der Ordenshäuser, die Aufsicht über Vermögen, Steuern und Darlehen. Den eigentlichen Stiftern blieben nur Ehrenrechte (Begräbnis im Kloster usw.). ${ }^{101}$

95 Vgl. den Anhang.

96 Dazu: Sauppe, Geschichte 1907 (wie Anm. 1), S. 114-117, 121-123; auch: ERnst Emil Struve (Hg.), Scriptores rerum Lusaticarum Neue Folge, Bd. IV: Magister Johannes Hass, Bürgermeister zu Görlitz - Görlitzer Rathsannalen, Bd. 3 (1521-1542), Görlitz 1870 (im Folgenden: SRL NF), S. 320-322.

97 NA Praha, RG 6 (Německé missivy/Deutsche Missive 1530), S. 176 (5.3.1530); RG 8, S. 328 (9.8.1533); RG 9, S. 517 (25.8.1533); SOA Litoměčice/Děčín, RA Clam-Gallas, Sign. 2168/72, Kart. 584, inv. č. 2169, S. 11 f.; NA Praha, Lž III/16/13 (Steuer), Kart. 252, fol. 99v; ČDKM IV, Kart. 169, fol. 50v, 54r, 63v f., 67r.

98 NA Praha, RG 9, S. 538 (Böhmische Kammer an Ferdinand I.; 25.8.1533; bzgl. der Türkensteuer mit dem Landstand): [...] das dasselb E. Mt. camer unnd hochaiten zu nahenndt unnd auch nachtailig sein mechte unnd bey unns vilfur pillicher unnd ordennlicher angesehen ist, das die unnd annder closterlewt von den stennden exempt gemacht unnd ire bilffen in dy camer genommen (?) unnd gefurdert werden; RG 8, S. 360 (2.11.1533).

99 Und aber dz gemelt closter Oybin von weillend kaiser Karlen [Karl IV. - P. H.] und anndern unnsern vorferdern konigen zu Behaimb, wie sy unns berichten, insonnderhait befreit sein, dz sy mit iren steuern nibt in ain lanndtschafft gezogen, sonnder, sovil inen pillich, neben andern ze geben gebuert, in unnser camer raichen oder ains lanndtvogts, doch zu unnser, als ains koniges, hannden uberantwurten sollen: NA Praha, RG 22 (Německé komorní listiny/Deutsche Kammerurkunden 1539-1546), fol. 92v .

100 Collection derer den STATVM des Marggrafthums Ober-Lausitz [...], Budissin 1771, Bd. II, S. 1322-1324.

101 Dazu: Chládek, Spor (wie Anm. 7), S. 273-275, 283, 286-288, 290-292; Zdichynec, Ferdinand I. (wie Anm. 7), S. 102; zu Hz. Georg dem Bärtigen als sog. obersten Kollator: Volkmar, Reform (wie Anm. 6), S. 290, 297, 326-334, 340-342, 426-429 (doch beanspruchte für sich Hz. Georg nie den Titel des sog. Obersten Vogts), S. 511, 615, 619; Ders., Stunde des Laienstandes (wie Anm. 6), S. 384; Bünz/Volkmar, Landesherrliches Kirchenregiment (wie Anm. 6), S. 108; Schulze, Fürsten und Reformation (wie Anm. 
Während man also die ,Oberste Vogtei` wohl für einen Import aus Österreich halten kann, waren die Stellung der Klöster als königliche Kammergüter und der königliche Schutz, den über das Kloster Oybin seit 1370 anstelle des Königs der Zittauer Rat ausübte, heimischen Ursprungs. ${ }^{102}$ Sie lassen sich schon unter den letzten Přemysliden belegen und in nachfolgender Zeit wurden sie sukzessiv vom Königtum ausgebaut; zuungunsten der eigentlichen Stifter. ${ }^{103}$ Ferdinand I. griff also auf längst vorhandene Instrumente zurück; doch in einer bis dahin so nie dagewesenen Intensität. ${ }^{104}$ Im Fall seiner Geldnot war er sogar bereit, ganze Klöster an Laien zu verpfänden (wie in Neuzelle 1547). ${ }^{105}$

6), S. 56 (Wilhelm III. von Thüringen als „territorialer Ordensoberer“); HRACHOvEc, Auflösung (wie Anm. 83), S. 421.

102 Die Könige Sigismund (1419-1437), Albrecht (1437-1439), Georg von Poděbrad (14581469/71), Matthias (1469-1490) und Wladislaw II. (1471/90-1516) befreiten Oybin von der Bezahlung der königlichen Berna; doch war es Wladislaw II., der suscipit specialiter priorem et conventum in Regiam suam protectionem sowie den Konvent in Steuersachen allein seiner Kammer unterordnete: Item sollen die Königl. Böhmische Hülffe und Stener so einen auferlegt würde von den übrigen selbst samlen und abnebmen und nicht mit andern unsern Land und Städten sondern selbst zu Unserer Cammer oder unsern Voigt und Ambtmann der Lande und Sechß Städte etc. der zur selben Zeit seyn wird, überantwortten, die zu unsern Nutz oder Hülffe und enthaltung Ibres Closters zuwenden: Sauppe, Regesta (wie Anm. 21), S. 371, 375 f.

103 In den deutschen Territorialstaaten scheinen die Fürsten die ehemaligen Klostergüter meistens erst im Zuge der Reformation ihrer Kammer untergeordnet zu haben: Wolgast, Einführung der Reformation (wie Anm. 14), S. 161; Sitzmann, Mönchtum und Reformation (wie Anm. 14), S. 62 f.; SPRInger, Deutsche Dominikaner (wie Anm. 17), S. 221, 241, 249, 255 f., 281, 291, $353 \mathrm{f}$.

104 VANĚČEK, Základy I (wie Anm. 76), S. 6-24 (Bestimmung der einzelnen Rechte wie Schutz, Inkammerierung usw.), S. 56-64 (Schutzrechte); das vergleichsweise hohe Aus$\mathrm{maß}$ an Inkammerierung der Klöster in den böhmischen Kronländern betont: Borovský, Kláštery (wie Anm. 71), S. 11, 15-20, 70-72 (Konzentrierung der meisten Gründerrechte in Mähren in der Hand des Königs bereits im 13. Jahrhundert auch bei den adligen Klosterstiftungen), S. 73-104 (Fortsetzung dieser Klosterpolitik auch unter den Luxemburgern; Versuch Karls IV., alle Klöster in seinem Territorium zu inkammerieren), S. 105-132 (die steuerpolitischen Folgen dieser Inkammerierungspolitik), bes. S. 127-129 (die Klosterpolitik Ferdinands I.), S. 268 f.; D'Elvert, Kammer-Beihilfen (wie Anm. 71), S. 26, 31, 36; CHLÁDEK, Spor (wie Anm. 7), S. 273, 275, 277 f., 280, 284, 286, 288 f., 290, 292; Zdichynec, Klášter Osek (wie Anm. 7), S. 91 f., 95, 100 f., 115; Ders., Předání (wie Anm. 7), S. 45-48, 55, 59, 63; Ders., Ferdinand I. (wie Anm. 7), S. 101 f.; Wutke, Schlesische Besitzungen (wie Anm. 37), S. 43 f., 48 f., 59 f., 63; TöPler, Kloster Neuzelle (wie Anm. 76), S. 98, 166, 186; Wenzel, Inventarisiert (wie Anm. 5), S. 175 f.; Hrachovec, Auflösung (wie Anm. 83), S. 421-429; in Österreich: Eder, Glaubensspaltung (wie Anm. 74), S. 16; HöFER, Landesfürstliche Visitation (wie Anm. 79), S. 69, 72; Pickl, Fiskus (wie Anm. 74), S. 94, 100, 106; Andraschek-Holzer, Erbländische Klöster (wie Anm. 71), S. 70; Rudolf Maurer, Ausgestorben aufgehoben. Das zweimalige Ende des Augustinerklosters Baden bei Wien, in: Thomas Aigner/Ralph Andraschek-Holzer (Hg.), Abgekommene Stifte und Klöster in Niederösterreich (Geschichtliche Beilagen zum St. Pöltner Diözesanblatt 23; Beiträge zur Kirchengeschichte Niederösterreichs 6), St. Pölten 2001, S. 165-189, hier S. 169; zur "Schirm- und Schutzherrschaft" der Wettiner über ihre Klöster: Volkmar, Reform (wie Anm. 6), S. 253-255; Schulze, Fürsten und Reformation (wie Anm. 6), S. 139-142.

105 Töpler, Kloster Neuzelle (wie Anm. 76), S. 96 f.; Pickl, Fiskus (wie Anm. 74), S. 103; Maurer, Ausgestorben (wie Anm. 104), S. 172; Eder, Glaubensspaltung (wie Anm. 
Ferdinand I. bemühte sich erneut um die Anbindung des Klosters Oybin an seine Kammer. Erste Belege erscheinen in der Kopialüberlieferung zum Jahr 1532. ${ }^{106}$ Für den Zweck des landesherrlichen Kirchenregiments war es sicher sehr nützlich, möglichst viele Kloster- und Kirchengüter zu Kammergütern zu erklären (Inkammerierung), denn dadurch konnte auch ein romtreuer König mit dem Kirchengut als seinem Dominium ziemlich frei disponieren. Eine solche Unterordnung gegenüber dem Königtum verschaffte zwar der altgläubigen Kirche mehr Schutz gegen die Protestanten, sie hatte jedoch auch eine erhöhte landesherrliche Besteuerung und Visitationen, d. h. eine intensivierte königliche Kontrolle, zur Folge. ${ }^{107}$

Ferdinand I. war dabei wenigstens vor dem Pönfall 1547 bereit, sein klösterliches Kammergut gegen die Sequestrierungsversuche des Zittauer Rats zu schützen. Den passenden Anlass zum Ausschalten dieses Kontrahenten im Ringen um das Oybiner Kloster hatte er, als er in einen gewaltsamen Streit zwischen dem Zittauer Rat und dem Oybiner Konvent zugunsten des Klosters eingriff. Dieser Streit, zu welchem dem zeitgenössischen Görlitzer Chronisten Johannes Hass zufolge die Zittauer ihre evangelischen Geistlichen mit einbezogen haben sollen, hatte neben der Geldstrafe von 3000 fl. rh. für den Zittauer Rat auch die Folge, dass er wiederum die Rente (nun) 90 Schock Groschen jährlich dem Kloster abführen musste. ${ }^{108}$ Wahrscheinlich hörte der Zittauer Rat mit der Überweisung der

74), S. 81-85; D’Elvert, Kammer-Beihilfen (wie Anm. 71), S. 27 (außerordentliche Darlehen), S. 31 und 36 (Darlehen und Erlaubnis zur Verpfändung des Klostervermögens), S. 37-40 (Darlehen).

106 Es ist auch ain reich unnd vermuglich closter Oybin, so in Beheim unnd an den guetern in Lausiz [...] unnd sonnst etliche anndere closter mer, welcher etlich herrn in Beheim, fundatores, die auch ains tails unnder irem district unnd jurisdiction, aber bisheer in vorigen bilffen von der camer gestewrt sein. Wissen wir nit, ob sich gezimben oder fuegen wolle, von E. Mt. \#wegen\#, darauf ain anslag ze machen. Dieweil sy doch <...> on zweifl deenen (?), unnder der gepiet sy gesessen, auch hilff unnd stewr thuen mochten. Doch were es unnsers bedunckhens zu versuechen, ob man daran etwas erhallten unnd sy also in E. Mt. camer bringen mecht[en]: NA Praha, RG 9, S. 197 (Böhmische Kammer an Ferdinand I.; 27.6.1532), S. 233 (27.7.1532), S. 538 (24.10.1533).

107 In diesem Sinne ist es interessant, das Ch. Volkmar in seiner Dissertation über die Kirchenpolitik Hz. Georgs des Bärtigen nur einmal (und darüber hinaus ziemlich flüchtig) die Stellung der Klostergüter als landesherrliche Kammergüter berührt: Volkmar, Reform (wie Anm. 6), S. 253. An diesem Beispiel (sowie bzgl. der päpstlichen Privilegien) kann man wohl einen sehr deutlichen Unterschied zwischen dem Kirchenregiment böhmischer Könige beobachten, für welche die Kirchengüter ein Teil ihrer Domäne bereits seit dem Hochmittelalter waren, und der augenscheinlich wesentlich schwächeren Stellung der sächsischen Wettiner; auch: BüNZ/VolKMAR, Landesherrliches Kirchenregiment (wie Anm. 6): erwähnen mit keinem Wort die Inkammerierung der Kirchen- und Klostergüter als Instrument des landesherrlichen Kirchenregiments.

108 Es ging um einen Streit wegen Wasserleitungen: SRL NF IV (wie Anm. 96), S. 361-363, in dessen Folge der Zittauer Rat im nachfolgenden Jahr vom König zu einer Strafe von 3000 fl. rh. verurteilt wurde: SOA Litoměčice/Děčín, RA Clam-Gallas, Sign. 2168/72, Kart. 584, inv. č. 2169, S. 7; RA Görlitz, LM (1534-1536), fol. 329r, 342v , 368r' ; NA

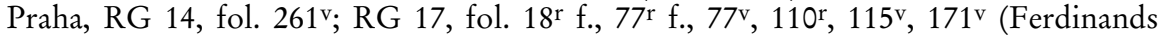


Rente an den Konvent bereits in der frühen Reformationszeit auf. Seit 1537 musste Zittau eine Hälfte der Rente dem Konvent und die andere der königlichen Kammer überweisen. ${ }^{109}$ Der Zittauer Rat musste jedoch trotz solcher Aufteilung eine doppelte Rente abführen: Da nun der Konvent und die Kammer auf den Böhmischen Groschen bestanden, die sich auf das Doppelte der sog. Meißner Groschen beliefen, in denen der Rat bisher die Rente überwiesen hatte. ${ }^{110}$ Darüber hinaus ermöglichte dieser Konflikt dem König, den Schutz des Zittauer Rates über das Kloster, den dieser seit 1370 ausübte, aufzuheben und das Kloster allein ihm selbst bzw. seinem Landvogt und seiner Kammer unterzuordnen. ${ }^{111}$ In den folgenden Jahren musste der König seinen Entschluss, den Schutz über das Kloster in seine Hände zu übernehmen, mehrmals ausdrücklich behaupten, da augenscheinlich sowohl der Zittauer Rat als auch der Konvent selbst mit der neuen Rechtslage nicht einverstanden waren. ${ }^{112}$

Auch später bestanden die Habsburger immer auf der Stellung Oybins als königliches Kammergut, so während der Verpfändung des Klosters an Zdislav

schreiben an die von Sithaw, die $3.000 \mathrm{~g}$ [u]ld[en] zwischn bie und Galli [16.10.1537] zu erlegen; 21.8.1537), fol. 172v , 217r; RG 8, S. 557, 564; RG 15 (Dobrozdání české komory ke dvoru/Gutachten der Böhmischen Kammer an den Hof 1535-1540), fol. 136r; Sauppe, Geschichte 1903 (wie Anm. 1), S. 192 f.; Ders., Geschichte 1907 (wie Anm. 1), S. 116-119; OetTel, Auflösung (wie Anm. 1), S. 23.

109 NA Praha, RG 17, fol. 110r, fol. 172ri RG 8, S. 557; RG 15, fol. 135v f.

110 Vgl. die symptomatische Beschwerde des Zittauer Rates in einem undatierten Schreiben an Ferdinand I. (vor dem 7.2.1538): NA Praha, Lž II 34/2, Kart. 171, fol. $2^{\mathrm{r}}$ f., $4^{\mathrm{r}}-6^{\mathrm{r}}$.

111 Vgl. die Anklage des Königs dem Zittauer Rat gegenüber: Dieweil inen [den Zittauern - P. H.] das closter, als unnser chamergut zu schutzen, vertraut und eingeraumbt, das sy sich ainer solchn gwaltsamen handlung an denselbn unnsern chamerguetern baben dorffen einlassen: NA Praha, RG 17, fol. 115 (6.6.1537); sowie die Entscheidung des Königs vom 21.8.1538, indem er den ,Schutz ' über das Kloster Oybin anstelle der Zittauer von nun an selbst übernahm: Zum anndern, so wellen wir den schuz, so ir [die Zittauer - P. H.] uber das closter gehabt, widerumb zu unnsern, oder wemb wir solchs bevelhn werden, hanndn genomben haben. Ernstlich bevelhund, das ir solchn schüzbrief [Kaiser Karls IV. von 1370 - P. H.] unns zu unnsern bannden raicht und zuestellt, auf das wir solchn, dem wir er bevelhn werden, einraumben mugen: ebd., fol. $172^{\mathrm{r}}$.

$112 \mathrm{Vgl}$. einen Brief des Königs an den Oybiner Konvent vom 14.3.1543: Wir \#sein\# in erfarung kumben, als solt ir euch vernemben lassen, als hetten wir den schuz uber euch und das kloster Oybin von dem wolgebornen etc. Zdislaven Berkn etc. aufgehaben und den ersamen unsern lieben getrenen n. burgermaister und rathmannen der stat Zithau widerumben eingeraumbt. Zum andern [...] dardurch wol abzunemben, das ir villeicht lieber die von der Sithau als unsern landvogt zu einem schuz wissen mocht [...]. Und ist darauf unser ernstlicher bevelch, das ir bei vermeidung unserer schwern straf, ungnad und entsezung eurer ambter [...] das sloß in guter verseebung erbaltet, mit fursteeung des stiffts, das von dem haus an grundpoden, waldern und gepirgen nichts entzogen und sovil auch da uber den kosten oder erbaltung des haus versamblt, nichtes an andere orter verschicket und sovil ir in mangel oder euch auch durch jemanden ainich beschwerung zugefugt werden wolte, euch zu unserm behmischen landhofmaister, als der orth landvogt [Zdislav Berka - P. H.], und eurem euch auf dismals von uns verordentem schuz zueflucht habt, ruckhn, schuz und scherm suecht [...]: NA Praha, RG 26, fol. $45^{\mathrm{r}} \mathrm{f}$.; weiter dazu: ebd., fol. $44^{\mathrm{r}}, 44^{\mathrm{v}}$. 
Berka (1547-1550/51), ${ }^{113}$ ebenso (selbstverständlich) während der direkten Verwaltung des Klosters und seiner Klostergüter durch das Königtum unter dem Hauptmann Jakob Hag (1551-1556) sowie während der Pacht- bzw. Pfandinhaberschaft der Oybiner Güter durch den Zittauer Rat seit 1556 bzw. seit 1562.114 Ebenso verwalteten die Prager Jesuiten (1556-1562)115 und die königlichen Hauptleute Benno von Salza (1562-1566)116 und Hermann Ygl (1566-1570)117 Oybin als königliches Kammergut. Und als sich Zittau vor 1570 um die Übernahme der gesamten oybinischen Güter bemühte, bestand sogar der Stadtrat selbst darauf, dass sich nichts bzgl. der Rechtsstellung der Oybiner Güter als Kammergüter ändern wird. ${ }^{118}$

Ein anderer Aspekt des Ferdinandäischen Kirchenregiments lag in der Sorge um die letzten verbliebenen Cölestiner. In den Quellen erscheinen vor allem die beiden letzten Priore Christoph Uthmann und Balthasar Gottschalk. Uthmann entstammte einer Görlitzer Ratsfamilie. ${ }^{119}$ Er studierte um 1510 an der Universität Leipzig. Seine lateinischen Briefe bezeugen hohe Bildung. Sie waren gespickt mit Zitaten und Paraphrasen aus den römischen Klassikern und zeitgenössischen Humanisten. ${ }^{120}$ Außerdem verfasste er eine kurze ,Chronik' des Klosters für die

113 Vgl. die eindeutige Äußerung des Königs im Streit zwischen dem Oybiner Pfandinhaber Zdislav Berka und dem Liegnitzer Hz. Friedrich III. um die schlesischen Güter des Klosters: [...] das wir alls d[er] obrist herzog inn Slesien unnd dasselb dorff unnser erbguet [...] ob wir wol obrister herzog inn Slesien unnd diß geistlich leben unnser erbguet [...]: NA Praha, RG 40, fol. $217^{\mathrm{r}}$.

114 Aber dieweill solch stifft ane mitel E. Mt. camerguet ist [...]: NA Praha, ČDKM IV, Kart. 169, fol. 115 ${ }^{\mathrm{r}}$ (25.4.1552); [...] damit Irer Mat. camberguet, das stiefft Oybin, zue mebrer nuzunge befordert [...]: Lž III/15/1a (Posudné/Biergeld), fol. $33^{\mathrm{r}}$ (6.5.1552); [...] Irer Mt. camme[r]gutte des stieffts Oybin [...]: RA Görlitz, Varia 226, unpag. (29.10.1552).

115 [...] la quale sono tanti anni che ha governato per un Capitanio quel monastero et applicato li beni alla camera Boemica [...]: Briefwechsel Canisius I (wie Anm. 57), S. 615, Nr. 202; S. 627, Nr. 205.

116 NA Praha, RG 79 (Dobrozdání české komory ke dvoru/Gutachten der Böhmischen Kammer an den Hof 1565), fol. 320r (25.9.1565); HStA Dresden, 10024 Geheimer Rat (Geheimes Archiv), Loc. 9346/13, fol. 41 ${ }^{\mathrm{r}}$ (24.3.1556).

117 HStA Dresden, 10024 Geheimer Rat (Geheimes Archiv), Loc. 9346/13, fol. 45v $5^{\mathrm{v}}$ (26.10.1567).

118 [...] gemelte Oywinische güeter ydoch einen weg wie den andern Ew[e]r Khay. Mt. etc. cam $[m]$ ergueth vorbleiben, Ewer Kay. Mt. etc. auch der gaistligkheit darundter nichts verwendt noch endtzogen wirdt: NA Praha, ČDKM IV, Kart. 169, fol. 257v , 258v, $261^{\mathrm{v}}$ f., $267^{\mathrm{v}}, 291^{\mathrm{v}}$.

$119 \mathrm{Zu}$ den Beziehungen der Görlitzer Ratsfamilien zum Oybin: Speer, Bedeutung (wie Anm. 36), S. 319-322.

120 Herzog-August-Bibliothek in Wolfenbüttel (im Folgenden: HAB), Cod. Guelf. 108 Noviss. $2^{\circ}$, fol. $123^{\mathrm{r}}-125^{\mathrm{v}}$ (6.4.1532 und 12.1.1533); Otто Clemen, Zur Geschichte dreier Dekane des Kollegiatstifts St. Petri zu Bautzen im 16. Jahrhundert, in: Archiv für Reformationsgeschichte 33 (1936), S. 259-284, hier S. 280-283, Nr. 14 f.; NA Praha, ČDKM IV, Kart. 169, fol. 6r-7v (Uthmann an Ferdinand I.; 22.12.1532); Uthmanns deutsche Briefe an den Görlitzer Rat, in: RA Görlitz, Varia 226, alle unpag. (6.12.1532, 23.1.1536, 15.12.1538, 8.6.1544); weiter dazu: LM (1534-1536), fol. 93 ${ }^{\mathrm{r}}$ f. (21.4.1535), 93v (Görlitz an Zittau; 21.4.1535), 95 (Görlitz an Zittau; 25.4.1535). 
Jahre 1532 bis 1545.121 Nach der Verpfändung Oybins an Zdislav Berka von Dubá im Jahre 1547 hatte er sicher von Berka eine Pension erhalten, auch wenn sich seine Pensionierung aus der Böhmischen Kammer erst für die Zeit der Hauptmannschaft Jakob Hags (1551-1556) belegen lässt.122 Die Mönche erhielten damals Pensionen - gegen ihren Verzicht auf die Verwaltung der Klostergüter zugunsten der Landesherren - sowohl von den katholischen als auch den protestantischen Herrschern. ${ }^{123}$ Uthmann starb am 2. September $1555 .{ }^{124}$ Trotz seiner scharfen Kritik an den lutherischen Häretikern von $1532^{125}$ schenkte er dem Zittauer Rat Luthers Schrift über den Galaterbrief von $1538^{126}$ und machte eine Stiftung zugunsten der (schon evangelischen) Armen beim Zittauer Gotteskasten (Gemeiner Kasten). ${ }^{127}$ König Ferdinand I. war nicht begeistert, wenn die Mönche

121 SOA Litoměčice/Děčín, RA Clam-Gallas, Sign. 2168/72, Kart. 584, inv. č. 2169; und Anhang.

122 Vgl. die Rechnungen des Klosters: It[em] auf besoldung ist außgeben, unnd namblich dem prior [Christoph Uthmann - P. H.] daselbst auf dem kaiserlichen gestifft Oybin ist man als ainer incorporiertten ordenßpersonen schuldig, die notturfft zu geben, thuett $4 \beta \beta 48 \mathrm{~g}$ [288 Gr.]; dem vatter Balthaser [Gottschalk - P. H.], so ausserbalb des schlo $\beta$ auf der vatter hoff zur Sidtaw wondt, ime zu underhalttung $52 \beta \beta 24 \mathrm{~g}$ [3 $144 \mathrm{Gr}$.]; dem altten Jacob, ist auch ain incorporate person, $3 \beta \beta 5 \mathrm{~g} 3 d$ [185 Gr. 3 d]: NA Praha, ČDKM IV, Kart. 169, fol. 64v (1552/53); fol. 54r f. (1553/54): dem prior [Christoph Uthmann - P. H.] als einer incorporierten orden $\beta$ personen $31 \beta \beta$ [1 $860 \mathrm{Gr}$.]; dem vatter Balthawser [Gottschalk - P. H.], so sich ausserbalb des schloß auf der vatter hoff zu der Sittaw selbst vercost, $63 \beta \beta 48 \mathrm{~g}$ [3 $828 \mathrm{Gr}$.]; dem altten Jacob, als ainem incorporaten personen, die nodturff zu geben $2 \beta \beta 30 \mathrm{~g}[150 \mathrm{Gr}]$; Der Grund, warum Gottschalk mehr Geld als Prior Uthmann erhielt, lag darin, dass Gotschalk nicht im Konvent, sondern in Zittau auf dem Väterhof wohnte, wo er sich selbst verköstigte und wo er sicher die Oybiner Almosenverpflichtungen ausüben musste.

123 Wolgast, Einführung der Reformation (wie Anm. 14), S. 32, 48, 65, 97, 100, 110, 151, 168 f., 195, 251 f., 284; Schirmer, Reformation und Staatsfinanzen (wie Anm. 79), S. 190; Schilling, Gewesene Mönche (wie Anm. 14), S. 25; Ders., Klöster und Mönche (wie Anm. 14), S. 178; KüHn, Einziehung (wie Anm. 6), S. 47, 61 f., 64, 67 f., 96, 104, 209, 220; Sitzmann, Mönchtum und Reformation (wie Anm. 14), S. 62, 64-68; SPRINGER, Deutsche Dominikaner (wie Anm. 17), S. 91, 95, 122, 142, 214, 220, 223, 239, 267 f., 285, 340; Oenmig, Mönchtum (wie Anm. 14), S. 258; Ders., Stadt und Säkularisation (wie Anm. 14), S. 156-169; BüNZ, Schicksale (wie Anm. 14), S. 91, 97 f., 101.

124 CWB Zittau, Mscr. A 122b (Chronik Arnsdorff), fol. 292v.

$125 \mathrm{Vgl}$. Anm 65.

126 SAuppe, Geschichte 1903 (wie Anm. 1), S. 237.

$127<C$ 2: Der wirdige vater Christophorus [Uthmann - P. H.] hot den armen 31/2 m[a]rg zugeeygent. Es sein aber $7 \mathrm{~m}$ [a]rg. Die Blumelin sol die gebn. $1 / 2$ sein bey Jorg Bornsteyne gekumert umb die sybn, die sol die frau von Pa[n]cratio, dem diener, gemanet werden. Dergestalt 31/2 m[a]rg Zitt[isch] will der vater nehmen und die andere den armen lossen. D[a]t [um], so ich recht gedencke >: CWB Zittau, Mscr. A 250 (ältestes Verwaltungsbuch des Zittauer Gotteskastens; ohne Datum), fol. 23r ${ }^{\mathrm{r}}$ 26v Reiner Neumann (Hg.), Register zu verschiedenen Handschriften des Zittauer Gotteskastens aus der Zeit der ersten 100 Jahre seit der Gründung im Jahre 1527, Zittau 2007 [elektronische Quelle], S. 39, Nr. 126 und S. 40 f., Nr. 138; auch der letzte Wismarer Dominikanerprior vermachte 1574 den evangelischen Stadtarmen im einstigen Dominikanerkloster eine Summe: Ingo UlPTS, Die Bettelorden in Mecklenburg. Ein Beitrag zur Geschichte der 
über ihr ,Eigentum' frei verfügten, und besprach deswegen mit seinem Sohn Ferdinand (von Tirol) kurz nach Uthmanns Tod Maßnahmen, wie dies künftig zu verhindern ist, da sie die Profanierung der Kirchengüter befürchteten. ${ }^{128}$ Der König wollte in diesen Fällen sein ius spolii wahrnehmen, d. h. sich des Nachlasses der Klostervorsteher nach deren Tod bemächtigen. ${ }^{129}$

Der letzte Oybiner Prior Balthasar Gottschalk (1555-1568) aus Zittau scheint zuerst kein gutes Verhältnis zum Prior Uthman gehabt zu haben. ${ }^{130}$ Spätestens seit den späten 1540er-Jahren wohnte er auf dem Väterhof, dem Wirtschaftshof des Klosters in Zittau; trotz der Befehle des Königs, der wollte, dass sich Gottschalk am Leben des Konvents auf dem Oybin beteiligte. ${ }^{131}$ In Zittau wurde Gottschalk 1551 eines der Opfer des Zittauer Kaufmanns und Fälschers Christoph Geisler, bei dem er 50 Taler bzw. 114 Schock Gr. angelegt hatte. Ob Gottschalk sein Geld wiedersah, ist aus den Quellen nicht ersichtlich. ${ }^{132}$ Nach dem Tod Uthmanns ernannte Ferdinand I. Gottschalk zum neuen Prior. ${ }^{133}$ Während seines Priorats musste er sich mit ungeliebten Konventsgenossen auf dem Oybin, den Prager Jesuiten, auseinandersetzen, aus deren Zittauer Pension in der Höhe von 1400 Talern jährlich er ausbezahlt wurde. ${ }^{134}$ Doch diese doppelte Führung des Konventes führte zu

Franziskaner, Klarissen, Dominikaner und Augustiner-Eremiten im Mittelalter (Saxonia Franciscana 6), Werl 1995, S. 366; ebenso in Lauban/Lubań legierte am 7.3.1556 der letzte Franziskanermönch der Stadt zur besseren Erholung von der Pest und darauf folgend dem Stadtbrand (1553/54) einen Zins: Gallus Haselbeck (Hg.), Urkunden, Akten, Briefe und chronikalische Aufzeichnungen zur Geschichte der Thüringischen Ordensprovinz 1521-1600 (Obersächsische Provinz vom hl. Johannes dem Täufer), Bd. II, Fulda 1930, S. 265 f., Nr. 14, S. 267-269, Nr. 20.

128 NA Praha, ČDKM IV, Kart. 169, fol. 336 fr. (24.9.1555); ebenso wollte die böhmische Kammer das ,Testament' und die Stiftung eines der letzten Oybiner Laienbrüder zugunsten der Zittauer Armen nicht anerkennen: APA I - Historica, Sign. C 148/3, Kart. 2260, unpag.; SM-UR, Sign. 111, Kart. 15, unpag.; zu Uthmann auch: Pescheck, Geschichte (wie Anm. 26), S. 27; MoschKau, Oybin-Chronik (wie Anm. 27), S. 143; Sauppe, Geschichte 1903 (wie Anm. 1), S. 234-237.

129 Dazu: Chládek, Spor (wie Anm. 7), S. 271 f., 281 f.; D’Elvert, Kammer-Beihilfen (wie Anm. 71), S. 28, 37.

130 Interim nobis iustis monachus quidam infrenis cognomine Gotschalck, ex Sitta oriundus, ne non responderet nomine suo: $\mathrm{HAB}$, Cod. Guelf. 108 Noviss. $2^{\circ}$, fol. $123^{\mathrm{r}}$ f.; Clemen, Zur Geschichte (wie Anm. 120), S. 280-282, Nr. 14.

131 NA Praha, RG 39 (Německé missivy/Deutsche Missive 1547), fol. 70r.

132 Tino Fröde (Hg.), SRL VIII: Chronik der Stadt Zittau 1255-1623 [Christian-WeiseBibliothek Zittau, Mscr. A 89], Görlitz 2013, S. 173-175; NA Praha, RG 48 (Německé missivy/Deutsche Missive 1551), fol. $63^{\mathrm{r}} \mathrm{f} ., 63^{\mathrm{v}}, 150^{\mathrm{v}}, 164^{\mathrm{r}}, 325^{\mathrm{v}} \mathrm{f}$.

$133 \mathrm{Zum}$ andern, dieweil dann frater Balzer, Celestianerordens, from, gotsfürchtig, eines guten wandels und der guter gelegenheit, wie wir bericht, kundig sein solle, dann er sie zuvor verwaltt haben solle, lassen wir uns gnediglich gefallen, das er zu eim prior und neben ime, wo möglich, drey, zween od[er] aufs minist ein leichenpriester geordnet würde: NA Praha, CDKM IV, Kart. 169, fol. $337^{\mathrm{r}}$ (24.9.1555).

134 Vgl. Anm. 209 f.; zum Verhältnis der Jesuiten zu den letzten Cölestinern vgl. auch: Briefwechsel Canisius I (wie Anm. 57), S. 496-498, Nr. 159 (14.10.1554); S. 553, Nr. 175 (15.7.1555); nach einem anderen Brief von Canisius soll im Oybiner Kloster große Unordnung geherrscht haben: ancorchè quel grandissimo et ricchissimo monasterio 
zahlreichen Streitigkeiten zwischen Gottschalk und den Jesuiten, ${ }^{135}$ sodass Erzherzog Ferdinand I. bereits am 7. Januar 1559 mit seinem Vater die abschaffunng des prior Balthasars weltlichen administration auf dem Oybin besprach. ${ }^{136}$ Der Erzherzog teilte damals Gottschalk mit, dass er zu alt für die Verwaltung des Klosters sei. ${ }^{137}$ Doch dieser alte streitbare Mönch wollte sich dem königlichen Befehl augenscheinlich nicht beugen und setzte seine Auseinandersetzungen mit den Jesuiten fort. ${ }^{138}$ Schließlich wurde Gottschalk am 28. April 1559 von den Jesuiten aus ihrer Zittauer Pension großzügig abgefunden, doch musste er versprechen, den Oybin zu verlassen, sich auf den Väterhof in Zittau zu begeben und sich in die Verwaltung des Klosters durch die Jesuiten nicht einzumischen. ${ }^{139}$ Gottschalk lebte bis zu seinem Tod im Jahr 1568 im Väterhof in Zittau. ${ }^{140}$ Zur Verfügung stand ihm eine Köchin, die kurz vor ihm starb. ${ }^{141}$

Gottschalk muss sich einer großen Beliebtheit seiner Zeitgenossen erfreut haben. Seit 1549 gehörte er zu den häufigsten Taufpaten der Zittauer (evangelischen) Kinder. ${ }^{142} 1555$ empfahl er sogar dem Görlitzer Rat für die vakante Stelle des

majori ex parte sia spogliato et ora malamente inhabitato dalli secolari et donne: S. 614, Nr. 202 (17.5.1556); zu solchem ingressus feminarum in die Männerklöster der Reformationszeit: SitzmanN, Mönchtum und Reformation (wie Anm. 14), S. 169 f.

135 Wohl schon: Briefwechsel Canisius I (wie Anm. 57), S. 634 f., Nr. 206 (nach dem 10.6.1556); Briefwechsel Canisius II (wie Anm. 57), S. 374, Nr. 338 (11.3.1559).

136 NA Praha, ČDKM IV, Kart. 169, fol. $152^{\mathrm{r}}-153^{\mathrm{r}}$.

137 Wirdiger lieber andachtiger, wir füegen dir genedig[e] mainung zu wissen, das auß bevelch der Ro. Kay. M. etc. der ersam gelert unser lieber andachtiger magister Hurtedus Periz [SJ - P. H.] zu ainem rector gen Oybin verordnet und dieweil du dann mit alter und leibsschwachait beladen, so bevelchen wir dir, demnach von wegen Irer Kay. M. etc., das du dich hinfüran biß zu ankhunfft der Kay. Mt. etc. verordenten comission, welche in khurz beschehen wirdet, der weltlichen administration und hauswirtschafft nicht weitter underfabest noch anmassest, sonnder dieselb ganz und gar gedachtem magistro Hurtado anf- und ubergebest und $d u$ allain deinem gepett und andacht aufrearttest und dich umb nichts zeitlichs mer bekhomerst: NA Praha, ČDKM IV, Kart., fol. $154^{\mathrm{r}}$ f. (7.1.1559); weiter: fol. 153r.

138 NA Praha, ČDKM IV, Kart. 169, fol. 160r, 161 ${ }^{\mathrm{v}}$ (13.2.1559).

139 NA Praha, Lž III/8/26 (Oybin), unpag.; ČG - L, inv. č. 2214, Sign. L II 1621; ÖStA FHKA, Böhmische Gedenkbücher, Bd. 309 (1558-1560), fol. 202v f.; NA Praha, Lž III/8/26 (Oybin), unpag. (30.7.1559); ČDKM IV, Kart. 169, fol. 163 r f., 179r ${ }^{\mathrm{r}}, 183^{\mathrm{r}}$.

140 CWB Zittau, Mscr. A 122b (Chronik Arnsdorff), fol. 308r.

141 Walpurgis, des andechtigen vaters Balthasar Gotschalcks köchin auff der vetter hoffe, gelautet mit der grossen $<k>$ glock[en] eodem die [5.2.1567]: Archiv am Evangelischlutherischen Pfarramt (im Folgenden: PfA) Zittau, Sammelband über Begräbnisgeläut - Heft D: Begräbnisgeläut mit der Großen Glocke (1556-1567), ohne Sign., unpag.

1421549 stand er fünfmal als Pate, 1550 elfmal, 1551 einundzwanzigmal, 1552 zwölf- bzw. dreizehnmal, 1553 zwölfmal, 1554 zehnmal, 1555 fünfmal, 1558 und 1559 einmal: PfA Zittau, Zittauer Taufbuch (1539-1564) und seine Abschrift von Erich Pröwig ebd.; Gottschalks evtl. Wirken als Taufpate in den 1560er-Jahren muss noch eruiert werden. Die Taufen damals waren in Zittau überkonfessionell; vgl. als Beispiele: 21. Venture Vicen weib Katharina hat geborn eine tochter Agnetha. Die paten: vater Balthasar Gotschalgk [altgläubiger Cölestinermönch - P. H.], Margaretha, Onofrius Herczoges weib [eines Zwinglianers - P. H.], der Hanspochin tochter eode [m] die [28.1.1554]. [...] 98. Thomas Scholczen weib hat geborn einen son Bartholom[aeus]. Die paten: her 
evangelischen Predigers in der Görlitzer Pfarrkirche den Sohn des Zittauer Reformators Lorenz Heydenreich Esaias (1532-1589), den späteren bekannten lutherischen Theologen in Breslau. ${ }^{143}$ In seinem nicht mehr überlieferten Testament soll Gottschalk darüber hinaus das Freytågige Catechismus-Examen in Zittau gestiftet haben. ${ }^{144}$ Es gab zu seiner Lebenszeit noch keine feste konfessionelle Abgrenzung. Dabei war Gottschalk sicher immer altgläubig, denn der König lobte seine Frömmigkeit ${ }^{145}$ und der Oybiner Jesuitenrektor Hurtado Perez hatte wegen der unkanonischen Verdrängung Gottschalks aus Oybin im Jahr 1559 Gewissensbisse, woran er sicher im Fall der Häresie dieses letzten Oybiner Cölestiners nicht gelitten hätte. ${ }^{146}$

\section{Liturgischer Stiftungsvollzug im reformatorischen, Umbruch`}

Bisher haben wir uns die pekuniären und kirchenpolitischen Absichten des Königtums in Bezug auf die Oybiner Klostergüter veranschaulicht. Doch König Ferdinand I. wünschte, funktionierende Konvente in seinen Ländern zu sehen. Nur so konnte man der Reformation auf der spirituellen Ebene erfolgreich die Stirn bieten, zugleich könnte man dadurch die Bestimmungen der spätmittelalter-

Conrad[us] Nesenus, licentiat [Lutheraner (?), Bruder des Wittenberger Humanisten Wilhelm Nesen - P. H.], vater Balthasar Gotschalgk [altgläubig - P. H.], virgo Hedwigis, Hans Huberiges tochte (!) [eines Lutheraners - P. H.], mitwoch dornach [25.4.1554]: PfA Zittau, Zittauer Taufbuch (1539-1564), ohne Sign., unpag. Diese rituelle ,Akonfessionalität' war in der Oberlausitz keine Seltenheit, empfingen z. B. die Bautzener Lutheraner das Taufsakrament fast bis zum Jahr 1600 ausschließlich vom dortigen (katholischen) Kollegiatstift: KaI Wenzel, Der Dom St. Petri zu Bautzen. Architektur und Ausstattung, in: Ders./Birgit Mitzscherlich/Nicole Wohlfarth, Der Dom St. Petri zu Bautzen (Schriftenreihe des Archivverbundes 4), Bautzen 2016, S. 19-209, hier S. 96 f.; z. B. auch in Kulmbach 1530 figurierte der dortige Augustinerprior als Taufpate des Sohnes des evangelischen städtischen Superintendenten: Sitzmann, Mönchtum und Reformation (wie Anm. 14), S. 78; seit 1548 (Augsburger Interim) nahmen z. B. in Pfalz-Neuburg evangelische Prediger katholische Taufen wahr: Wolgast, Einführung der Reformation (wie Anm. 14), S. 178.

143 RA Görlitz, LM (1551-1553), fol. 290v f. (31.1.1555); Pescheck, Geschichte (wie Anm. 26), S. 93, Nr. 2; Ders., Noch weitere Nachträge zur Geschichte des Oybins, in: Neues Lausitzisches Magazin 23 (1846), S. 285-334, hier S. 326 f.; nach: JoHannes Benedictus Carpzovius, Memoria Heidenreichiana [...], Leipzig 1717, S. 48, soll sich Esaias Heydenreich häufiger auf dem Väterhof bei den letzten Cölestinern aufgehalten haben.

144 Urban Gottlieb Haussdorff, Historia ecclesiastica Zittaviensis oder Kirchen- und Reformations-Geschichte der Churfl. Sächß. Sechs-Stadt Zittau/wie auch LebensBeschreibungen aller Evangelischen PASTORUM PRIMARIORUM in Zittau [...], Budissin 1732, S. 139.

$145 \mathrm{Vgl}$. Anm. 133.

146 Briefwechsel Canisius II (wie Anm. 57), S. 411, Nr. 349 (7.5.1559); Kroes, Untergang (wie Anm. 31), S. 241 f.; Ders., Geschichte I (wie Anm. 31), S. 48 f.; zu Gottschalk auch: Pescheck, Geschichte (wie Anm. 26), S. 25; Moschkau, Oybin-Chronik (wie Anm. 27), S. 143 f.; Sauppe, Geschichte 1903 (wie Anm. 1), S. 198, 237-239; Ders., Geschichte 1907 (wie Anm. 1), S. 159-161; Oettel, Auflösung (wie Anm. 1), S. 26. 
lichen Stifter in Bezug auf ihre Stiftungen (d. h. vor allem die liturgische Memoria) einhalten. Ferdinand I. war bestrebt, beides zu tun.

Zuerst versuchte der Oybiner Konvent selbst, sein durch die frühe Reformation erschüttertes Wesen zu festigen: Mit Hilfe der Mutterabtei bei Sulmona berief er in den frühen 1530er-Jahren etwa sechs Ordensbrüder aus Italien oder Frankreich. Doch die hielten sich auf dem Oybin nur kurz auf. Danach verhalf der König dem Vollzug der liturgischen Stiftungen im Konvent: durch Einsetzung seiner Dignitäre wollte er das Personal, die Religiosen, die eine unabdingbare Bedingung für den Vollzug der zu feiernden Liturgie im Kloster darstellten, stabilisieren. ${ }^{147}$ Ebenso bedung sich der König von den späteren Pacht- und Pfandinhabern des Konventes aus, auf dem Oybin mehrere Cölestiner zu unterhalten. ${ }^{148}$ Auch auf die Ordenszucht wurde geachtet: Der Mönch Balthasar Gottschalk hielt sich nämlich nicht im Kloster, sondern im Väterhof in Zittau auf, womit er die Regeln der monastischen Kommunität verletzte. Er begleitete seinen schwerkranken Ordensbruder im Frühjahr 1548 vom Oybin nach Zittau zur Kur. Auch der kranke Mönch sollte nach Oybin in den Konvent zurückkehren, falls ihm in der Stadt nicht mehr geholfen werden könnte, um den Vollzug der Liturgie auf dem Oybin durch die monastische Kommunität zu garantieren. ${ }^{149}$

Wegen des prekären personellen Mangels an Cölestinern gab sich der König mit Neuzeller Zisterziensern zufrieden (mindestens vier Ordensgeistliche sollten auf dem Oybin wirken), 150 und im dritten Viertel des 16. Jahrhunderts musste er

147 Vgl. Anm. 2 und 77.

148 Unnd ob dann uber die verordennt anzall der ordennsbrueder, so im closter gehalten werden sollen, noch ain abganng erschine, sollet ir auch derbalben bei anndern clöstern dizs ordenns ansuechung unnd verordnung thuen, auf das die vollig anzall daselbst hin geen Obin ersezt und der got $\beta$ diennst alda cristlich mit vleiß und andacht notturfftigclich gehalten und versehen werde: ÖStA - FHKA, Böhmische Gedenkbücher, Bd. 304 (1547-1548), fol. 151 ${ }^{\mathrm{r}}$ (Ferdinand I. an die Böhmische Kammer; 29.1.1548); NA Praha, RG 31 (Kopiář nařízení pro českou komoru/Kopial der Befehle für die Böhmische Kammer 1544-1553), fol. 68v.

149 NA Praha, RG 39, fol. 70r: [...] emphelben wir euch, das ir von Irer Mt. wegen nochmalln mit benannten brued[er]n Balthasarn alles ernstliches vlei $\beta$ handlet und ime aufleget, domit er sich bei aufgelegter straff on alle ferrere waigerung in das closster begeb, daselbst seinen orden und gottsdiennst, wie ime gebürt, beywone und auswarte

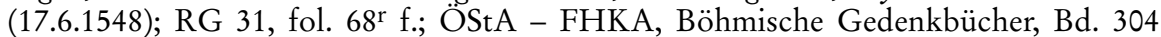
(1547-1548), fol. 150v f.; Sauppe, Geschichte 1907 (wie Anm. 1), S. 135 f.

150 NA Praha, RG 42 (Německé komorní listiny/Deutsche Kammerurkunden 1547-1552), fol. $17^{v}$ f. (21.8.1547); RG 31, fol. 43 $\mathrm{r}$ f. (1.8.1547); RG 43 (Německé missivy/Deutsche Missive 1548), fol. $125^{\vee}$ f.: An abt zur Neuen Zell, ain oder zwo ordensperson auff den Oybin zu verordnen. [...] Wirdiger andechtiger unnd lieber besonnder, unns hatt der wolgeborn etc. behemisch lanndhoffmaister [Zdislav Berka - P. H.] etc. unnderthenigist zu erkennen geben, das in unnsernn kloster auffm Oybin, in unnserm Marggraffthumb Oberlausiz gelegen, jeziger zeit nit mer als drey ordenspersonenn vorbannden, aus denselben auch ainen [wohl Br. Martin von Jauer - P. H.] der schlag oder gewalt gottes getroffen, welcher da alle stund, dann er ane das mit gutem alter befallen, des tods gewertig. Dieweil du dann ungezweiflt weiß, das wir unns, damit die stifftordensleut unnd gozsheusser nit zu grundt in abkhumben gedeyen, darob zu hanndthaben, mit 
sich schließlich wegen der allgemeinen Krise des ganzen Standes der Ordensgeistlichen nur noch mit den weltlichen Priestern abfinden. ${ }^{151}$ Zwischen 1556 bis 1562 probierte dann Ferdinand I. auf dem Oybin eine Lösung, die sich später als richtungsweisend für die Gegenreformation zeigte. Er vertraute das Klosterareal sowie die Pfarreien Oderwitz und Herwigsdorf dem damals entstandenen Prager Jesuitenkolleg St. Clement an. ${ }^{152}$ Auch die Jesuiten sollten sich den Wünschen des Königs zufolge an der katholischen Liturgie auf dem Klosterberg beteiligen, obwohl ihnen der Oybin eher als eine äußere wirtschaftliche Stütze, als Quelle ihrer Pension in Höhe von 1400 Talern jährlich seitens des Zittauer Rates, diente. 1557 sandte der Stellvertreter des Provinzials Peter Canisius, Johannes de Victoria, die ersten beiden Jesuiten auf den Oybin. Schließlich gab es dort bis zu sechs Ordensbrüder, geleitet von einem Rektor. ${ }^{153}$

Die letzten Cölestiner und die weltlichen Priester, die die altgläubige Liturgie auf dem Oybin aufrechterhalten sollten, wurden während der, jesuitischen Episode‘ aus dem Zittauer Pachtzins in der Höhe von 1400 Talern unterhalten, aus

dem hochsten befleyssen und auf das diß loblich stifft unnd gotsdiennst darinen gepflannzt unnd erbalten. Demnach ist an dich unnser genedig begeeren bevelbund, $d u$ wellest dich zu erhaltung des gotsdienst auf gemeltem stifft ain geschickte teugliche unnd der alten loblich[en] religion anbengig ordensperson oder annder dabin zu bringen befleissen unnd khain muwe sparen, darduch die anzall alda wider erstatet (27.4.1548); ebd., fol. 126 ${ }^{\text {r }}$ doch der Neuzeller Abt lehnte diese Aushilfe ab: fol. 159v (24.5.1548); Töpler, Kloster Neuzelle (wie Anm. 76), S. 143 f.

151 NA Praha, ČDKM IV, Kart. 169, fol. 337r (24.9.1555); einer dieser Oybiner ,Laienpriester' war der Prager Kanoniker Martin Marier: Antonius Podlaha (Hg.), Series praepositorum, decanorum, archidiaconum, praelatorum et canonicorum S. Metropolitanae ecclesiae Pragensis a primordiis usque ad praesentia tempora (Editiones archivii et bibliothecae S. F. Metropolitani capituli Pragensis 10), Pragae 1912, S. 127, Nr. 701 (belegt als Prager Domherr in den Jahren 1549-1559); weiter zu ihm: NA Praha, RG 29 (Německá komorní nařízení/Deutsche Kammerbefehle 1543-1544, 1556-1565, 1580), fol. 109v; RG 60 (České missivy/Tschechische Missive 1556-1558), fol. 284v; ČDKM IV, kart. 169, fol. 140v, 330v, 169v, 334r ; APA I - Historica, Sign. C 148/3, Kart. 2260, fol. $12^{\mathrm{r}}$ f.; Klement Boroví (Hg.), Jednání a dopisy konsistoře katolické i utrakvistické [Verhandlungen und Briefe des katholischen sowie utraquistischen Konsistoriums], Teil II: Akta konsistoře katolické [Akten des katholischen Konsistoriums] (Monumenta historiae Bohemica/Staré paměti dějin českých), Praha 1869, S. 316, Nr. 820; SAUPPE, Geschichte 1907 (wie Anm. 1), S. 146, 148, 150 f., 173.

152 Zum pastoralen Impetus der tridentinischen Orden: Robert Bireley, Neue Orden, katholische Reform und Konfessionalisierung, in: Wolfgang Reinhard/Heinz Schilling (Hg.), Die katholische Konfessionalisierung (Schriften des Vereins für Reformationsgeschichte 198), Gütersloh 1995, S. 145-157, hier S. 147 f., 155.

$153 \mathrm{Zu}$ den Jesuiten auf dem Oybin: Briefwechsel Canisius II (wie Anm. 57), S. 143, Nr. 266; S. 258, Nr. 295; S. 314, Nr. 314; S. 436, Nr. 357; S. 486, Nr. 369; S. 632, Nr. 431; S. 650, Nr. 435; Briefwechsel Canisius III (wie Anm. 57), S. 143, Nr. 266; Kroes, Untergang (wie Anm. 31), S. 240 f.; Ders., Geschichte I (wie Anm. 31), S. 45, 47 f.; Michael Sievenich, Die urbane Option des Ignatius von Loyola am Beispiel der Metropole Prag, in: Petronilla Cemus/Richard Cemus (Hg.), Bohemia Jesuitica, Bd. I, Praha 2010, S. 173-192, hier S. 183, 186 f.; SK Praha, Sign. DC III 20, fol. 24v $, 25^{\mathrm{r}}, 25^{\mathrm{v}}, 26^{\mathrm{r}}, 29^{\mathrm{r}}, 31^{\mathrm{v}}$, $33^{\mathrm{r}}, 34^{\mathrm{v}}, 40^{\mathrm{v}}, 46^{\mathrm{v}}, 48^{\mathrm{r}}, 49^{\mathrm{r}}, 49^{\mathrm{v}}$. 
dem seit der Ansiedlung der Jesuiten auf dem Oybin nun eine Pension des Zittauer Rates für das Prager Kolleg wurde. Der protestantische Zittauer Rat und die Jesuiten sollten gemeinsam für die Besetzung des Oybins mit katholischem Klerus sorgen, und der Prager Jesuitenrektor sollte regelmäßig diese Geistlichen visitieren. ${ }^{154}$ Vor allem Peter Canisius (1521-1597) war über diese Verpflichtungen nicht ganz wegen der damit verbundenen Kosten sowie in Ermangelung der katholischen Geistlichen begeistert, was er mehrmals in seinen Briefen an den Ordensgeneral Ignaz von Loyola und Loyolas Nachfolger zum Ausdruck brachte. ${ }^{155}$ Das abgelegene Kloster Oybin war seines Erachtens zwar für kontemplatives Leben sehr geeignet, 156 jedoch nicht für den pastoralen Schwerpunkt seines Ordens, der in Groß- und Hauptstädten lag. ${ }^{157}$

Später - nach dem Rückzug der Jesuiten vom Oybin nach Prag - scheint der Zittauer Rat die Verpflichtung zum Vollzug des Kultus allein in den dörflichen Klosterpfarreien ausgeübt zu haben. Dabei durfte der protestantische Zittauer Rat in Oderwitz und Herwigsdorf die Konfession der Pfarrkinder nicht ändern. ${ }^{158} \mathrm{Als}$

154 Deßgleichen soll und will ain ratt zwaimall im jar den offtgedachten unnsers collegi rectorn, oder wen er an seiner statt verordnen wurde, geen Oybin unss[er] closster zur visitation und besichtigung der haußhaltung auch zu forderest bestallung des gottesdiennst auf und ab geen Prag mit roß, wagen und khnechten versehen, doch aber der rector, oder wen er schickhen wurde, sich selbs mit der zerung verlegen: NA Praha, RG 56 (Německé komorní listiny/Deutsche Kammerurkunden 1554-1558), fol. $76^{\mathrm{r}} \mathrm{f}$. (23.4.1556); ČDKM IV, Kart. 169, fol. 326 ${ }^{\mathrm{r}} 327^{\mathrm{r}}$; APA I - Historica, Sign. C 148/3, Kart. 2260, fol. $2^{\mathrm{v}} \mathrm{f}$.

155 Briefwechsel Canisius I (wie Anm. 57), S. 615, 621, Nr. 202; S. 625-630, Nr. 205; Briefwechsel Canisius II (wie Anm. 57), S. 113, Nr. 250; S. 418 f., Nr. 352; S. 424, Nr. 354; S. 434 f., Nr. 357; S. 464, Nr. 363; Quanto vediamo le difficulta nel negotio d' OWin, piu presto se augmentano che sminuiscono: S. 465, Nr. 363; de scaricarsi di quel pezzo graue de oibin gia si e scritto un' altra nolta et a quella me rimetto: S. 474, Nr. 365; S. 476, Nr. 366; S. 488, Nr. 369; S. 501, Nr. 372; S. 655, Nr. 438; Briefwechsel Canisius III (wie Anm. 57), S. 18, Nr. 507; [...] utque liberemur onere grauj Oybinensis Monasterij: S. 287, Nr. 619; S. 299, Nr. 628; S. 317, Nr. 637; Kroes, Untergang (wie Anm. 31), S. $235 \mathrm{f} ., 242 \mathrm{f}$.

156 Et questa diligenzia in scrivere et notare tutte le cose et comandare poi la procurazione a quelli Signori Zittaviensi, per se ci ha tolto quattordici di. Sia lodato Iddio il quale ba dato tanta pazienza et buona volontà di eseguire tutto in particolare et di andare a piedi per tanti luoghi aspri et selvatici et montosi. Conciosa cosa che questo monasterio, il quale anche è detto Mons Paracleti, sia sopra una altissima montagna et in mezzo delli monti et selve, talmente che non si podria quasi desiderar megliore luogo per far una vita eremitica et penitenziale, massime nell' invernata, quando il freddo lì è grandissimo et tutto il luogo orribilissimo et quasi inacessibile: Briefwechsel Canisius I (wie Anm. 57), S. 627 f., Nr. 205 (Peter Canisius an Ignaz von Loyola; 11.6.1556); zu beiden Besuchen des Canisius auf dem Oybin: Kroes, Geschichte I (wie Anm. 31), S. 42-44; Ders., Untergang (wie Anm. 31), S. 236-238.

157 Briefwechsel Canisius I (wie Anm. 57), S. 496 f., Nr. 159; S. 628 f., Nr. 205; Kroes, Geschichte I (wie Anm. 31), S. 17 f.; zur jesuitischen Präferenz der Großstädte: Sievenich, Urbane Option (wie Anm. 153), S. 173, 177, 188.

158 NA Praha, ČDKM IV, Kart. 169, fol. $337 \mathrm{v}$ f. (24.9.1555): die Verpachtungsurkunde vom 26.4.1556: RG 56, fol. $75^{v}$ f.; ČDKM IV, Kart. 169, fol. 325r ; APA I - Historica, Sign. C 148/3, Kart. 2260, fol. 2r ${ }^{\text {r }}$ die Verpfändungsurkunde vom 10.1.1562: [...] das gedachte 
Peter Canisius 1556 mithilfe einer königlichen Kommission beide lutherische Geistliche von ihren Pfarrstellen in Herwigsdorf und Oderwitz absetzte, war spätestens seit diesem Zeitpunkt dem Zittauer Rat die Ernsthaftigkeit der Lage klar. ${ }^{159}$ Der Rat argumentierte mit dem Tenor der Verpachtungsurkunde von 1556, in der Ferdinand I. die Veränderung der ,Religion' auf den klösterlichen Patronatspfarreien verboten hatte, ${ }^{160}$ womit - nach Meinung des Rats - nur die (ursprüngliche) evangelische Religion gemeint sein konnte. ${ }^{161}$ Ebenso wollte Peter Canisius die durch die Absetzung beider lutherischer Pfarrer angespannte Atmosphäre nicht weiter aufheizen, sodass er weiterhin protestantische Begräbnisse auf den Dorfkirchhöfen als ,Werke der Barmherzigkeit' duldete. ${ }^{162}$ Diese Amtsenthebung durch Peter Canisius von 1556 hatte nur eine kurze Wirkung, denn ein Jahr später hatten lutherische Geistliche diese Pfarrämter wiederum inne, da es den Jesuiten an katholischen Weltpriestern mangelte. Deswegen erwog man, die Seelsorge mittels der Ordensgeistlichen selbst auszuüben. ${ }^{163}$

Auch Ferdinand I. dachte bei der Anvertrauung Oybins an den Orden daran, dass die Jesuiten pastoral in der Oybiner Umgebung wirken werden. ${ }^{164} 1558$ erlaubte ihnen der König sogar, in der Stadt Zittau vom Väterhof aus ,katholisch zu lehren und zu predigen'.165 Die Jesuiten verzeichneten dabei wirklich einen gewis-

von der Sitaw alle dorffer, so zu unserm stifft Oybin, in unserm Marggraffthumb Oberlaußniz gelegen, [...] sambt aller [...] khirchleehen (doch one ennderung der religion, bei der sy di unnderthanen, wie sy jezo sein, verbleiben lassen sollen) mit den erb-und obergerichten, die sy auf disen güettern, inmassen wie wir die khunfftiger zeit den stennden in Oberlaußniz verleiben werden, halten sollen: ČG-L, inv. č. 2183, Sign. L II 1686, S. 2; RG 63 (Německé komorní listiny/Deutsche Kammerurkunden 15591563), fol. $12^{\mathrm{r}}, 197^{\mathrm{r}}$; ČDKM IV, Kart. 169 , fol. $318^{\mathrm{v}}$ f., $171^{\mathrm{r}}$.

159 Briefwechsel Canisius I (wie Anm. 57), S. 630, Nr. 205; Kroes, Geschichte I (wie Anm. 31), S. 44.

160 Vgl. Anm. 158.

161 NA Praha, Lž III/8/26 (Oybin), unpag. (Zittauer Rat an Erzhz. Ferdinand (von Tirol); 17.2.1559).

162 Briefwechsel Canisius II (wie Anm. 57), S. 442, Nr. 358; S. 462.

163 In Praga se questa difficultà. Essendo li nostri hora patroni di quello monasterio de Oibin, et consequentemente hauendo de instituire 2 pastori in 2 ville incorporate al detto Monasterio [Herwigsdorf und Oderwitz - P. H.], se niede per la esperientia, che le wille con li suoi pastori fanno comi li vicini suoi, id est nella dottrina, fede et administratione delli Sacramenti sono heretici, et li preti ouero pastori vogliano restare ussorati. Hora se noi voliamo leuar questi pastori, non potemo trouar altri catholici preti, et se li trouassimo (che io penso impossibile) il popolo essendo tanto corotto non se contentarebbe de quelli. Se questo caso proponeremo al Re, potria dire che, li nostri pigliassino la cura saltem ad tempus, et che circhino persone disposte, le quali tutta via manchino, talmente che se trovino molte città, intorno senza prete alcuno: Briefwechsel Canisius II (wie Anm. 57), S. 52 f., Nr. 229 (vor Mitte Januar 1557).

164 Briefwechsel Canisius I (wie Anm. 57), S. 629, Nr. 205; Kroes, Untergang (wie Anm. 31), S. 235, $238 \mathrm{f}$.

165 Jesuiter abschid. Die Romisch. Kay. auch zu Hungern unnd Behem etc. Ku. Mt., unser allergnedigister herr, haben der Jesuiter zu sand Clement in der Alten Statt Prag demuetigs suppliciern nachvolgennder sachen halben gnedigist angebört unnd mögen in irem haus zur Sittaw, zum closter gehörig [Väterhof - P. H.], catholisch leern unnd 
sen Erfolg. Obwohl sie 1561 von den lutherischen Bauern auf den Klosterdörfern physisch bedroht wurden, oder man verbot den Besuch der jesuitischen Predigt, gab es zur Fastenzeit jenes Jahres bereits zehn Kommunikanten bei den Jesuiten. ${ }^{166}$ Einige Zittauer mögen wirklich dauerhaft zur römisch-katholischen Religion konvertiert sein: Als 1560 ein Zittauer im Prager Kolleg Koch werden wollte, ${ }^{167}$ oder als im März 1582 drei Zittauer, die in ihrer Heimatstadt wegen ihres Glaubens verfolgt wurden, bei den Prager Jesuiten sub una kommunizierten. ${ }^{168}$

Vor allem der ehemalige Wiener Rektor Johannes de Victoria, der seit 1558 als Canisius' Superintendent in Prag das dortige Kolleg beaufsichtigte, hatte trotz der gegensätzlichen Meinung des Provinzials Peter Canisius mit dem Oybin und Zittau große Pläne. Oybin war für ihn die einzige sichere Quelle der Finanzierung des Prager Kollegs. Er sandte Jesuiten auf den Oybin, die dort katholische Gottesdienste für das Gesinde feierten, und wollte den Zittauer Pachtvertrag zugunsten des Jesuitenordens vorzeitig beendigen und den Ertrag aus den Oybiner Gütern auf 3000 Taler jährlich erhöhen. ${ }^{169}$ Auf dem Oybin sollte ein Noviziat errichtet werden. ${ }^{170}$ Victoria plante sogar, das verlassene Zittauer Franziskanerkloster zu übernehmen und darin ein neues Kolleg zu errichten; ${ }^{171}$ eine Idee, die auch Ferdinand I. gefiel. ${ }^{172}$ Doch bereits im folgenden Jahr haben die Jesuiten den Oybin verlassen. ${ }^{173}$ Das Klosterareal übernahm Benno von Salza, ein königlicher Hauptmann.

Auf dem Oybin musste sich seit 1562 der Hauptmann von Salza im Einvernehmen mit dem Prager Erzbischof um die Ausübung der altgläubigen Liturgie küm-

predigen unnd sollen sich auch geistlichs und cristlichs wanndls verhalten. So wellen auch Ir Ro. Kay. Mt. etc. derselben burgermaister unnd ratmannen der statt Sithaw entlich[en] auferlegen, das sy gedachte Jesuiter zu aller gebur unnd pillichait schuzen unnd sonnsten von Irer Mt. wegen, als sy gnedigclich nit zweifln, in guetem pillichen bevelh haben sollen, damit inen zur ungebur nichts zuegefuegt werde: NA Praha, RG 58 (Německé patenty/Deutsche Patente 1555-1564), fol. 126v (30.11.1558).

166 Kroes, Geschichte I (wie Anm. 31), S. 49 f.

167 SK Praha, Sign. DC III 20, fol. $9^{\mathrm{v}}$ (23.2.1560).

I 68 Ebd., fol. 205v.

169 [...] ordinanit iam P. Victoria ut homines quotidie audiant missam, famulae Dominjcis et festis diebus, ac Veneris: Briefwechsel Canisius II (wie Anm. 57), S. 411, Nr. 349 (7.5.1559); Briefwechsel Canisius III (wie Anm. 57), S. 347 f., Nr. 652; Kroes, Geschichte I (wie Anm. 31), S. 46-50; Sievenich, Die urbane Option (wie Anm. 153), S. 188.

170 Briefwechsel Canisius II (wie Anm. 57), S. 436 f., Nr. 357 (3.6.1559); S. 442, Nr. 358 (10.6.1559); Kroes, Untergang (wie Anm. 31), S. 243; Ders., Geschichte I (wie Anm. 31), S. 135.

171 Briefwechsel Canisius III (wie Anm. 57), S. 32, Nr. 515 (31.1./1.2.1561); S. 37, Nr. 516 (1.2.1561); S. 78, Nr. 531 (15.3.1561); die Editionen vgl. in: Hrachovec, Auflösung (wie Anm. 83), S. 433.

172 NA Praha, ČDKM IV, Kart. 169 (Oybin), fol. 173v-174v (vor dem 14.6.1561), fol. $186^{\mathrm{r}}$ f.; die Editionen vgl. in: Hrachovec, Auflösung (wie Anm. 83), S. 433.

173 Briefwechsel Canisius III (wie Anm. 57), S. 401, Nr. 672 (4.4.1562); S. 768-770, Nr. 383 (24.3.1562); Kroes, Geschichte I (wie Anm. 31), S. 50-52. 
mern. Der König behielt sich die Ernennung eines Weltgeistlichen vor. ${ }^{174}$ Ferdinand I. zahlte deswegen an von Salza 100 Taler Kammerzins jährlich. ${ }^{175}$ Auch der nachfolgende Hauptmann Hermann Ygl, ja sogar noch der Zittauer Rat bei seiner Pfandübernahme des Klostergeländes im Jahr 1570 mussten einen vom König auf den Oybin entsandten katholischen Kaplan unterhalten. ${ }^{176}$ Diese Verpflichtung erlosch erst mit dem Kauf Oybins durch den Rat im Jahr 1574.

\section{Die Kontinuität der an das Kloster angelagerten Stiftungen}

Während der Reformation achtete der König mit Nachdruck nicht nur auf den Vollzug der Verpflichtungen gegenüber dem Kloster Oybin, sondern das Kloster selbst musste auch weiterhin seine gestifteten Zinse und Almosen an Dritte abführen. ${ }^{177}$ Vor allem ging es um ein großzügiges Almosen, das das Kloster spätestens seit 1501 (Örtelsche Stiftung) bzw. schon seit den Zeiten Karls IV. auf dem Väterhof den Zittauer Armen verteilen sollte. ${ }^{178}$ Deswegen wurden diese Stiftungszinse in der Verpachtungsurkunde vom 23. April 1556 sowie in der ersten Verpfändung der Oybiner Güter an den Zittauer Rat im Jahr 1562 ausdrücklich bestätigt. ${ }^{179}$

174 [...] unnd sol er, der von Salza, unnd sein erben einen caplan und kbirch[en]diener auff Oybin zu verrichtung gottesdienst halten, welchen caplan wir ime hinnauff verordnen werden, mit gebuerlicher notturfft an unnsern entgelt underbalten: NA Praha, RG 63, fol. 373v f., 204r (2.1.1562); Lž III/8/26 (Oybin), unpag.; ČDKM IV, Kart. 169, fol. 273v; HStA Dresden, Loc. 9593/21, 10024 Geheimer Rat (Geheimes Archiv), fol. 41 r-42v; weiter dazu: NA Praha,ČDKM IV, Kart. 169, fol. 195r, 218r; RG 57 (Německé patenty/ Deutsche Patente 1554-1564), fol. 546r (18.9.1563); ÖStA - FHKA, Böhmische Gedenkbücher, Bd. 310 (1561-1564), fol. 334v.

$175 \mathrm{Vgl}$. die betreffende kaiserliche Bewilligung vom 4.2.1562: NA Praha, Lž III/8/26 (Oybin), unpag.; ÖStA - FHKA, Böhmische Gedenkbücher (1561-1564), Bd. 310, fol.

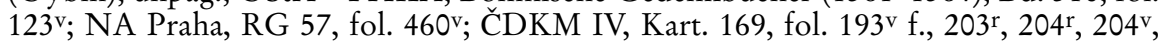
$206^{\mathrm{r}}, 208^{\mathrm{r}}$ f., $211^{\mathrm{r}}, 219^{\mathrm{r}}, 227^{\mathrm{r}} \mathrm{f}$.

176 NA Praha, ČDKM IV, kart. 169, fol. 294 (15.4.1570); RG 76 (Německé komorní listiny/Deutsche Kammerurkunden 1564-1570), fol. 399v: Und allen (?) dy von der Sittau, einen caplan und kirchendiener auf Oybin $<$ zuverb $>$ zu verrichtung des gotsdiensts halben, welichen caplan wir inen hinauf verordnen werden, mitt gebuebrlicher notturfft obn unsern entgelt underhalten (23.4.1570).

177 Zur ausgesprochen zähen Kontinuität der vorreformatorischen karitativen Stiftungen nach der Reformation, die in dieser Hinsicht keinen Traditionsbruch darstellte: Hermann Queckenstedt, Die Armen und die Toten. Sozialfürsorge und Totengedenken im spätmittelalterlich-frühneuzeitlichen Osnabrück (Kulturregion Osnabrück 8), Osnabrück 1997, S. 50-52, 59, 64, 69-76, 80, 85, 138, 168, 195 f., 198, 264 f., 267; Moddelmog, Königliche Stiftungen (wie Anm. 12), S. 58 f.

178 Item dz gestifft, solanng es weret zu eewig[en] zeit[en], ist alle wochen, 2 scheffl khorn zu melmallen unnd darauß prothpachen zu lassen schuldig unnd pflichtig, welches proth man also alle freitag in di stat Sittau in der vetter hau $\beta$ fuert unnd alda den armen le üten dasselbig alle $\beta$ außtaillet: NA Praha, SM - UR, Sign. 111, Kart. 15, unpag.; APA I Historica, Sign. C 148/3, Kart. 2260, unpag.

179 Pacht 1556: NA Praha, RG 56, fol. 76r; ČDKM IV, Kart. 169, fol. 325v; APA I Historica, Sign. C 148/3, Kart. 2260, fol. $2^{\text {r }}$; Pfand 1562: ČG-L, inv. č. 2183, Sign. L II 
Und Zittau musste sich an dieser Almosenausteilung und Zinsenüberweisung beteiligen, auch nachdem es das Kloster 1574 gekauft hatte, da sich dies Kaiser Maximilian II. ausdrücklich in der Verkaufsurkunde ausbedungen hatte. ${ }^{180}$

Aus der Stadt Görlitz bezog das Kloster Oybin zahlreiche gestiftete Zinse. Es bot dafür liturgische, Gegengaben' in Form von Anniversarien für einzelne Bürger sowie Votivmessen für den Görlitzer Stadtrat (hauptsächlich anlässlich der Ratskür) an. ${ }^{181}$ Die letzte solche Ratskürmesse fand im August 1523 statt, seitdem ist der reformatorische Umbruch in den Quellen bemerkbar. ${ }^{182}$ Dieser äußerte sich vor allem im Unwillen der Görlitzer, die Zinse dem Kloster zu zahlen. In den 1520 er- bis 1540 er-Jahren gab es deswegen einen regen Briefverkehr beiderseits. ${ }^{183}$ Der Görlitzer Rat verlangte sogar die dem Kloster vermachten Gelder zurück. ${ }^{184}$ Im Jahr 1541 beauftragte Ferdinand I. den Oberlausitzer Landvogt Zdislav Berka, dem Konvent bei der Eintreibung der ihm zuständigen Zinsschulden zu helfen, einschließlich der Vermögensexekution oder sogar Verhaftung der säumigen Schuldner. ${ }^{185}$

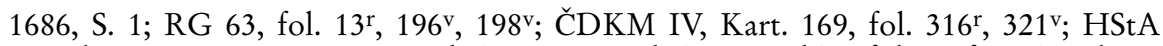
Dresden, Loc. 9593/21, 10024 Geheimer Rat (Geheimes Archiv), fol. 46r f.; weiter dazu: NA Praha, ČDKM IV, Kart. 169, fol. 171v.

180 Es sollen auch die von der Sittaw alle beschwerungen, so diesem guett anhengig, es sey an elemosien (!), raichung der däcem unnd wie die namen haben mogen, zu verrichten schuldig und verpflicht sein: NA Praha, RG 87A (Německé komorní listiny/Deutsche Kammerurkunden 1571-1582), fol. 135² (17.11.1574); ČDKM IV, Kart. 169, fol. 314v; ČDKM IV, Kart. 324, fol. 304v .

181 Dazu insbesondere: SpeEr, Bedeutung (wie Anm. 36), S. 294-297, 302-310.

182 RA Görlitz, LM (1520-1523), fol. 527r f. (26.8.1523); SPEER, Bedeutung (wie Anm. 36), S. 304 f., 307; das letzte Görlitzer Testament zugunsten des Oybiner Klosters wurde am 3.9.1521 vermacht: ebd., S. 309.

183 Der Oybiner Prior Andreas Ringehut an den Görlitzer Ratsherrn Franz Schneider bzgl. der seit vier Jahren vom Rat vorenthaltenen Zinse für die Gebrüder Christoph und Franz Uthman (9.2.1525): RA Görlitz, Varia 226, unpag.; der Görlitzer Rat schreibt an das Oybiner Kloster wegen der nicht bezahlten Görlitzer Zinse (17.3.1526): Varia 226; LM (1526-1528), fol. 29v f.; der Rat schreibt an den Oberlausitzer Landvogt, Hz. Karl von Münsterberg, in dieser Angelegenheit (7.6.1526), fol. 75 $5^{\mathrm{v}}-76^{\mathrm{v}}$; der Rat entschuldigt sich beim Oybiner Kloster wegen der Nichtbezahlung (14.10.1526): fol. 151 ${ }^{\mathrm{r}}$ f.; der Rat zeigt dem Oybiner Prior Christoph Uthmann seine Bereitschaft an, einen von diesen Zinsen dem Konvent zu entrichten (21.4.1535): LM (1534-1536), fol. 93 $3^{\mathrm{r}}$.; in derselben Sache schrieb der Görlitzer Rat auch an den Zittauer Rat (21.4.1535 und 25.4.1535): fol. $93^{\mathrm{v}}, 95^{\mathrm{v}}$.

184 RA Görlitz, LM (1528-1531), fol. 188v f. (20.1.1529); zu den Rücknahmen der Stiftungen und Schenkungen auch: Urkunden, Akten, Briefe II (wie Anm. 127), S. 258 f., Nr. 1 und 3 (31.8.1524 und 5.11.1526; beides in Lauban); Schilling, Klöster und Mönche (wie Anm. 14), S. 202; Springer, Deutsche Dominikaner (wie Anm. 17), S. 236.

185 NA Praha, RG 25 (Německé missivy/Deutsche Missive 1541-1542), fol. 47v (30.12.1541); die Bedeutung solcher landesherrlicher Amtleute als „zentrale[r] Schaltstelle, über die der Fürst Einfluß auf die Kirche ausübte,“ betonte: Volkmar, Stunde des Laienstandes (wie Anm. 6), S. 392-395. 
Im Fall von Görlitz ging es vor allem um Stiftungen, die Peter Walde, Johannes Örtel und Martin Brunisch im späten 15. Jahrhundert errichtet hatten, da diese in der Reformation eine besondere Rolle spielten. ${ }^{186}$ Während andere vorreformatorische Görlitzer Stiftungen (z. B. Jahrzeiten usw.) mit der Reformation wohl rasch eingingen, überlebten diese drei Stiftungen - wenn auch in umgewidmeter Form - sogar die Aufhebung des Klosters und wurden auch weiterhin vollzogen. Der Görlitzer Ratsherr Peter Walde bedachte den Oybin in allen drei seiner Testamente. Für unsere Fragestellung ist vor allem die dem Konvent vermachte eine Tonne Hering jährlich von Belang. ${ }^{187}$ Die zweite Stiftung tat der Görlitzer Bürger Johann Örtel von Budweis/České Budějovice. Dieser bestimmte eine Summe von 1000 fl. ung., die er über den Görlitzer Rat dem Oybiner Kloster überließ, weshalb sich der Rat verpflichtete, aus diesen 1000 fl. ung. dem Oybiner Kloster jährlich 40 fl. ung. zu ainem gestifft zur Zittaw zu überweisen. ${ }^{188}$ Während in diesem Vertrag von 1498 Örtel mit keinem Wort erwähnt wird, begegnet man ihm 1501 im Protokoll über die Errichtung des 1498 angedeuteten Altaristenbenefiziums in der Zittauer Dreifaltigkeitskirche. Zum Patron dieser jetzt nun mit $30 \mathrm{fl}$. ung. jährlichen Zinses durch den Görlitzer Rat dotierten Altaristenstelle wurde der Oybiner Konvent, weshalb 14 Dukaten der Altarist selbst erhalten und der Rest (16 Dukaten) in ein Almosen für mehrere ausgewählte Empfänger fließen sollte. ${ }^{189}$ Die dritte ,Stiftung' machte der Pfarrer aus Hermsdorf/Jerzmanki Martin Brunisch aus Lauban/Lubań, der später in den Oybiner Konvent eintrat. Es ging wiederum um eine Wiederkaufsrente zwischen dem Görlitzer Rat und Brunisch:

186 Sauppe, Geschichte 1903 (wie Anm. 1), S. 204; Ders., Geschichte 1907 (wie Anm. 1), S. $123,184$.

187 Erstes Testament vom 15.3.1474: RA Görlitz, Libri actorum [im Folgenden: LA] (1470-1478), fol. 87v (hier noch ohne die Heringe); das zweite Testament von 1483: Libri resignationum [im Folgenden: LR] (1470-1487), fol. 182 ${ }^{\mathrm{v}}$ (bereits eine Tonne Hering jährlich für den Oybin, die der Görlitzer Rat auszahlen sollte); das dritte Testament vom 8.3.1488: LR (1488-1505), fol. $2^{v}$ f. (Vermächtnis des eigenen Dorfes Kuhzahl bei Görlitz an den Görlitzer Rat, der daraus die Tonne Hering jährlich für den Oybin bestreiten soll); seit 1491 wurde diese Stiftung vollzogen: LA (1512-1521), S. 112; Libri obligationum [im Folgenden: LO] (1484-1520), Varia 219, fol. 15 f. (7.5.1491); NA Praha, SM - UR, Sign. 111, Kart. 15, unpag.; APA I - Historica, Sign. C 148/3, Kart. 2260, unpag.; Christian Speer, Frömmigkeit und Politik. Städtische Eliten in Görlitz zwischen 1300 und 1550 (Hallische Beiträge zur Geschichte des Mittelalters und der Frühen Neuzeit 8), Berlin 2011, S. 425 f.; Pescheck, Geschichte (wie Anm. 26), S. 97, Nr. 8; Ders., Noch weitere Nachträge (wie Anm. 143), S. 315 f.

188 NA Praha, ČDKM IV, Kart. 169, fol. 128 r-129v; SM - UR, Sign. 111, Kart., unpag.; APA I - Historica, Sign. C 148/3, Kart. 2260, unpag.; Pescheck, Noch weitere Nachträge (wie Anm. 143), S. 305 f.

189 APH-AMK, cod. VI/8, fol. 49v-50v (15.12.1501). Diese Almosenausteilung betraf: armen leuten gewanth czw [kau]fen unnd auszwteilen, brodt lossen backen unnd awsczwspenden, eczliche seelbade czw bestellen, eyns teyls auch unserem closter czw enthaldunge gestifft seint: RA Görlitz, Varia 226, unpag. (Oybiner Kloster an den Görlitzer Rat; 22.9.1525); sie sollte täglich vollzogen werden: uns als awstelern tegelich mit brote in die bende armer lewte unnd czw verordenter czeit mit cleydunge[n]: ebd., unpag. (Oybin an Görlitz; 12.10.1526). 
6 fl. ung. dem Oybin jährlich gegen 120 fl. ung. ${ }^{190}$ Sie sollte nach Brunischs Tod wahrscheinlich dem Oybiner Konvent zufallen. ${ }^{191}$

Wie im Fall der anderen gestifteten Görlitzer Zinse beklagte das Oybiner Kloster bereits 1525 ihre Nichtentrichtung. Die Korrespondenz darüber zwischen dem Konvent und dem Görlitzer Rat zog sich bis ins Jahr $1544 .{ }^{192} 1535$ bestätigte der Landvogt Zdislav Berka einen Vertrag zwischen dem Kloster und den Nachkommen Martin Brunischs, die die Rente von $6 \mathrm{fl}$. ung. für sich beanspruchten. Den Streit entschied der Görlitzer Ratsherr Franz Schneider, dem der Rentenbrief übergeben und der zum neuen Inhaber dieses Rentenanspruchs wurde. Darüber hinaus verzichtete Prior Uthmann zugunsten Franz Schneiders auch auf die Tonne Hering Peter Waldes. Zdislav Berka bestätigte diesen für den Oybin sicher sehr ungünstigen Vertrag anstatt des Königs ohne jedes Bedenken, jdoch sall solches alles der hochgedachten Kuniglichen Maiestat an ibrem interesse, regalien, herrlikaiten und sonst menniglichs beweislichen rechten unschedlich sein. ${ }^{193}$ Dies wurde augenscheinlich zum Stein des Anstoßes. Ferdinand I. kann diesem Vertrag nicht zugestimmt haben, denn seit 1536 trieb das Kloster diese Zinse wiederum allein für sich ein. ${ }^{194}$

Im Jahr 1544 versuchte der Landvogt Zdislav Berka erneut das Problem dieser drei Stiftungen zu lösen, da das Oybiner Kloster wegen der veranderunge in der $<$ reg > religion angeblich außerstande war, sie zu verwalten; in mangel der prister und geistlicher clösterpersonen durch sich, nach sonst durch andere weltliche prister. Er bekräftigte damals den Vertrag zwischen dem Görlitzer und Zittauer

190 NA Praha, SM - UR, Sign. 111, Kart. 15, unpag.; APA I - Historica, Sign. C 148/3, Kart. 2260, unpag. (4.11.1499); SAuppe, Geschichte 1903 (wie Anm. 1), S. 234.

191 RA Görlitz, Codex diplomaticus Lusatiae Superioris [im Folgenden: CDLS] 8/261, fol. $108^{\mathrm{v}}(28.10 .1535)$.

192 RA Görlitz, LM (1523-1526), fol. 310v f. (10.3.1525); ebd., Varia 226, unpag. (Oybin an Görlitz; 22.9.1525); ebd., unpag. (Oybin an Görlitz - zwei Termine nicht, der dritte nur z. T. bedient; 16.3.1526); ebd., unpag. (Oybin an Görlitz; 12.10.1526); ebd., unpag. (Oybin an Görlitz; 21.11.1527); ebd., unpag. (Oybin an Görlitz - partielle Entrichtung der Schulden von 1525 - laut dem Prior Andreas Ringehut: Dieweyle un $\beta$, wie anderen geistlichen, aller czufelliger geniß abegibet, alzo das wir haben inwendigk in viber joren ober $600 \mathrm{fl}$. must czubusße[n] czu allen unßere[n] eynkome[n]; 4.3.1528); ebd., unpag. (Oybin an Görlitz - die Zinse sind seit Walpurgis 1527 nicht bezahlt; am Walpurgistag 1527 beglich der Ratsherr Franz Schneider die alten Schulden des Görlitzer Rats; der Prior beabsichtigte, arme [n] leuthen itczund[er] off dißen winter gewanth czu sneyden und ander dingk außczurichten; 17.11.1529); ebd., unpag. (Prior Chr. Uthmann an Görlitz - der Termin Michaelis 1532 ist nicht bezahlt; 6.12.1532); Pescheck, Noch weitere Nachträge (wie Anm. 143), S. 313-315.

193 RA Görlitz, CDLS 8/261, fol. 108v-110r (28.10.1535); Pescheck, Noch weitere Nachträge (wie Anm. 143), S. 319-321; Sauppe, Geschichte 1907 (wie Anm. 1), S. 116.

194 RA Görlitz, Varia 226, unpag. (Oybin an Görlitzer Bürgermeister Johannes Hass bzgl. der Heringe; 23.1.1536); ebd., unpag. (Oybin an Görlitz wegen der jenes Jahr nicht entrichteten Heringe; 15.12.1538); CDLS 8/261, fol. 142v; Varia 226, unpag. (Oybin quittiert dem Görlitzer Rat den Empfang der Örtelschen und Brunischen Zinse für den Termin Walpurgis 1544; 8.6.1544); Pescheck, Noch weitere Nachträge (wie Anm. 143), S. 321 . 
Rat. Beide Magistrate wollten die Örtelsche Stiftung in andere güttige wege zue ebren gottis und milden sachen anwenden, sie also in ein Universitätsstipendium zw underbaldung armer knaben im studio umwidmen. Berka bestätigte dies wiederum anstatt des Königs, doch mit dem Vorbehalt, dass dies nicht auf Kosten der königlichen Rechte geschehen darf. ${ }^{195}$ Diese Stiftungsumwidmung trat im Unterschied zu jener von 1535 wirklich in Kraft. In den Quellen lassen sich später regelmäßige Überweisungen der Görlitzer von 30 fl. ung. jährlich (20 fl. für den Zittauer Studenten und $10 \mathrm{fl}$. für das Zittauer Almosen), geteilt in zwei Raten, nach Zittau nachweisen. Während der Oybiner Hauptmannschaft Jakob Hags (15511556) verlangte der König diese drei Stiftungszinse vom Görlitzer Rat als sein Kammergut zurück. ${ }^{196}$ Berka hatte nichts zu vergeben, was nicht sein Eigentum war. ${ }^{197}$ Hag ließ diese drei Görlitzer Zinse in das Oybiner Urbar von 1553 eintragen. ${ }^{198}$ Darüber hinaus erbat er sich 1554 beim König, 20 fl. ung. jährlich aus diesen Zinsen seinem Bruder Hans zu entrichten. ${ }^{199}$

195 NA Praha, Lž III/8/26 (Oybin), unpag. (6.8.1544); RA Görlitz, CDLS 8/261, fol. 201v f.; Pescheck, Noch weitere Nachträge (wie Anm. 143), S. 306 f.; der Görlitzer Rat ließ diesen Vertrag am 30.1.1545 auch in sein Stadtbuch eintragen: RA Görlitz, LO (15201555), Varia 78, fol. 43v $44^{\mathrm{v}}$; daraus ist ersichtlich, dass diese Umwidmung, die zur ebre gottis und ad pios usus gewa[n]t, sunderlich der armen, für je einen Student aus Zittau und Görlitz erfolgte (und die gedachten altarist[en]zcinse uns und dem rathe zur Sittaw, in einer jeden stat eynen studenten im studio universali den elemosinen, doch in alwege unschedlich, zu erbalt [en], gnediglich vorliehen). Die Höhe der Örtelschen jährlichen Zinse sollte sich dabei schon auf $50 \mathrm{fl}$. ung. belaufen, weshalb immer noch ein Teil dieses Geldes für die Armenfürsorge angewendet sein sollte, wie es schon der vorreformatorische Stifter gewünscht hatte: Und dieweil dan der fundator Johan Ortel in seine [m] testame[n]t verordent, den armen leuten zur Zittaw jerlich[en] $16 \beta_{c}$ [960 Gr.] auszuspenden, so hab [en] wir und der rath zur Sittau mit wiss[en] und willen des priors und convents ufm Oywin uns nach noturft beret und verglich [en], das von solch [en] funfzigk fl. $h$. jerlich[en] den armen leuten zur Sittau 10 fl. an golt hung[risch] und von den ande[r]n $40 \mathrm{fl}$. jder stat $20 \mathrm{fl}$. zu underhaldung eins student[en] sollen folgen und von uns, de[m] rathe zu Gorrliz, entricht werd[en]; Editionen: CHRISTIAN AdolPH Pescheck, Handbuch der Geschichte von Zittau, Bd. I, Zittau 1834, S. 653-655, Nr. 6; Ders., Noch weitere Nachträge (wie Anm. 143), S. 307-309.

196 RA Görlitz, I - 246 -62 , fol. 6 ${ }^{\mathrm{r}}-7 \mathrm{v}$; Varia 226, unpag. (Jakob Hag an den Görlitzer Rat; 29.10.1552); ebd., unpag. [Jakob Hag an Erzhz. Ferdinand von Tirol; vor dem 2.11.1554].

197 NA Praha, RG 55 (Německé patenty, české missivy/Deutsche Patente, tschechische Missive 1554-1613), fol. 9v (31.7.1554); RA Görlitz, CDLS 9/262, fol. 35v f.; Varia 226, unpag. (Jakob Hag an Erzhz. Ferdinand von Tirol; vor dem 2.11.1554); am 12.1.1555 bezeichnete Hag den Vertrag von 1544 als ainen unbundigen und uncrefftigen consens: Varia 226, unpag.

198 NA Praha, SM - UR, Sign. 111, Kart. 15, unpag.; APA I - Historica, Sign. C 148/3, Kart. 2260, unpag.

199 NA Praha, RG 56, fol. $2^{\text {r }}$ f.; RG 57, fol. 7ri ČDKM IV, Kart. 169, fol. 54rir RG 55, fol. $9^{r}$ f. (31.7.1554); RA Görlitz, CDLS 9/262, fol. 35v f.; weiter dazu: Varia 226, unpag. (Jakob Hag an den Görlitzer Rat; 14.10.1554); Jakob Hag zahlte diese Zinse d[er] 40 ungerisch [en] gulden schon an di örtter, dabin es Ir Mt. verordenet, gereicht, aus dem Klostervermögen voraus und verlangte nachträglich ihre Begleichung vom Görlitzer Rat: Varia 226, unpag. [Jakob Hag an Erzhz. Ferdinand von Tirol; vor dem 2.11.1554]; 
Doch weder Jakob Hag noch sein Bruder Hans haben die Zinsen vom Görlitzer Rat wohl je erhalten. ${ }^{200}$ Der König ließ zwar die Görlitzer Stiftungszinse für Oybin sowohl im Pachtvertrag der Oybiner Güter von 1556 als auch im Pfandvertrag von 1562 erwähnen, ${ }^{201}$ die Umwidmung der Örtelschen Stiftung in ein Stipendium vom Jahr 1544 konnte der Görlitzer Rat jedoch augenscheinlich durchsetzen. Es war dabei paradoxerweise der Zittauer Rat, der, seitdem ihm der Oybiner Besitz verpfändet worden war, vom Görlitzer Rat eine buchstabengetreue Einhaltung der vorreformatorischen Stiftungsverpflichtungen ohne Rücksicht auf den Umwidmungsvertrag von 1544 verlangte. ${ }^{202}$ Doch die Görlitzer bestanden auf der Einhaltung der Umwidmung von 1544. Diese Zinse sollen darüber hinaus immer ein Görlitzer Ratseigentum gewesen sein. Oybiner Mönche wurden nur zue executorn desselben testament geordnet. Deswegen durften sie nie zum Objekt der Verpfändung der Oybiner Güter an Zittau werden. ${ }^{203}$ Die Zittauer argumentierten jedoch weiterhin mit der Aufhebung des Umwidmungsvertrages von 1544 durch den König sowie damit, dass sie diese Zinse dem Willen der spätmittelalterlichen Stifter zufolge für die immer vollzogene Almosenausteilung auf dem Väterhof in Zittau und für die Entrichtung der Pension für die Jesuiten brauchen. ${ }^{204}$ Dabei trat der protestantische Zittauer Rat gegenüber seinen ebenso lutherischen Kollegen sogar als ein Förderer des Prager Kollegs hervor. ${ }^{205}$ Doch schließlich konnte der Görlitzer Rat seinen Standpunkt durchsetzen. Davon zeugen bis heute dutzende Quittungen des Zittauer Rates seinen Görlitzer Kollegen gegenüber über den Empfang der Zinse für das Stipendium des Zittauer Studenten aus der 1544 umgewidmeten Örtelschen Stiftung. ${ }^{206}$ Görlitz überwies diese (Oybiner) Zinse nach Zittau wohl die ganze Frühe Neuzeit hindurch.207

CDLS 9/262, fol. 50v (26.12.1554); Varia 226, unpag. (Aufforderung Jakob Hags an Görlitz, 60 fl. rh. vorenthaltener Zinse zu entrichten; 12.1.1555); Varia 226, unpag. (die ausweichende Antwort der Görlitzer auf Hags Aufforderung; 20.1.1555); LM (15511553), fol. 288 r ; NA Praha, ČDKM IV, Kart. 169, fol. $125^{\mathrm{r}}$ f., $126^{\mathrm{r}}$ f., $139^{\mathrm{r}}$ f. (28.10.1555); RA Görlitz, LM (1555-1561), fol. 116 v f. (8.12.1555); Pescheck, Geschichte (wie Anm. 26), S. 101, Nr. 12.

200 Obwohl Hans Hag auf Ersuchen seines Bruders Jakob am 23.4.1564 von Ferdinand I. seine Provision der ,Oybiner' $20 \mathrm{fl}$. ung. jährlich um weitere zehn Taler aufgestockt wurde und ihm bis zu seinem Tod ausgezahlt werden sollte: NA Praha, RG 57, fol. 612ri RA Görlitz, LM (1561-1566), fol. 312r f. (18.6.1564).

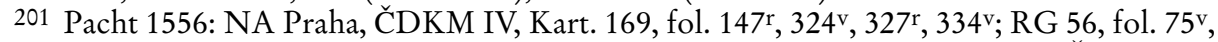
$76^{\mathrm{v}}$; APA I - Historica, Sign. C 148/3, Kart. 2260, fol. 1 1 $3^{\text {r }}$; Pfand 1562: ČDKM IV, Kart. 169, fol. 171 r $171^{\mathrm{v}}$, $319^{\mathrm{r}}$; Č G - L, inv. č. 2183; Sign. L II 1686, S. 2; RG 63, fol. $12^{\mathrm{r}}$, $197 \mathrm{r}$ f.

202 RA Görlitz, I - 246 v - 62, fol. 30 r f. (5.3.1565).

203 RA Görlitz, LM (1547-1567/68), fol. 459v-460v (26.3.1565).

204 RA Görlitz, I - 246 v -62 , fol. $31^{\mathrm{r}}-34^{\mathrm{v}}(13.4 .1565)$.

205 RA Görlitz, I - 246 $\mathrm{v}-62$, fol. 31v f. (13.4.1565).

206 Die erste überlieferte Quittung stammt vom 9.6.1561: RA Görlitz, I - 246 v - 62, fol. $41^{\mathrm{r}}$ f., die letzte vom 15.10.1613: fol. 108 $\mathrm{r}-109^{\mathrm{v}}$.

207 Sicher in den Jahren 1661 und 1673: RA Görlitz, I - 246 ${ }^{\mathrm{v}}-62$, fol. 46 f., 151 ${ }^{\mathrm{r}}-152^{\mathrm{v}}$. 
Petr Hrachovec

\section{Die Zittauer/Oybiner Jesuitenpension}

Über das Schicksal des Oybiner Klosters wurde bereits im zweiten Viertel des 16. Jahrhunderts entschieden. Seit 1547 lag die Verwaltung des Oybiner Klosters und der Oybiner Güter nicht mehr in den Händen der Cölestiner, denn der König sequestrierte dieses Vermögen, indem er es meistens Laien anvertraute. 1547 bis 1551 erhielt die ganze Oybiner Herrschaft der Oberlausitzer Landvogt (15271549) Zdislav Berka von Dubá. Wegen ihres Interesses an den reichen Oybiner Wäldern beendigten die Habsburger zwar frühzeitig Berkas Pfand und ließen 1551 bis 1556 die Klostergüter durch den Hauptmann Jakob Hag verwalten, bereits 1556 verpachteten sie jedoch die meisten Oybiner Güter an den Zittauer Rat. 1562 wurde diese zehnjährige Pacht in ein zwanzigjähriges Pfand umgewidmet. Allein das Klosterareal selbst und das Oybiner Tal wurden 1556 und 1562 vom König ausgeklammert. 1556 bis 1562 verwalteten es die Prager Jesuiten und 1562 bis 1570 wiederum die königlichen Hauptleute: Benno von Salza zu Rengersdorf (1562-1566) und nach ihm Hermann Ygl von Hartenreut (1566-1570). 1570 war der Zittauer Rat imstande, auch das Klosterareal mit dem Oybiner Tal zu gewinnen (als Nachtrag zum Pfand von 1562). Bereits in den 1540er-Jahren wurden kleinere entlegenere Güter (die Pließnitzwiese bei Görlitz, die Stegemühle in Herwigsdorf und wohl auch der Besitz bei Leitmeritz/Litoměřice in Nordböhmen) veräußert. 1562 verkaufte die Böhmische Kammer auch die niederschlesische Herrschaft des Klosters: die Dörfer Gränowitz/Granowice und Keulendorf/ Kulin, vier Bauerngüter zu Mertschütz/Mierczyce und eines zu Damsdorf/Damianowice für 8250 Taler. Der Zittauer Rat gewann somit 1574 für (nominell) 68000 Taler allein die Klostergüter im Zittauer Land in seinen erblichen Besitz. ${ }^{208}$

Man könnte meinen, dass das Oybiner Kloster 1574, indem es zum Ratsbesitz wurde, ganz aufgehoben wurde. Doch trotzdem blieb auch in den folgenden Jahrhunderten manches übrig. Abgesehen von den bereits behandelten umgewidmeten Görlitzer Stiftungen ging es vor allem um die Zittauer bzw. Oybiner Jesuitenpension, eine ewige Last in Höhe von 1400 Talern jährlich für das Prager Jesuitenkolleg, die auf den einstigen Oybiner Gütern haftete. Ihre Geschichte beginnt mit der Verpachtung der Oybiner Güter an den Zittauer Rat von 1556. Ferdinand I. sah darin einen sicheren Weg für die Finanzierung des Prager Kollegs. ${ }^{209}$ Jene 1400 Taler (je 700 Taler auf Georgi und Galli) der Zittauer Pachtsumme, die vom Stadtrat in den nächsten zehn Jahren zu leisten waren, bildeten zuerst eine wichtige

208 Ich muss hier diesen - wegen der sehr reich überlieferten Quellen in der Wirklichkeit sehr komplizierten - Besitzwandel aus Platzgründen sehr knapp formulieren; z. B. bezahlte der Leipziger Rat für die Klostergüter der drei aufgehobenen Klöster dem Landesherrn 83000 fl:: Wolgast, Einführung der Reformation (wie Anm. 14), S. 141; Oenmig, Stadt und Säkularisation (wie Anm. 14), S. 148-154; insgesamt gewann Hz. Moritz von Sachsen aus dem Verkauf der Kirchengüter etwa 230000 fl.: Schirmer, Reformation und Staatsfinanzen (wie Anm. 79), S. 191.

209 NA Praha, ČDKM IV, Kart. 169, fol. 336r ${ }^{\text {r }}$ (24.9.1555). 
Einnahmequelle für das Kolleg. ${ }^{210}$ Der Rat musste diese Pension auch aufgrund seines ersten Pfandvertrags über die Oybiner Güter vom 10. Januar 1562 abliefern, ${ }^{211}$ weshalb Ferdinand I. diese Summe dem Kolleg noch in der offiziellen Gründungsbulle vom 15. März 1562 bekräftigte.212 Wegen des Festhaltens der Jesuiten an dieser Pension scheiterte um 1560 sogar der Versuch, die Oybiner Güter für die Wiedererrichtung des Prager Erzbistums (1561) anzuwenden.213 Die Prager Jesuiten hofften immer noch, dass die Verpfändung Oybiner Güter an Zittau vom König zu ihren Gunsten vorzeitig beendigt wird oder dass ihnen diese Güter spätestens im Jahr 1582 nach dem Ablauf des Vertrages zufallen werden. ${ }^{214}$ Deswegen baten die Prager Jesuiten den König im Fall der Nichtentrichtung der Pension seitens des Zittauer Rates, sein Oybiner Pfand zu beschlagnahmen. ${ }^{215}$ 1567 versuchte wiederum der Prager Jesuitenrektor Heinrich Blissemius, die Bestrebungen der Zittauer zu vereiteln, ihr Pfand in einen erblichen Kauf zu verwandeln, ${ }^{216} \mathrm{da}$ er um die weitere Bezahlung der Pension bangte sowie die Klostergüter nach dem Ablauf des Zittauer Pfandes (1582) wiederum gewinnen wollte. Zugleich argumentierte Blissemius mit der Erhaltung des ursprünglichen Stiftungszwecks des Oybiner Klosters, des katholischen Gottesdienstes, ${ }^{217}$ mit der

210 RG 56, fol. 76 ${ }^{\text {r }}$ ČDKM IV, Kart. 169, fol. $325^{r}$ f.; APA I - Historica, Sign. C 148/3, Kart. 2260, fol. $2^{\mathrm{r}}$.

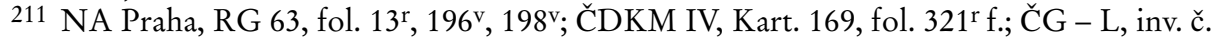
2183; Sign. L II 1686, S. 1, 4; HStA Dresden, 10024 Geheimer Rat (Geheimes Archiv), Loc. 9593/21, fol. 46r f.; Briefwechsel Canisius III (wie Anm. 57), S. 387, Nr. 668.

212 NA Praha, ČG-L, inv. č. 2193; Sign. L II 3649; Kroes, Geschichte I (wie Anm. 31), S. 57.

213 Briefwechsel Canisius II (wie Anm. 57), S. 655, Nr. 438 (Mai 1560 oder später); S. 707, Nr. 457 (24.8.1560); S. 717 f., Nr. 462 (24.8.1560); S. 757, Nr. 481 (4.11.1560); Briefwechsel Canisius III (wie Anm. 57), S. 18, Nr. 507 (4.9.1560); S. 198, Nr. 584 (23.8.1561); S. 258, Nr. 608 (14.10.1561); S. 314 f., Nr. 636 (30.11.1561); NA Praha, CDKM IV, Kart. 169, fol. 169 ${ }^{\mathrm{v}}, 1^{177^{\mathrm{r}}}$, 189 ${ }^{\mathrm{r}}$, 232 ${ }^{\mathrm{r}}$ f.; Lž III/8/26 (Oybin), unpag. (Erzhz. Ferdinand von Tirol an die Böhmische Kammer; 9.9.1560); SK Praha, Sign. DC III 20, fol. $26^{\mathrm{r}}(15.6 .1560), 36^{\mathrm{r}}$; nur kurz dazu: Kavka/SKÝBová, Husitský epilog (wie Anm. 74), S. 45 f.; Kroes, Untergang (wie Anm. 31), S. 244-246; Ders., Geschichte I (wie Anm. 31), S. 52-54.

214 Dazu schon: NA Praha, ČDKM IV, Kart. 169, fol. 163v f. (16.12.1559); Briefwechsel Canisius IV (wie Anm. 57), S. 250, Nr. 891 (13.6.1563); NA Praha, RG 58, fol. $263^{\mathrm{r}} \mathrm{f}$.

215 Wann die contribuenten, dabin wir verwisen, fürohin samig sein wurden, $d z$ wir alßdann gefreyet und volmechtiget seyen, die güetter, darauf wir verwisen, vermittelst ordenlichen khämmers selbst einzieben und unn $\beta$ darvon erbalten mogen: NA Praha, ČDKM IV, Kart. 169, fol. 238 r f. (Juni 1566).

216 [...] warumb die Oibinischen guetter sambt der befestungen (so unns von Ir Mth., hochloblichister gedechtnu $\beta$, zw undterhaltung dises khayserlich collegium verschriben worden) denen von Zyttaw erblichen nit sollen ubergeben und verschriben werden: NA Praha, ČDKM IV, Kart. 169, fol. 250r; weiter dazu: $243^{\mathrm{r}}-245^{\mathrm{v}}$.

217 Erstlichen, damit der gottsdienst in dem Oibinischen closter, welicher iezo wider den bevelch unnd ordnung Ir Rom. Khay. Mt., hochloblichister gedechtnuß, genzlich undterlaßen unnd versaumbet wirdt, widerumb aufgericht wurde unnd wir hinfuro \#bliben\# one ainige beengstigung des gewißen. Dann es also von Ir Rom. Khay. Mt., seligister gedechtnuß, angesehen worden unnd mit der mainung (wie dann die ver- 
drohenden Profanierung geistlicher Güter und dem ursprünglichen Willen des Stifters dieses Klosters. ${ }^{218}$

$\mathrm{Zu}$ weiteren Streitigkeiten kam es eben im Laufe des Verkaufes der Oybiner Güter an den Zittauer Rat im Jahr 1574. Der Orden wollte in die Veräußerung nicht einwilligen, da Maximilian II. bzw. die Böhmische Kammer seine Pension zuerst aus der Besteuerung der Kirche (doch diese Einnahme wäre situativ und nicht regelmäßig wie die bisherige Pension des Zittauer Rats aus den Oybiner Gütern) und weiter aus dem Grenzzoll entrichten wollte. Die Jesuiten präferierten augenscheinlich die sicheren regelmäßigen Bezüge vom Zittauer Rat. ${ }^{219}$ Sie waren nicht bereit, auf diesen Zittauer Zins, diesen ,Grund ihres Kollegs', zu verzichten. ${ }^{220}$ Daraufhin wollte ihnen die Hofkammer diesen Zins aus den Gefällen des sog. Ungelds im Tein/Týn in der Prager Altstadt zukommen lassen; doch auch hier kam es zu keiner Vereinbarung. ${ }^{221} \mathrm{Um}$ den Oybin rasch verkaufen zu können, empfahl die Hofkammer dem Zittauer Rat, seine Pension an die Prager Jesuiten weiter abzuführen. Die Zittauer sollten sich an ihrem Biergeld bzw. am Biergeld aus den anderen Sechsstädten entschädigen.222 Am 18. September 1574 stimmte Maximilian II. dieser Variante zu. ${ }^{223}$ Am 14. Oktober 1574 schlossen dann die königlichen Beauftragten eine Vereinbarung mit den Vertretern des Zittauer Rates bezüglich der Veräußerung Oybins an den Rat. Darin verpflichteten sich die Zittauer, bis zur Überweisung der letzten Rate für den Oybin in Höhe von 26000 Talern, den Jesuiten ihre Pension weiterhin zu zahlen, weshalb der Rat 23000 Taler aus der letzten Rate behalten durfte. ${ }^{224}$ Die betreffende Passage der könig-

schreibung vermag) ermelte guetter unns eingegeben worden, $d z$ alzeit ein caplan, welcher der khürchen vorstehn khonte, auf dem schloß solle erhalten werden, welches, dieweil es nit beschicht, haben wir es in aller undterthenigkheit Eur Rom. Khay. wollen zu verstehen geben, damit wir unnserm gewißen genueg theten: NA Praha, ČDKM IV, Kart. 169 , fol. 250 r.

218 Zum andern, damit die khürchenguetter, so gott, dem herrn, sein aufgeopfert worden, nit in frembde bendt unnd gebrauch gerieten, sonnd[er] bey den geistlichen personen des ersten fundatoris willen unnd der geistlichen recht[en] nach beliben: NA Praha, ČDKM IV, Kart. 169, fol. 250r.

219 NA Praha, RG 91 (Dobrozdání české komory ke dvoru/Gutachten der Böhmischen

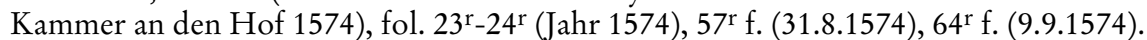

220 So berichten anjezo bierauf gedachte Jesuiter, das auf disen 1.400 tallern die gannze grundtubest ires collegii stee, [...] so kbündten sy sich aines so richtigen einkhombens, welches in $d[e r]$ landtaffl auch einverleibt und $d[e r]$ ganze grundt ires collegii sei, willigclich nit begeben unnd was and[er]s darfur annemen: NA Praha, ČDKM IV, Kart. 169, fol. 298r-299r (14.9.1574).

221 NA Praha, ČDKM IV, Kart. 169, fol. $299^{r}$ f. (14.9.1574), $302^{r}$ f.

222 Ebd., fol. 300r f. (14.9.1574).

223 NA Praha, RG 90A (Německé missivy/Deutsche Missive 1573-1574), fol. 318 r $-319^{\text {r }}$.

224 NA Praha, ČDKM IV, Kart. 324, fol. $314^{\vee}$ f.; am 18.10 .1574 wurde dieser Vertrag an Maximilian II. zur Entscheidung gesendet: fol. $310^{\mathrm{r}}$ f., $311^{\mathrm{r}}-312^{\mathrm{v}}$ (vor dem 23.10.1574). Im Jahr 1562 bezahlte der Zittauer Rat 12000 Taler, 1570 für die Erweiterung des Pfandes um das Klosterareal 10000 Taler. Weitere 20000 Taler sollte er beim Verkauf Oybins im Jahr 1574 entrichten, sodass die letzte Rate 26000 Taler betrug. 
lichen Verkaufsurkunde vom 17. November 1574 orientierte sich eng am Vertrag vom 14. Oktober 1574. ${ }^{225}$

Bereits am 14. Februar 1575 musste sich der Zittauer Rat wiederum verpflichten, dem Prager Kolleg die Pension zu überweisen. Im Fall der Nichtbezahlung durften die Jesuiten die Verwaltung der Oybiner Güter übernehmen. ${ }^{226} \mathrm{Zu}$ weiteren Verhandlungen zwischen dem König, der Böhmischen Kammer, den Prager Jesuiten und dem Zittauer Rat kam es erst in den Jahren 1580/81.227 Die Jesuiten stellten sich immer gegen die Ablösung dieser Pflicht quer. ${ }^{228}$ Rudolf II. versuchte zuerst diese Pension auf das Biergeld der Prager Städte zu transferieren, doch die Verhandlungen scheiterten. Schließlich konnte sich der Zittauer Rat für die Einrichtung der Pension an dem Biergeld der Sechsstädte entschädigen. ${ }^{229}$ Dabei versprach der Zittauer Rat dem Kaiser ein neues Darlehen (23000 bzw. 21000 Taler), woraus Rudolf II. auf 2000 Taler zugunsten des Rats verzichtete. Während der Rat diese Summe für die letzte Rate für die Oybiner Güter hielt (inzwischen entrichtete er nämlich aus den restlichen 26000 Talern 3000 Taler), betrachtete dies Rudolf II. für einen bloßen Wiederkaufszins. ${ }^{230}$ Der Kaiser verpflichtete sich allein am 8. März 1581 wegen dieses Darlehens von 21000 Talern, vom Zittauer Rat die letzte Rate über 23000 Taler für die Oybiner Güter nicht mehr zu verlangen.231 Dies bedeutete jedoch für den Rat eine ewige Verpflichtung zur Jesuitenpension.

Am selben Tag verschrieb der König dem Zittauer Rat - gegen sein Darlehen von 21000 Talern - 1400 Taler aus dem städtischen Biergeld; also genau in der Höhe der Zittauer Jesuitenpension. Dieses Darlehen konnte mit 23000 Talern

225 Unnd nachdem den Jesuittern vermüg derselben in dem guett Oybin erlangten gerechtigkhait aintausent vierbundert schockh Meichsnisch (!), solang dieselben nicht erledigt, von inen, denen von der Sittaw, alweg jarlich geraicht werden muessen unnd aber dise beschwerung in dise khaufshandlung nicht miteingezogen. Unnd wir doch genedigist bedacht, mit inen, den Jesuittern, derhalben gebuerliche vergleichung zu trefen. So sollen demnach die von der Sittaw an dem lezten termin fur die aintausent vierbundert taller dreyundzwainzigtausent taller, solang und-vil innenbebalten, biß die erledigung bemelter ir, der Jesuitter, gerechtigkhait ervolget oder sy derwegen von unn $\beta$ in ander weg notturfftig versehen. Alsdann, wan solches beschicht, sollen sy schuldig und pflichtig sein, die vollige khaufsumma unß vermug des mit inen durch unsere commissarien aufgerichten vertrag unsaumblich zu erlegen und auszuzelen: NA Praha, RG 87A, fol. 135'; ČDKM IV, Kart. 169, fol. 314v f.; ČDKM IV, Kart. 324, fol. 304v f.; Kroes, Geschichte I (wie Anm. 31), S. 485 f.

226 NA Praha, ČG - L, inv. č. 2618; Sign. L II 2019a; ebd., ČDKM IV, Kart. 324, fol. 1 ${ }^{\mathrm{r}}{ }^{-2}{ }^{\mathrm{v}}$.

227 NA Praha, ČDKM IV, Kart. 324, fol. 302r f., 307r-309v; HStA Dresden, 10024 Geheimer Rat (Geheimes Archiv), Loc. 9582/1, fol. $169^{\mathrm{r}} \mathrm{f}$.

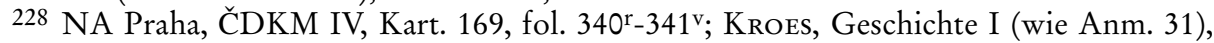
S. 487.

229 NA Praha, ČDKM IV, Kart. 324, fol. $3^{\mathrm{r}}-12^{\mathrm{v}}, 15^{\mathrm{r}}$ f., $244^{\mathrm{r}}$ f., $246^{\mathrm{v}}-248,261^{\mathrm{r}}, 22^{\mathrm{r}}$ f., $264^{\mathrm{r}}-267^{\mathrm{v}}, 269^{\mathrm{r}}-273^{\mathrm{v}}, 274^{\mathrm{r}}-277^{\mathrm{v}}, 279-281^{\mathrm{v}}, 283^{\mathrm{r}}-284^{\mathrm{v}}, 286^{\mathrm{r}}-290^{\mathrm{v}}, 293^{\mathrm{r}}-295^{\mathrm{v}}, 298^{\mathrm{r}}-299^{\mathrm{r}}$, $301^{\mathrm{v}}$.

230 NA Praha, ČDKM IV, Kart. 324, fol. 253r $-254^{\mathrm{v}}, 256^{\mathrm{r}}-259^{\mathrm{v}}, 262^{\mathrm{r}} \mathrm{f}$.

231 NA Praha, ČG - L, inv. č. 2873; Sign. L II 2189; RG 87A, fol. $405^{v}$ f. 
vom König abgelöst werden.232 Am 1. April 1581 stellte Rudolf II. noch zwei Urkunden aus: In der lateinischen für die Prager Jesuiten bestätigte der König dem Prager Kolleg erneut seine 1400 Taler jährliche Pension. Der Kaiser erklärte diese Pension für ewig unverwechselbar und unwiederkäuflich mit den Oybiner Gütern verbunden. ${ }^{233} \mathrm{Im}$ Fall der Nichtentrichtung dieser Pension waren die Jesuiten berechtigt, die Oybiner Güter zu übernehmen.234 Am 1. Juli 1583 inkorporierte auch Papst Gregor XIII. (1572-1585) dem Prager Kolleg die jährliche Pension von 1400 Talern aus den Oybiner Gütern. ${ }^{235}$ Zittau scheint in den künftigen Jahren seine Pension wirklich abgeführt zu haben. Zu schweren Streitigkeiten zwischen den Jesuiten und dem Zittauer Rat kam es erst im 17. und 18. Jahrhundert. Aber dies ist schon eine andere Geschichte.

\section{Fazit}

„Obwohl die Reformation zu einer deutlichen Schwächung des Konvents geführt hatte, war es letztendlich der katholische König von Böhmen, der dem Kloster die wirtschaftliche Basis entzogen hatte": so urteilte in Bezug auf den Untergang Oybins neuerdings Gunter Oettel. ${ }^{236}$ Die königliche Klosterpolitik der Reformationszeit stellte sicher eine gewisse Aporie dar: einerseits eine exzessive finanzielle ,Ausnutzung' der Klöster in Form zahlreicher Steuern und Darlehen, andererseits die Beharrung auf dem altgläubigen Stiftungsvollzug innerhalb der Klostermauern. G. Oettel hatte also sicher mit seinem Urteil Recht; doch man könnte auch einen weiteren Grund erwähnen, und zwar den kontemplativen und liturgischen Schwerpunkt des Cölestinerordens: denn die durch die Reformation veränderte religiöse Lage begünstigte eher die moderneren pastoral ausgerichteten Kongregationen. ${ }^{237}$ Dies bezeugt der Versuch Ferdinands I. und einiger Jesuiten, 1560 in Zittau ein Kolleg zu entrichten, was sicher einen erfolgreichen Abschluss der Reformation in Zittau erheblich in Frage gestellt hätte. Vielleicht mag diese Bedrohung etwaiger Rekatholisierung den Zittauer Rat zur schleunigen und legalen Aufhebung von vier der fünf Klöster im Zittauer Land vor 1574 (des Franzis-

232 NA Praha, RG 87A, fol. 406v-408vi HStA Dresden, 10024 Geheimer Rat (Geheimes Archiv), Loc. 9582/1, fol. 23r $-24^{\mathrm{r}}$.

233 [...] sed illum censum ex iis bonis Oybinensib[us] perpetuis temporibus debere immobilem, immutabilem, irredimibilem semperq[ue] inde [et] non aliunde solvendum permanere neq[ue] ullam haben[tem] rationem illor[um] viginti trium millium talleror[um] penes Zittavien[sibus] relictor[um], de quibus inter nos et illos aliter transactum est: NA Praha, ČG - L, inv. č. 2874; Sign. L II 2197a 1.

234 NA Praha, ČG - L, inv. č. 2874; Sign. L II 2197a 1; die andere (kürzere) deutsche Urkunde Rudolfs II. vom selben Tag summierte den Inhalt der langen lateinischen Urkunde: ČG - L, inv. č. 2875; Sign. L II 2197a 2.

235 NA Praha, ČG - L, inv. č. 2938; Sign. L II 3651.

236 Oettel, Auflösung (wie Anm. 1), S. 26.

237 Borchard, Cölestiner (wie Anm. 20), S. 160, 319. 
kanerklosters etwa 1565, beider Johanniterkommenden 1570/71 und des Oybins 1574) bewogen haben; einem Vorgang, der in den Nebenländern wohl sonst seinesgleichen sucht.

Doch der König wünschte keine Aufhebung des Cölestinerklosters, da er immer den liturgischen (altgläubigen) Stiftungsvollzug weiterhin garantieren wollte, wofür die letzten Mönche von der königlichen Kammer Pensionen erhalten sollten. ${ }^{238}$ Die Kammer hatte hauptsächlich am Erhalt des umfangreichen Oybiner Besitzes großes Interesse, was sich in zahlreichen Verpfändungen der Teile des klösterlichen Großgrundbesitzes seit 1547 widerspiegelte (Sequestrierung an Laien). Seit den 1540er-Jahren schritt man dann zu einer partiellen Veräußerung der (entlegenen) Güter dieses Klosters, die allzu schwierig zu verwalten waren, ohne dadurch das Wesen dieser Klosterstiftung infrage zu stellen.

Doch für diese frühen Rekatholisierungsmaßnahmen waren die Strukturen der durch die Reformation erschütterten römischen Kirche damals noch zu schwach. Nur der Versuch, die Jesuiten um 1560 auf dem Oybin anzusiedeln bzw. ihnen sogar das Zittauer Franziskanerkloster zu übertragen, weist in die Richtung, die später erfolgreich angewandt wurde. Man kann also die Habsburger doch z. T. in Schutz nehmen. Sie interessierten sich nicht nur für finanzielle Aspekte der untergehenden Oberlausitzer Klöster, sondern sie bestanden immer auf einem Mindestmaß an altgläubigem Stiftungsvollzug innerhalb der Klostermauern, auch wenn ihn Weltgeistliche oder Mitglieder anderer Orden ausüben sollten. Die Klöster stellten also für sie keine bloßen Wirtschaftseinheiten dar. ${ }^{239}$ Schließlich war es eben der notorische Mangel an Trägern dieser Stiftungen, d. h. der altgläubigen Religiosen (Cölestiner, Zisterzienser, Jesuiten) sowie der katholische Weltgeistlichen, der über das Schicksal des Oybiner Klosters entschied. Ohne Mönche hatte es für die habsburgischen Könige keinen Sinn, diese Klosterstiftung zu erhalten, sodass sie sie lieber an den protestantischen Zittauer Rat gegen eine ansehnliche Summe veräußerten.

Was blieb nach der Aufhebung der Oybins übrig? Erstens die Pension des Zittauer Rates an die Prager Jesuiten, und zweitens die an das Kloster angelagerten einst liturgischen - Stiftungen, die eine Anpassung an die neuen sozio-kulturellen Gegebenheiten erfuhren (Universitätsstipendien, Almosen). Manche vorreformatorischen Almosenstiftungen wurden auch nach der Reformation vollzogen; und die letzten Cölestiner stifteten aus dem Klostervermögen weitere caritative Stiftungen für evangelische Arme. ${ }^{240}$ Die Reformation stellte also nur einen partiellen

238 Allein die natürlichen Personen oder Personenverbände der Religiosen konnten zu dauerhaften Trägern der Klosterstiftungen werden und somit ihren Vollzug garantieren; SPRINGER, Deutsche Dominikaner (wie Anm. 17), S. 288 und 291 (Prior als ausschließlicher Rechtsträger seines Konvents im protestantischen Umland), S. 308 (Personalmangel), S. 319 (Wichtigkeit der persönlichen Anwesenheit); dazu auch: SiTzmanN, Mönchtum und Reformation (wie Anm. 14), S. $139 \mathrm{f}$.

239 Dazu: Zdichynec, Ferdinand I. (wie Anm. 7), S. 108.

$240 \mathrm{Zu}$ solchen Umwidmungen und den damit verbundenen zahlreichen Kontinuitäten des Monastizismus auch nach der Reformation: WARTEnBerg, Landesherrschaft (wie Anm. 
- wenn auch deutlichen - Umbruch auf dem Feld der Klosterstiftungen dar. Ein Teil der ,alten' Oybiner Klosterstiftung wurde dabei - in Form der Zittauer Jesuitenpension - in die ,neue' Stiftung des Prager Jesuitenkollegs umgewidmet.

Jedenfalls zeigt sich auch an diesem Oybiner Beispiel die reformatorische Klosterauflösung als langer Prozess (etwa zwischen 1523 bis 1574). ${ }^{241} \mathrm{Ob}$ der Oybiner Fall für eine Klosterschließung bzw. Klosteraufhebung oder Klosterauflösung zu halten ist, erscheint fraglich. Man kann beiden Momenten begegnen: passiver Aufhebung (königliche Verkaufsurkunde von 1574) wie auch aktiver Auflösung (z. B. die Klosterflucht der 1520er-Jahre)242; Beharrung (z. B. Oybiner Klage an den König gegen die Gewalt seitens des Zittauer Rats 1536/37; oder der Widerstand des letzten Priors Balthasar Gottschalk gegen die Jesuiten) wie auch Anpassung (z. B. Stiftungen der letzten Oybiner Cölestiner für die Zittauer evangelischen Einrichtungen). Ebenso kann man in der Auflösung/Aufhebung Oybins keine Züge der Modernität erkennen, in dem Sinne, dass das ehemalige Klostergut für die „Verdichtung der Staatlichkeit“ angewendet wurde. ${ }^{243}$ Darum ging es den Habsburgern in unserem Fall sicher nicht. Sie versuchten umgekehrt, wenigstens einen Teil des Oybiner Stiftungsvermögens - wenn sie schon das Kloster nicht mehr retten konnten - der römischen Kirche in Form der Oybiner bzw. Zittauer Pension für die Prager Jesuiten zu erhalten. Für einen Zug der ,Modernität‘ im Prozess der Aufhebung des Oybiner Klosters kann man wohl allein nur die Förderung der ,modernen ' tridentinischen Kongregation der Jesuiten durch die Habsburger aus dem einstigen Oybiner Klostervermögen halten.

6), S. 128, 140-142, 177 f., 239; KüHN, Einziehung (wie Anm. 6), S. 103 f., 112; ScHILLING, Gewesene Mönche (wie Anm. 14), S. 32 f.; Ders., Klöster und Mönche (wie Anm. 14), S. 81, 91, 132, 141, 156, 164, 201, 209-211, 223-225; Sitzmann, Mönchtum und Reformation (wie Anm. 14), S. 11-17, 22 f., 36, 42-45, 54-57, 61, 92-101, 111-119, 132, 183-186, 239-253; SPRINGER, Deutsche Dominikaner (wie Anm. 17), S. 61, 64, 95 f., 146148, 164, 166, 245, 270, 281-284, 342-358; SAuerbrey, Straßburger Klöster (wie Anm. 14), S. 173-175, 255, 292.

241 Wolgast, Einführung der Reformation (wie Anm. 14), S. 72, 120, 181, 265 f. (größere Beharrung der Frauenklöster); Sitzmann, Mönchtum und Reformation (wie Anm. 14), S. 52, 238 (größere Beharrung der Frauenklöster); Springer, Deutsche Dominikaner (wie Anm. 17), S. 339, 374; OCKer, Church robbers (wie Anm. 14), S. 84-90, 97-101; SAUerbrey, Straßburger Klöster (wie Anm. 14), S. 108 f.

242 Sauerbrey, Straßburger Klöster (wie Anm. 14), Straßburger Klöster, S. 78, 102-130, 349.

243 Springer, Deutsche Dominikaner (wie Anm. 17), S. 358. 


\section{Anhang: \\ Eine Chronik des Klosters Oybin (1532-1545)*}

Aufbewahrungsort: SOA Litoměčice/Děčín, RA Clam-Gallas, Sign. 2168-72, Kart. 584, inv. č. 2169 (Oybin); 34,8 x 22,3 cm (Pergamentumschlag); 31,2 x $22 \mathrm{~cm}$ (eigentliches Dokument aus Papier).

\section{Pergamentumschlag 244}

vorderes Blatt - recto 245

Verzaichnus, was und wievil der prior und convent vom gemainem cassten $z u$ Oybin vom [15]32. jar jar (!) bis schier auf dz 1546. (sic! 1545) jare zu allerbannd notturfft herausgenomben und enthan (?) baben.

Friedland 246

* Diese Quelle wurde schon (nur in moderner deutscher Übersetzung) herausgegeben von: JoAchim Prochno, Eine neue Quelle zur Geschichte des Klosters Oybin (Ausgaben aus dem gemeinen Kasten des Klosters 1532 bis 1544), in: Zittauer Geschichtsblätter 12 (1935), S. 30-34. Doch es geht um mehr als eine bloße Rechnung, sondern eher um eine kurze Chronik. Ihr Verfasser war der Oybiner Prior Christoph Uthmann († 1555). Die Editionsgrundlagen dieses Textes stützen sich auf die zeitgenössischen Regeln für die Wiedergabe neolateinischer Texte. Die Änderungen wurden vor allem in der grafischen Form des Textes vorgenommen: wie die Großbuchstaben (in den Toponymen und ihren Adjektiven, in den Bezeichnungen der Wochentage und Monate, der Kirchenfeste, Titulaturen, Würden und Funktionen: wie z. B.: Episcopus, Commisarius, Rex, Prior, Reverendissimus Dominus usw.). Die Distribution $i / j$ a $u / v$ wurde der Vokalisierung angepasst; mit Ausnahme der Gruppe qu/su). Die Interpunktion folgt den deutschen Regeln. Die Doppelzeichen $\propto, \propto$ wurden als Grapheme ae und oe wiedergegeben. Die Schreiberzeichen und Siglen werden in eckigen Klammern entschlüsselt. Die unübliche Schreibweise wurde beibehalten, falls sie keinen Einfluss auf die Wortbedeutung hatte (i/y - inclytus, v/w - Wiennesis, $\bar{e}$ im Sinne von ae Dominice, nestio statt nescio). Ebenso wurden die Dubletten wie z. B.: erario/aerario beibehalten. Alle römischen Zahlen wurden als arabische wiedergegeben. Für die Hilfe bei dieser Edition danke ich Dr. Kateřina Valentová-Bobková (Prag).

244 Auf dem Pergamentumschlag befindet sich ein „Fragment, das grob ins 14. Jh. (Mitte oder 2. Hälfte)“ datiert werden kann (aus Südfrankreich oder Norditalien), das sog. Casus breve super decretales Gregorii IX. des Ps.-Johannes Andreae beinhaltet; genau aus Buch I (De judicis) und Buch II (Kapitel: De iuramento calumnia, De feriis, De dilationibus und De ordine cognitionum); freundliche Mitteilung von Dr. Gunhild Roth und Prof. Dr. Volker Honemann (9.11.2015).

245 Die Texte auf dem Pergamentumschlag sind durch Rasuren und das Ausbleichen fast unleserlich.

246 Archivalische Anmerkung mit dem Bleistift am unteren Blattrand; der weitere Text des 16. Jahrhunderts auf dem Pergamentumschlag wurde wegen seiner Unlesbarkeit nicht mehr transkribiert. 


\section{Text}

/S. 1-4/ leer /S. 5/ Sub annu[m] d[omi]ni 1532, priusq[ue] Com[m]issarii regii, Dominus videlicet Stislaus a Bercka ${ }^{247}$ et Johannes Gotschenus ${ }^{248}$, perlustrarent atq[ue] consignarent hic res nostras, et sacras et p[ro]phanas, omnes, nos ob causas, neq[ue] leves, neq[ue] hic narrandas, emimus agros Superioris allodii in Olbersdorff 249 ab ipso Caspero Renger 190 marc[is] Bobemicalib[us]. Nec eramus tunc solvendo, nisi ex pecuniis depositis 250 non nibil acciperemus. Quanq[ue] et colono nostro Georgio Rumpeler debebamus eo tempore 25 sexagenas. Eratq[ue] nu[n]cius aere nostro conducendus ablegandusq[ue] in Italiam ad sacru[m] capitulu[m] Celestinoru[m], patru[m] nostroru[m], ut et curam pastoralem, qua[m] vocant, secu[m] illuc deferret ac reportaret ad nos aliunde monachos aliuquot, qui pusillu[m] bunc gregem facerent auctiorem succenturiati. Nec solu[m] fratres optatos, sed et patres provinciales et visitatores meruimus ex Italia suscipere, in quoru[m] gracia[m] et luxu[m] cogebamur brevi multa profundere, quibus nostra frugalitas longo tempore fuisset co[n]tenta. Posteaq[ue] igitur rursus binc abirent Com [m] issarii regii, neq[ue] serio preciperent, ne pecunia[m] ab ipsis consignata[m] attingeremus imposteru[m]. Nos, Prior totusq[ue] conventus buius monasterii, ne non solvendo essem[us], accepimus unanimi co[n]sensu ducentos ducatos de pecunia illa, quam nos ipsi deposuimus aliquando in usus pauperu[m] et extremam nostram necessitatem quamq[ue] arbitramur et confidimus nobis, cu[m] Rege tam clemente ex aequo com[m]unem esse.

Anno d[omi]ni 1534 die Martis post Esto mibi [17.2.1534], boc est in Carnisprivio, venit ad nos R[everendissi]mus D[ominus] Johannes, Episcopus Wienensis, 251 postulans a nobis Regis nomine 1.500 ducatos, quos, cu[m] nequiremus, citra maximam reru[m] iactura [m] simul effundere exhibuimus vel quadringentas marc[as] vel calices viginti ita, ut optio penes D[ominum] Episcopu[m] esset. /S. 6/ Episcopo re infecta abeunti, submissus est atq[ue] successit D[omi]n[us] Doctor Henricus Rybisch, Eques auratus et regius Questor, ${ }^{252}$ qui neq[ue] quandringentis marcis, neq[ue] calicibus viginti contentus, mille tandem ducatos extorsit, id quod inclyti Regis liter[a]e testantur, mille scilicet ducatos suae regiae clemenciae fuisse oblatos et per nos ducentos antehac absu[m]ptos. Talem hanc fortunaru[m] nostraru[m] imminutionem videntes sex nuper ex Italia transmissi fratres desponderu[n]t animu[m] neq[ue] aliud quicq[ue] flagitabant die noctuq[ue], q[uam] com[m]eatum et faculatem eo redeundi, unde paulo ante sumptuosis impendiis erant evocati.

247 Zdislav Berka von Dubá († 1553), der oberste Landrichter des Königreichs Böhmen (1523-1533/34), der oberste Hofmeister des Königreichs Böhmen (1534-1553) sowie der Landvogt der Oberlausitz (1527-1549).

248 Hans Schaffgotsch auf Kynast/Chojnik, Kammermeister.

249 Ein Vorwerk des Klosters in Olbersdorf, südlich von Zittau.

$250 \mathrm{Zu}$ diesen verschlossenen Deposita in den Cölestinerklöstern: BorchardT, Cölestiner (wie Anm. 20), S. 297-299.

251 Wiener Bischof Johann Fabri (1478-1541).

252 Heinrich Rybisch (1485-1544), königlicher Rentmeister und Breslauer Ratsherr. 
Accipientes itaq[ue] a nobis loco viatici nonaginta ducatos et equos duos, malueru[n]t bonorifice dimitti, q[uam] in turpem fugam se publice co[n]jicere. Pro nonaginta vero ducatis, quos annumeratos abstuleru [n]t, post se, reliqueru[n]t chirographu[m] suu [m] bic inclusu[m], manifeste testantes predictos nonaginta ducatos ex com [m] uni aerario, quod depositu[m] vocam[ur], fuisse depromptos.

Non longe post, cu[m] occasio se offerret, ut comode emeremus aliquot agri, ingera et prata predio nostro co[n]termina, ${ }^{253}$ intelexissemusq[ue] antebac non bscure ex regiis Com[m]issariis, quod pecuniam tantam pocius in usu[m] aliquem expendere deberemus, q[uam] sic abscondere p [er]petuo. Accepimus ex deposito 125 fllorenos] in grossis gladiatis ${ }^{254}$ et 10 ducatos atq[ue] adjicientes de quotidianis nostris su[m]ptibus duodecim fllorenos]. Dedimus rustico Sebastiano Luco pro agris et pratis suis 162 marcas Bobemicas anno Domini 1534 sub festu[m] Dominice An[n] $u[n]$ ciationis [25.3.1534].

/S. 7/ Eodem anno sub festu[m] divi Joannis Baptistae [24.6.1534] nos videntes, quod rusticus quidam nomine Laurencius Leyske ex pago civium Sittaviensiu[m] pro suo libitu uteretur fertilissimo prato in medio bonoru[m] nostroru[m] sito, unde nec gramina, nec cordu[m] absq[ue] monasterii damno posset avebere, propter lites molestiasq[ue] vitandas, et ut pratu[m] $\mathrm{cu}[\mathrm{m}]$ suo fructu rediret, tandem ad avitos suos legitimosq[ue] possessores, a quibus olim fuit nullo iure alienatu[m], emimus illud ducentis marc[is] Bobemicis. Atq[ue] cu[m] nobis vix tres et quadraginta marcae ex annuis monasterii proventibus superessent, coacti sumus iteru[m] centu[m] ducatos recipere ex com[m]uni erario, cui quidquid decerpit[ur] et decrescit, boc monasterii fundis et possessionibus adjicitur et accrescit ita, ut nemo sane mentis facile nos possit vel repetundaru [m] accusare, vel temeritatis.

Anno d[omi]ni 1537, cu[m] lis incidisset inter nos et cives Sittenses de fundis et finibus utrinq[ue] tuendis et nos cogeremur hinc inde peregrinari, nuncios et legatos mittere, consulere iurisperitos, conducere advocatos et patronos, largitiones effundere, privilegior [um] confirmationem petere ac redimere, damna eciam refarcire per aquaru[m] innundancia[m] illata, nec annuus proventus alioqui malignus sufficeret ad hec omnia boneste conficienda, accepimus binc de pecunia nostra com$[m]$ uniter olim deposita \#bis\# centu[m] ducatos, ne nervi belligerentibus non essent. De ducentis istis ducatis oblati sunt centu[m] D[omi]no Zdislao a Bercka per D[ominum] Doctorem Nostitz. ${ }^{255}$

/S. 8/ Anno domini 1538 post ferias Paschales [21.4.1538], ut possemus solvere prediu[m], quoddam rusticu[m] ille sexagenis emptu[m], in villa Olberstorff, accepimus binc ex deposito, ut vocamus, ducentas sexagenas in grossis Misnensibus, quoru[m] 7 valent florenu[m] Renensem. Eodem anno sub festo sancti Matthei [21.9.1538] dono dedimus generoso ac magnifico D[omi]no D[omi]no Stislao a Bercka, Advocato et patrono nostro singulari, centu[m] florenos Renenses in auro,

253 Vorwerk in Olbersdorf.

254 Schwertgroschen: eine wettinische Groschenprägung.

255 Ulrich von Nostitz († 1552): Hauptmann von Bautzen (seit 1546), Oberlausitzer Landeshauptmann (seit 1549). 
quos eciam ex communi erario nostro deprompsimus, unacu[m] aliis nonaginta octo ducatis, quibus comparavimus oves et avenam, hoc tempore charissimam. ${ }^{256}$ Deinde, ubi exustu[m] fuit, sub finem authu[m]ni allodiu[m] in Drausendorff perieru[n]tq[ue] inibi per familiae nostrae incuria[m] stabula et horrea, iumenta deniq[ue] ac pabula cu[m] frumentis omnibus. ${ }^{257}$ Cepimus ex aerario nostro 94, ut vocant, nobiles ${ }^{258} \mathrm{cu}[\mathrm{m}]$ aliquot coronis aureis ac vix tandem toto triennio sequenti rursus edificavimus, quod totu[m] in unico momento fuit in cineres redactum.

/S. 9/ Es ist noch vorhanden im closter vom czubrochen und anderem inventirten sylber: 1 gros monstrantz vorgult und czum Sacrament gebreuchlich, 1 par ampullen vorgult, 1 klein crucifix off eynem sylbern ledelein, 3 ader 4 kleine pacificalia czum teil vorgult, 2 guldene ringelein mit schlechten steinlein, 42 vorgulte und 2 sylbern kellich. Das ander alles durch gnedigste czulossunge Rhomischer Konig[liche]r M[aies]t[e]t, unsers allergnedigst[en] hern, wie beweislich, ist czu Gorlitz geschmeltzt und czu feinem sylber gemacht, an Gorlitzer gewicht bas in die 60 m[ark], sunder anm Pragischen widerumb geschmeltzt nicht meher, wie man uns mundtlich bericht, den $48 \mathrm{~m}$ [ark] lauthers sylbers, dorfur in sum [m]a /S. 10/ vomm bern landvoit entpffangen 335 Schwerthschock ${ }^{259}$ und ins clostersgebew und armer leuthe nutz gewandt anno 1539 sub festu[m] Jo[hann] is Baptis[tae] [24.6.1539].

Anno d[omi]ni 1540 sub diem Sancto Laurencio sacru[m] [10.8.1540] Dominus Stislaus a Bercka, regius Advocatus et patronus noster singularis, optavit per D[ominum] D[octorem] Ulrichu[m] a Nostitz, ut vel nos ipsi com[m]odato suae magnificenciae daremus sexagenas, ut vocant, sexingentas vel annuum censu[m] ut solveremus de totidem sexingentis sexagenis aliunde mutuo acceptis, quibus iam egeret pro sua, nestio (!) qua, necessaria utilitate. Ad quam bicornem petitionem, $\mathrm{cu}[\mathrm{m}]$ nobis boc tempore appareret responsione dignu[m], nisi quod esset $\mathrm{cu}[\mathrm{m}]$ periculo presenti damnoq[ue] manifesto co[n]iu[n]ctu[m], /S. 11/ dono dedimus D[omi]no illi nostro gratioso, coram id est presentes presenti, centu[m] grossos Talenses 260 in rubeo sacculo de sam [m]eto, mane templu[m] nostru[m] egresso.

Anno d[omi]ni 1542, cu[m] grassaretur pestilencia circu[m] quaq[ue] et infestaret magna[m] Bobemiae partem, D[omi]n[u]s Zdislaus a Bercka etc., Advocatus provinciae et patronus monasterii benemeritus, ut in tutiori aliquo loco esset, ad nos $\mathrm{cu}[\mathrm{m}]$ familia at gyneceo suo toto co[n]fugit hic byematurus. Tam honestos igitur tamq[ue] numerosos hospites, ut honeste tractarem[us], buc studiu[m] opera[m] q[ue] omnem impendimus, ne quid reru[m] necessariu[m] usq[ue] deesset. Et misimus ad ducem Lignicensem ${ }^{261} 30$ f[lorenos] Ung[aricales] pro co[n]trubutione contra Turcas, bisq[ue] citati Pragam, non modica[m] pecuniae sum [m]a[m] in illis

\footnotetext{
256 Hier ein Zeigefinger auf das Unterstrichene abgebildet.

257 Ein Vorwerk des Klosters in Drausendorf, nordöstlich von Zittau.

258 Eine englische Goldmünze.

259 Eine wettinische Groschenprägung.

260 Joachimstaler.

261 Friedrich II. von Liegnitz-Brieg (1480-1547).
} 
duob[us] itinerib[us] absu[m]psimus. Nec erat unde tocies ultra an[n] uos proventus, tantos faceremus sumptus. Ex com[m] uni igitur nostro erario cepimus 150 f[lorenos] Ung[aricales], de quibus statim 40 f[lorenos] mutavimus predictis hospitib[us] abitionem parantibus. Sequenti anno iteru[m] ad Schlesia[m] pro contributione contra Turcas misimus 12 fl[orenos] Ung[aricales] in auro, quos ex deposito, ut vocant, deprompsimus sub festu[m] Sancti Bartholomei anno 1543 [24.8.1543].

/S. 12/ Anno d[omi]ni 1544 Dominica Judica [30.3.1544] transmisim[us] D[omi]nis Cancellariis 66 sexagenas per Do[m]i[nu]m Advocatu[m], patronu[m] nostru $[m]$ singularem, pro recessu quoda [m] et registratura ejusdem, in auro scilicet, quod presentes presenti annumeraui[mus] ex deposito. Anno 1545 sub festu[m] Divi Valentini [14.2.1545] loco subsidii contra Turcas dedimus cuida[m] regio questori 40 ducatos aureos ex com [m] uni erario depromptos, ponderis quidem iniqui, sed num[m]is aliquot argenteis tandem bene co[m]pensatis, \#p[er] D[ominum] D[octorem] [scil. Ulrichum de Nostitz - P. H.].\# Ad Slesiam misim[us] pro steura 10 fllorenos] Ung[aricales] anno eodem in vigilia Sancti Bartholomei [23.8.1545]. Et hos 10 florenos] coacti sum[us] eciam ex deposito $n$ [ost]ro accipere. 